\title{
Managing anticoagulant therapies using innovative thrombin generation assays
}

Citation for published version (APA):

Bloemen, S. (2014). Managing anticoagulant therapies using innovative thrombin generation assays.

[Doctoral Thesis, Maastricht University]. Maastricht University. https://doi.org/10.26481/dis.20141219sb

Document status and date:

Published: 01/01/2014

DOI:

10.26481/dis.20141219sb

Document Version:

Publisher's PDF, also known as Version of record

\section{Please check the document version of this publication:}

- A submitted manuscript is the version of the article upon submission and before peer-review. There can be important differences between the submitted version and the official published version of record.

People interested in the research are advised to contact the author for the final version of the publication, or visit the DOI to the publisher's website.

- The final author version and the galley proof are versions of the publication after peer review.

- The final published version features the final layout of the paper including the volume, issue and page numbers.

Link to publication

\footnotetext{
General rights rights.

- You may freely distribute the URL identifying the publication in the public portal. please follow below link for the End User Agreement:

www.umlib.nl/taverne-license

Take down policy

If you believe that this document breaches copyright please contact us at:

repository@maastrichtuniversity.nl

providing details and we will investigate your claim.
}

Copyright and moral rights for the publications made accessible in the public portal are retained by the authors and/or other copyright owners and it is a condition of accessing publications that users recognise and abide by the legal requirements associated with these

- Users may download and print one copy of any publication from the public portal for the purpose of private study or research.

- You may not further distribute the material or use it for any profit-making activity or commercial gain

If the publication is distributed under the terms of Article $25 \mathrm{fa}$ of the Dutch Copyright Act, indicated by the "Taverne" license above, 


\section{Managing anticoagulant}

\section{therapies using innovative}

thrombin generation assays 
(C) Saartje Bloemen, Maastricht 2014

Thesis Maastricht University

ISBN 978-90-822614-2-4

Printed by: Graphic Services, Facility Company azM

Cover design by: Bart Verlaak

All rights reserved. No part of this thesis may be reproduced, stored in a retrieval system or transmitted in any form or by any means, without the permission in writing from the author, or, when appropriate, of the publishers of the publications. 


\section{Managing anticoagulant \\ therapies using innovative \\ thrombin generation assays}

PROEFSCHRIFT

ter verkrijging van de graad van doctor aan de Universiteit Maastricht, op gezag van de Rector Magnificus, Prof. Dr. L.L.G. Soete volgens het besluit van het College van Decanen, in het openbaar te verdedigen op vrijdag

19 december 2014 om 10.00 uur

door

Saartje Bloemen

Geboren op 10 november 1986 te Bree 


\section{Promotores:}

Prof. Dr. T. M. Hackeng (De Jure)

Prof. Dr. H.C. Hemker (De Facto)

\section{Copromotores:}

Dr. R. Al Dieri

Dr. B. de Laat

\section{Beoordelingscommissie:}

Prof. Dr. H. J. Crijns (voorzitter)

Dr. T. Baglin (Addenbrooke's Hospital, Cambridge, United Kingdom)

Prof. Dr. L. J. de Windt

Prof. Dr. S. Middeldorp (Universiteit Amsterdam)

The research in this thesis was supported by an unrestricted grant of Synapse B.V. and Diagnostica Stago.

Financial support by the Dutch Heart Foundation for the publication of this thesis is gratefully acknowledged.

Financial support by Synapse B.V., Phenom-World and Stago BNL for the publication of this thesis is gratefully acknowledged. 
Live as if you were to die tomorrow.

Learn as if you were to live forever.

Mahatma Gandhi 



\section{Table of contents}

$\begin{array}{lll}\text { Chapter } 1 \quad \text { General introduction } & 9\end{array}$

$\begin{array}{lll}\text { Chapter } 2 & \text { Is there a reason for testing thrombin generation? }\end{array}$

Chapter $3 \quad$ Procoagulant effect of vitamin $\mathrm{K}$ antagonists?

Chapter 4 Vitamin $\mathrm{K}$ antagonist therapy can be evaluated by whole blood CAT and results in high plasma levels of factor VIII as well as fibrinogen

Chapter 5 Detection of bleeding risk in patients taking vitamin $\mathrm{K}$ antagonists

Chapter 6 Large inter-individual variation of the pharmacodynamic effect of anticoagulant drugs on thrombin generation

Chapter $7 \quad$ Thrombin peak prolongation in the presence of direct factor Xa inhibitors

Chapter $8 \quad$ Will one size of anticoagulant dosage fit all?

Chapter 9 General discussion and summary

Samenvatting

Valorization

Curriculum vitae

Publications

Dankwoord 



\section{Chapter 1}

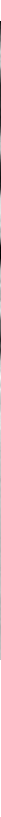


When damage to a blood vessel occurs numerous mechanisms are set in motion in order to achieve hemostasis at the site of the injury. The arrest of bleeding is accomplished by interactions between a cellular (platelets and red blood cells) and a protein component. Platelets will aggregate in the wound area and form a plug. Tissue factor (TF) that is present on subendothelial surfaces, interacts with the blood that contains multiple non-activated clotting factors. TF together with factor (F) VIla will trigger coagulation. The central enzyme of hemostasis is thrombin. This protease will not only result in the conversion of fibrinogen into fibrin and form a network of fibers to cover the wound; thrombin will also activate platelets that provide a surface of phospholipids ( $\mathrm{PL}$ ) on which coagulation reactions take place and thereby localize the thrombin formation to the site of the injury [1, 2].

\section{Coagulation}

When TF is exposed to FVIla, present in the circulation, TF will bind to FVIla. The TF/FVIla complex activates FX into FXa, which will then convert prothrombin (FII) into thrombin (Flla). Thrombin can activate FV into FVa. When FVa is bound together with FXa on a procoagulant phospholipid surface, they constitute the prothrombinase complex $\left(\mathrm{FVa} / \mathrm{FXa} / \mathrm{PL} / \mathrm{Ca}^{2+}\right)$. Prothrombin also binds to the surface, thereby facilitating the conversion to thrombin [3].

The TF/FVIla complex not only activates FX, but also FIX. Thrombin will enable its own formation again by activating FVIII and FXI. Activated FVIII is a cofactor for FIXa and will produce more FXa (this complex is called intrinsic tenase). This feedback activation is also known as the Josso loop [4]. Activated FXI will activate additional FIX. Besides thrombin there is another activator of FXI. FXIla can activate FXI and prekallikrein in the presence of high molecular weight kininogen (HMWK). This process is referred to as 'contact activation' or the 'intrinsic pathway'. The physiological function of this pathway remains to be elucidated [3].

At low TF concentrations thrombin generation (TG) ensues mainly through the activation of FVIII, FIX and FXI, whereas at higher TF concentrations coagulation occurs mostly through the extrinsic pathway (or TF pathway) [5]. 
Thrombin not only promotes, but also limits its own formation. Thrombin binds thrombomodulin (TM) which is bound to the endothelium [6]. This complex will activate protein $C$ into activated protein $C$ (APC) which, with the help of cofactor protein S, inactivates FVa and FVIIla and thereby limits the rate of TG[3]. The extrinsic pathway is inhibited by tissue factor pathway inhibitor (TFPI) at low TF concentrations. First FXa will bind the Kunitz 2 domain of TFPI followed by binding of TF/FVIla to the Kunitz 1 domain, forming a quaternary complex and, together with cofactor protein S, preventing TG $[7,8]$. Furthermore, thrombin that is in solution can be inhibited by antithrombin (AT). This inhibitor affects most enzymes in the clotting cascade (FIXa, FXa, FXla and FXIla) but to a lesser extent [9]. A schematic representation of the most important reactions is given in figure 1.

Ultimately, coagulation generates increasing levels of FXa and consequently more thrombin resulting in the formation of a fibrin clot. Fibrinogen is transformed into fibrin by thrombin via cleaving of fibrinopeptide $\mathrm{A}$ and $\mathrm{B}$, forming fibrin monomers. When the concentration of these monomers increases, they spontaneously form protofibrils. The assembly of the protofibrils results in fibrin fibers. Besides cleaving fibrinogen into fibrin, thrombin activates FXIII which covalently cross-links the fibrin fibers and stabilizes the network that is formed. Within this network, circulating red blood cells can be trapped [10].

Platelets provide a procoagulant phospholipid surface which enhances the assembly of the prothrombinase and tenase complex. Procoagulant phospholipids are usually located on the inner membrane of the platelets, but when platelets are activated these phospholipids become exposed on the outer membrane via a 'flipflop' mechanism. However, before platelets are activated, they first adhere to the site of injury. The adhesion of platelets to collagen exposed at sites of tissue injury takes place via von Willebrand factor (VWF) under high shear stress. VWF unfolds and binds to the membrane glycoprotein Ib-V-IX (GPIb-V-IX) receptor. Additionally, platelets can bind directly to collagen through their GPla-lla receptor. When platelets are activated they release thromboxane A2 (TXA2), ADP, calcium and serotonin, facilitating the activation of other platelets and enabling contraction of the vascular smooth muscle cells to stop bleeding. After activation of platelets the 


\section{Chapter 1}

GPIlb-IIla integrin receptor for fibrinogen undergoes a conformational change, increasing its affinity towards fibrinogen [3].

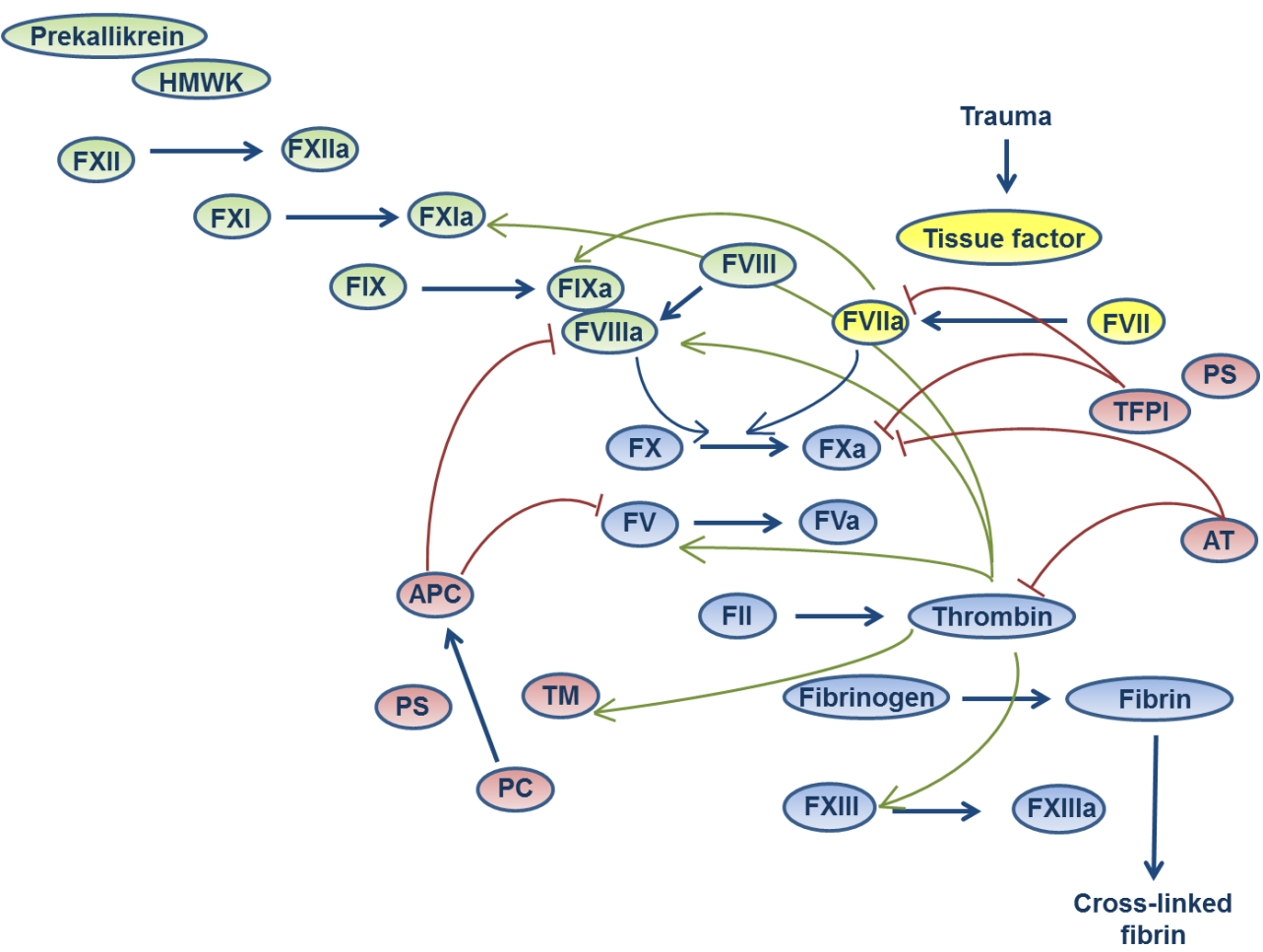

Figure 1: Schematic representation of coagulation. The factors in yellow are the extrinsic factors, the factors in green are the intrinsic factors and the ones in blue are the factors in the common pathway. The proteins indicated in red are natural anticoagulants. Green arrows indicate positive feedback reactions, whereas red arrows indicate negative feedback reactions.

\section{Fibrinolysis}

Once the fibrin network is formed, degradation will occur via a mechanism named fibrinolysis. The main enzyme in this system is plasmin. Plasmin can degrade both fibrinogen and fibrin, limiting clot formation and clearing the clot once formed. Tissue plasminogen activator (tPA) converts plasminogen into plasmin. IPA and 
plasminogen are both bound to carboxy-terminal (C-terminal) lysine residues on fibrin, facilitating the inactivation of fibrin by plasmin. Plasminogen that is bound is more effectively converted to plasmin, which limits the activity to the clot. Plasmin degradation of fibrin will result in more lysine residues which amplifies this process.

Thrombin also plays a role in limiting fibrinolysis. When thrombin binds to TM it can activate thrombin activatable fibrinolysis inhibitor (TAFI). TAFI can bind plasminogen and remove the lysine residues of fibrin, which results in a decreased number of TPA and plasminogen binding sites, limiting plasmin generation and thereby inhibiting fibrinolysis [11]. Moreover, fibrinolysis is inhibited by plasminogen activator inhibitor (PAI-1), which is the main inhibitor of tPA, and by $\alpha_{2}$-antiplasmin, the primary inhibitor of plasmin and plasminogen [12].

\section{Venous and arterial thrombosis}

Thrombosis can occur in the veins as well as in arteries. Arterial thrombi are composed largely of platelets whereas venous thrombi are rich in fibrin and red blood cells, giving rise to white and red blood clots, respectively.

Arterial thrombi can block an artery and manifest as e.g. myocardial infarction or stroke. They are usually caused by a rupture in an atherosclerotic plaque. Platelet adhesion and aggregation to plaque components is mediated by GPVI and GPlaIla. Then TF (derived from the atherosclerotic plaque) triggers coagulation resulting in the formation of thrombin and fibrin [13]. Arterial thrombosis is usually treated by antiplatelet therapy possibly in combination with anticoagulant agents, which target proteins of the coagulation pathway.

Although venous thrombi are located in veins, fragments can break off, embolize and travel through the vasculature. Venous thrombi occur as deep vein thrombosis (DVT) and consequently as pulmonary embolism (PE). In general they are referred to as venous thromboembolism (VTE). The cause of DVT can be a result of changes in any of the three components of Virchow's triad [14]. According to Virchow's triad an interplay takes place between three main components: the 


\section{Chapter 1}

vessel wall, the flow of blood through the vessel and the composition of blood [15]. The treatment of VTE consists of anticoagulant agents.

\section{Anticoagulants and antithrombotics}

Complications of the hemostatic system such as bleeding and thrombosis are lifethreatening and, together, more people are killed by these than by any other cause. When focusing on the thrombotic complications and more specifically VTE, the treatment has barely changed over the past 60 years. The mainstay of treatment has been heparins and vitamin $\mathrm{K}$ antagonists (VKAs). However, recently non-vitamin $\mathrm{K}$ antagonist oral anticoagulants (NOACs) have been developed that show promising results. Unlike heparins and VKAs they are said not to require monitoring (Table 1, p. 20). These new anticoagulants are direct thrombin inhibitors (DTI) and direct FXa inhibitors [1]. An overview of the anticoagulants and their targets is given in figures 2 and 3 .

\section{Heparins and heparin-like inhibitors}

Heparin accelerates the function of AT by introducing a conformational change and thereby enhancing the anticoagulant effect of AT. The binding of heparin to AT is facilitated by a pentasaccharide structure, the A-domain. This part is responsible for the increased inhibition of FXa. When heparin possesses at least 13 saccharides (C-domain) in addition to the pentasaccharide sequence, it will also be able to augment the inhibition of thrombin $[16,17]$. Unfractionated heparin (UFH) consists of molecules ranging from 5 to $30 \mathrm{kDa}$. Low molecular weight heparin (LMWH) contains chains between 1 to $10 \mathrm{kDa}$. The anticoagulant effect of LMWH mainly results from the inhibition of $\mathrm{FXa}$, but, depending on the preparation, can also have varying activities against thrombin [18]. Although heparin favorably binds to AT, the activity of heparin cofactor II (HCII) is also stimulated. UFH and LMWH have some important drawbacks such as heparin induced thrombocytopenia (HIT). UFH also displays a number of unspecific interactions to plasma proteins, platelets 
and endothelial cells. Therefore it has largely been replaced by LMWH for many indications [19].

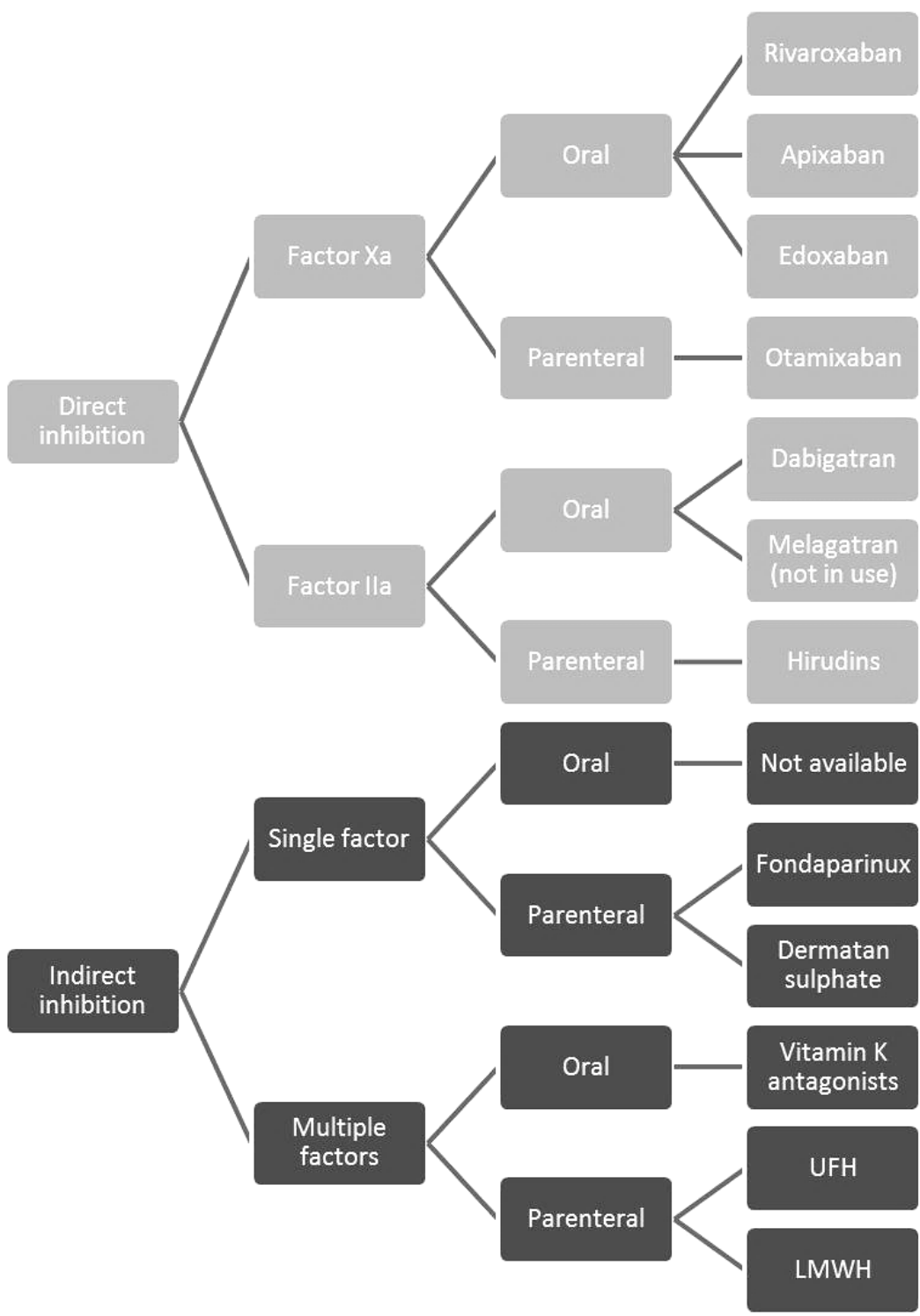

Figure 2: Overview of the different anticoagulant agents. UFH, unfractionated heparin; LMWH, low molecular weight heparin 


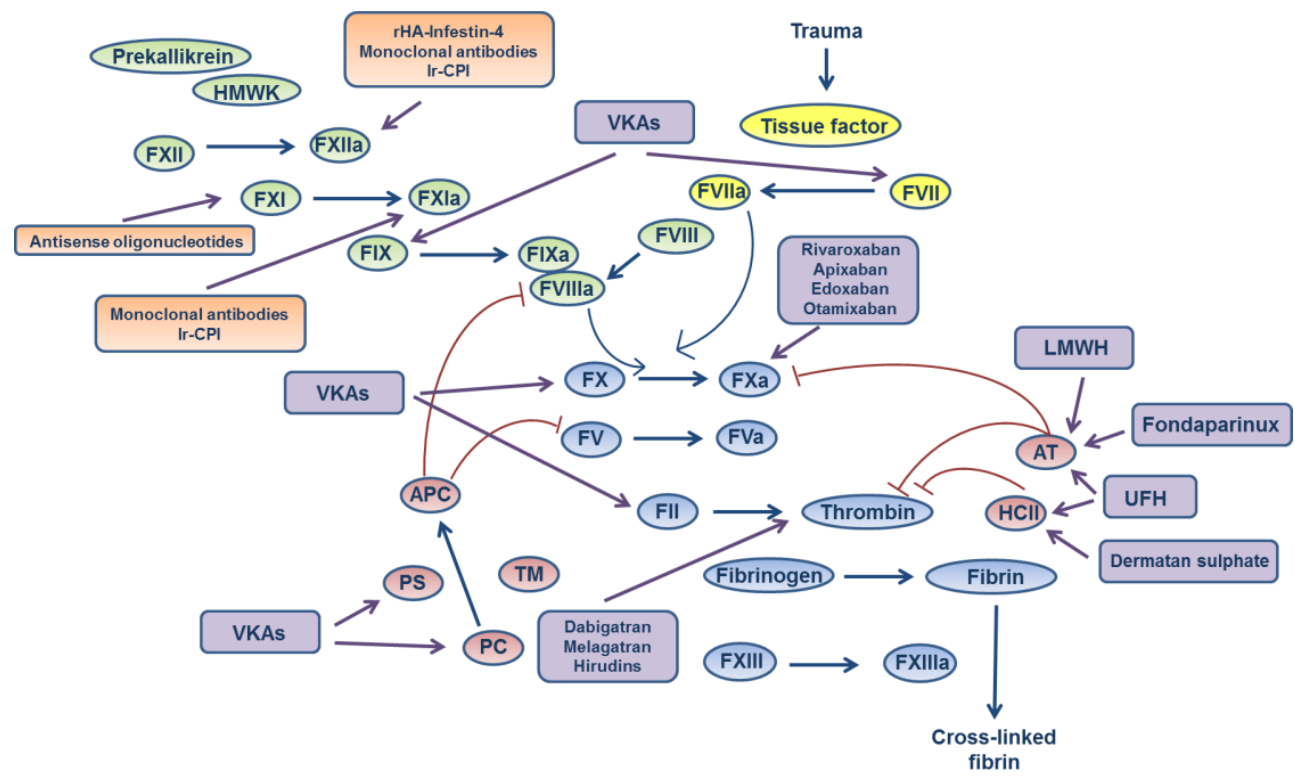

Figure 3: Schematic representation of the targets of different anticoagulant treatments. The colour coding of the coagulation scheme is identical to figure 1. The anticoagulants indicated in purple are the anticoagulants that are currently in use or which are being investigated in clinical trials (with the exception of melagatran which has been withdrawn from the market and otamixaban for which the trials have been terminated). The anticoagulants indicated in orange are being investigated in animal models. A phase I trial for the antisense oligonucleotides has been performed [28].

Different compounds exist in the class of heparins that contain only a structure based on the natural pentasaccharide sequence that binds AT. An example of such a pentasaccharide is fondaparinux, which can reversibly bind to AT molecules. A conformational change is induced in AT, exposing a loop necessary for FXa binding and consequently enhancing the affinity for FXa. Fondaparinux is able to inhibit clot-bound FXa, but does not possess the ability to inhibit FXa within the prothrombinase complex. Fondaparinux has little non-specific interactions. The incidence HIT with the use of fondaparinux is lower compared to UFH [18].

Dermatan sulfate is a selective inhibitor of thrombin through an interaction with $\mathrm{HCll}$. Fibrin bound thrombin is not accessible to UFH bound to $\mathrm{HCll}$, but is susceptible to dermatan sulfate in complex with HCII [20]. 
Monitoring the effect of UFH is recommended due to the non-specific interactions. This can be achieved by different tests. The first is the activated partial thromboplastin time (aPTT). This is a clotting test triggered by a surface activator that detects changes in the intrinsic factors as well as FX and thrombin [19]. Secondly, the level of anti-FXa or anti-Flla activity can be determined. However, these levels are estimates of the amount of heparin and do not represent the effect on the coagulation system of the patient [21]. Since there are no known drug interactions of LMWH and fondaparinux monitoring would not be necessary in prophylactic use, however under some circumstances (e.g. patients with renal insufficiency, pregnant patients) it can be useful [16, 18].

\section{Vitamin $K$ antagonists}

Vitamin $\mathrm{K}$ antagonists are the most commonly used oral anticoagulants to date. Their main indications are the prevention of VTE and the prevention of systemic embolism in patients with prosthetic heart valves or atrial fibrillation (AF). VKAs have some important drawbacks which make them challenging to use in clinical practice. The agents have a slow onset which makes bridging therapy (usually LMWH) necessary. Additionally, they also display a slow offset, prolonging their effect after cessation of therapy. The variable dose response among different patients, the narrow therapeutic window and the multiple interactions with food and drugs make routine monitoring necessary [1, 22].

VKAs exert their anticoagulant effect by inhibiting vitamin $\mathrm{K}$ epoxide reductase, an enzyme that is required for the $\mathrm{Y}$-carboxylation of vitamin $\mathrm{K}$ dependent factors II, VII, IX and $X$ in the liver. The $Y$-carboxylation induces a calcium-dependent conformational change which facilitates binding to negatively charged phospholipid surfaces. In the presence of VKAs the carboxylation is incomplete, resulting in undercarboxylated forms of proteins, referred to as PIVKAs (protein induced by vitamin $\mathrm{K}$ absence or antagonism) [23]. Aside from the procoagulant factors, the anticoagulant protein $\mathrm{C}$ and protein $\mathrm{S}$ are also affected, implying a procoagulant 


\section{Chapter 1}

potential [22]. Different types of VKAs are on the market, of which warfarin, acenocoumarol and phenprocoumon are most commonly used.

The protrombin time (PT) is the indicated test to monitor VKAs. The PT is a TF induced test capable of detecting decreases in FII, FVII and FX by a prolongation of the clotting time. To standardize the results these are expressed as a ratio of the patients PT to a mean normal PT, yielding the international normalized ratio (INR). For most indications the INR ranges between 2.0 and 3.0 (2.0 and 3.5 in the Netherlands), with an INR below 2.0 signifying a thrombotic risk and above 3.5 indicating a higher bleeding risk [24].

\section{Direct thrombin inhibitors}

The first oral reversible direct thrombin inhibitor was melagatran with ximelagatran as its prodrug. This compound showed promising results as a potent and selective thrombin inhibitor. However, due to hepatotoxicity the drug was withdrawn from the market. Dabigatran was the next inhibitor that was developed [25]. The compound is orally administered in the form of the inactive prodrug dabigatran etexilate. In an acidic environment the prodrug is absorbed and converted by esterases in plasma and the liver to the active substance dabigatran. Dabigatran is a small molecule that binds reversibly to the active site of thrombin, resulting in the inhibition of both bound and free thrombin [1].

So far, there is no standardization as to which is the optimal test to measure the effect of dabigatran. The aPTT displays a relatively good sensitivity, is cheap and widespread. The suggestion was made that this test could be used for monitoring and potential screening for a bleeding risk. The Hemoclot thrombin inhibitor assay was found to be reproducible, sensitive and showed an excellent linear correlation. Due to the limited availability of the test in labs its use as the gold standard for dabigatran monitoring is hampered [26]. 
Other direct thrombin inhibitors can be administered parenterally and are bivalent. Aside from blocking the active site of thrombin, these agents also block exosite 1. This class consists of hirudins, which bind thrombin irreversibly [27].

\section{Direct factor Xa inhibitors}

Several direct FXa inhibitors were developed, which can be taken orally (rivaroxaban, apixaban and edoxaban) and one was administered parenterally (otamixaban). Since these inhibitors do not require a cofactor, they can inhibit both clot-bound FXa as well as FXa in the prothrombinase complex. Due to the parenteral route of administration of otamixaban it could be used in acute situations [29]. However, investigations concerning this agent have been cancelled by the manufacturer due to disappointing results. Rivaroxaban and apixaban are oral anticoagulants that have been approved for some indications, as indicated in Table 1. Edoxaban is still under investigation.

Determining the effect of rivaroxaban can be done by a calibrated PT assay and in some situations a calibrated anti-FXa assay can be performed [30]. These antiFXa assays are also recommended for measuring the pharmacodynamics of apixaban [31].

\section{Factor XI and factor XII inhibitors}

Over the last year there has been a growing interest in targeting $\mathrm{FXI}(\mathrm{a})$ and $\mathrm{FXII(a)}$ as a possible anticoagulant treatment. Studies have been performed in animal models investigating the inhibition of these factors. Antibodies were developed against factor XII interfering with the conversion to FXIla [32] and against FXI [33]. Several proteins derived from hematophagous parasites were studied, including Infestin-4 fused to recombinant human albumin as an inhibitor of FXIla [34] and Ixodes ricinus contact phase inhibitor (Ir-CPI) which interacts with FXIa, FXIla and kallikrein [35]. Antisense oligonucleotides that selectively inhibit FXI mRNA expression have been tested in mice and baboons [28]. From these studies was 


\section{Chapter 1}

concluded that these factors are important for thrombosis, although FXII does not play a major role in hemostasis. Inhibition of FXI or FXII resulted in an antithrombotic effect without increasing the bleeding risk [36].

Table 1: Characteristics of anticoagulants

\begin{tabular}{|c|c|c|c|c|c|}
\hline Anticoagulant & Target & $\begin{array}{l}\text { Half-life } \\
\text { (h) }\end{array}$ & $\begin{array}{c}\text { Route of } \\
\text { administration }\end{array}$ & Antidotes & Clinical use \\
\hline \multicolumn{6}{|l|}{ Heparins } \\
\hline Unfractionated heparin & $\begin{array}{l}\mathrm{lla} / \mathrm{Xa} \\
\text { (via AT) }\end{array}$ & $0.5-2.5$ & IV/SC & Protamine sulphate & $\begin{array}{l}\text { VTE therapy, VTE prophylaxis and } \\
\text { ACS }\end{array}$ \\
\hline $\begin{array}{l}\text { Low-molecular-weight } \\
\text { heparin }\end{array}$ & $\begin{array}{l}\mathrm{lla} / \mathrm{Xa} \\
(\mathrm{via} A T)\end{array}$ & 3-6 & sc & Protamine sulphate & $\begin{array}{l}\text { VTE therapy, VTE prophylaxis and } \\
\text { ACS }\end{array}$ \\
\hline Pentasaccharide & Xa (via AT) & $17-21$ & sc & Recombinant Vlla† & $\begin{array}{l}\text { VTE therapy, VTE prophylaxis and } \\
\text { ACS (without interventions) * }\end{array}$ \\
\hline Vitamin $K$ antagonists & $\begin{array}{l}\text { II, VII, IX, } \\
\text { X, PC, PS }\end{array}$ & 40 & Oral & Vitamin K, PCC & $\begin{array}{c}\text { VTE prophylaxis, thromboprohylaxis } \\
\text { after AF or prosthetic heart valves, } \\
\text { AMI }\end{array}$ \\
\hline \multicolumn{6}{|l|}{ Thrombin inhibitors } \\
\hline Dabigatran etexilate & Ila & $8-15$ & Oral & No specific antidote & $\begin{array}{l}\text { non-valvular AF, thomboprophylaxis } \\
\text { after knee- or hip-replacement * }\end{array}$ \\
\hline \multicolumn{6}{|l|}{ FXa inhibitors } \\
\hline Rivaroxaban & $\mathrm{Xa}$ & $7-11$ & Oral & PCC† & $\begin{array}{c}\text { non-valvular AF, thromboprophylaxis } \\
\text { after knee- or hip-replacement, DVT } \\
\text { and PE, ACS (with antiplatelet } \\
\text { agents) * }\end{array}$ \\
\hline Apixaban & $\mathrm{Xa}$ & 8-15 & Oral & No specific antidote & $\begin{array}{l}\text { thromboprophylaxis after knee- or } \\
\text { hip-replacement, } \mathrm{AF}^{*}\end{array}$ \\
\hline Edoxaban & $\mathrm{Xa}$ & $9-11$ & Oral & No specific antidote & Under investigation \\
\hline
\end{tabular}

*According to the European Medicines Agency.

†Experimental treatment [37]

AT, antithrombin; PC, protein C; PS, protein S; IV, intravenous; SC, subcutaneous; PCC, prothrombin complex concentrate; VTE, venous thromboembolism; ACS, acute coronary syndrome; AF, atrial fibrillation; AMI, acute myocardial infarction; DVT, deep venous thrombosis; PE, pulmonary embolism; ACS, acute coronary syndrome

\section{Antiplatelet therapy}

There are three main classes of antiplatelet agents: 1) cyclooxygenase-1 (COX-1) inhibitors, 2) adenosine diphosphate (ADP) $\mathrm{P}_{2} \mathrm{Y}_{12}$ receptor antagonists and 3) glycoprotein Ilb-Illa inhibitors. Aspirin is an irreversible COX-1 inhibitor and thus inhibits the synthesis of TXA2 from arachidonic acid. Aspirin is a cornerstone of 
antithrombotic treatment and is recommended for secondary prevention of ischemic events in the management of acute coronary syndrome or percutaneous coronary intervention, when used together with an oral ADP $\mathrm{P}_{2} \mathrm{Y}_{12}$ receptor inhibitor. Several $\mathrm{P}_{2} \mathrm{Y}_{12}$ receptor antagonists are available of which clopidogrel, prasugrel and ticagrelor are the agents that are most frequently used. Clopidogrel is a prodrug which is taken orally and then converted to its active metabolite which irreversibly binds to the $\mathrm{P}_{2} \mathrm{Y}_{12}$ receptor. Prasugrel is also an oral prodrug which undergoes hepatic conversion into the active substance. Due to its more efficient conversion prasugrel has a higher bioavailability compared to clopidogrel. Ticagrelor is an oral compound that is already active and reversibly binds the $\mathrm{P} \mathrm{Y}_{12}$ receptor. Glycoprotein Ilb-Illa inhibitors can only be administered intravenously and are therefore only used in acute situations. Abciximab, an example of such an inhibitor, blocks fibrinogen binding to the platelets by binding to the glycoprotein Illb-Illa receptor [38].

\section{Thrombin generation testing}

Assays have been developed that measure the ability of a sample to generate thrombin over time, instead of only evaluating the time necessary to form a clot (clotting assays). These assays are referred to as TG tests. Clotting assays only indicate the initiation phase of coagulation (formation of traces of thrombin that suffice for clot formation). TG assays, on the other hand, also portray the propagation and termination phase [39, 40]. Different parameters can be derived from a TG curve corresponding to different characteristics (Figure 4). The lag time represents the time during which the first traces of thrombin are formed and is equivalent to the clotting time. The peak indicates the maximal amount of thrombin formed. The time to peak (ttpeak) is the time needed to reach the peak level of thrombin formation. The endogenous thrombin potential (ETP) is the area under the thrombin curve and represents the enzymatic work performed by thrombin during the time in which it was active $[40,41]$. 


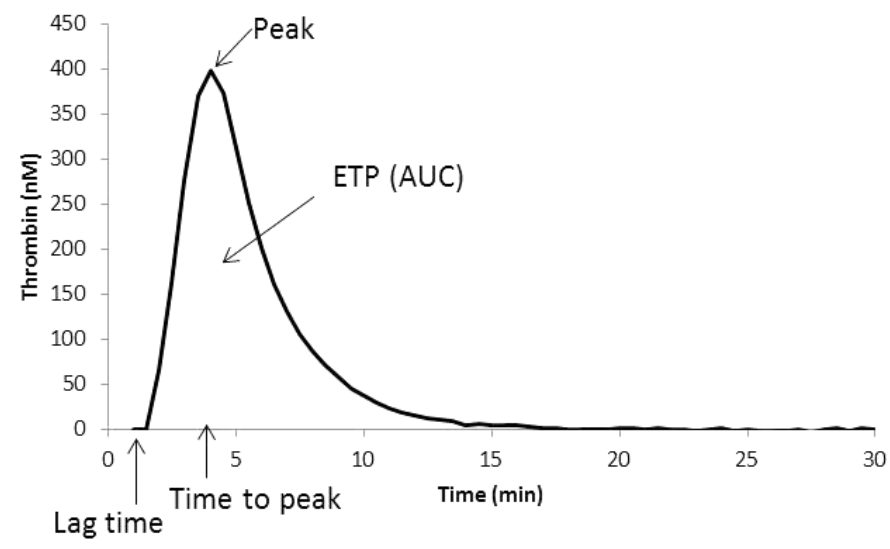

Figure 4: Thrombin generation curve with the most widely used parameters. Indicated on the curve are the two time dependent parameters, lag time and time to peak and the functional parameters, peak and endogenous thrombin potential (ETP, area under the thrombin curve).

Recently, a TG test in whole blood was developed. This method not only includes clotting factors and platelets, but also red and white blood cells. Centrifugation is abolished thereby excluding the possibility of activating cells and saving time. This method uses a thin layer of paper which contains the blood in order to avoid sedimentation of the red blood cells causing variable quenching. A different, Rhodamine-based substrate is used that results in a high fluorescent yield and is not consumed significantly [42].

There is increasing evidence that the thrombin generating capacity of blood is a reliable parameter in hemostatic and thrombotic diseases. High TG is an indication of prothrombotic conditions [43-45], whereas TG is lowered in haemophilic patients. By treating these patients with recombinant clotting factors, TG is restored to normal levels $[43,45]$. A definite bleeding risk is found when TG values are below 20\% [41]. All anticoagulants tested so far (indirect and direct inhibitors) lower thrombin generation [46, 47, 48]. In platelet rich plasma, TG is inhibited by platelet antagonists TG [49]. Based on these findings TG assays have the potential to be used as a laboratory test in clinical settings $[43,45]$ and the intra-laboratory 
variation is acceptable. The test, however, is not yet sufficiently standardized to obtain adequate inter-laboratory variation.

\section{Variability of anticoagulant effects}

The variation of thrombin generating capacity in a healthy population is substantial (coefficient of variation (CV) in plasma 16\%) [41]. The thrombotic and bleeding tendency of a population is also related to the TG capacity. Re-thrombosis occurs four times more often in people with an increased TG than in those with a TG below average [49]. Surgical bleeding is related to the level of TG as well [50, 51].

Aside from the variation found in a healthy population, different types of variation arise after the administration of an anticoagulant. The first type is the variability in plasma levels of a drug when the same dose is given to different patients (pharmacokinetics). The second type is the variability in the effect of the drug on the clotting system in plasma from different individuals (pharmacodynamics). It was shown that in a population, pharmacokinetic constants vary $\sim 18 \%$ for a thrombin inhibitor [52] and $\sim 10 \%$ for a FXa inhibitor [53]. Comparable levels of variation have been found for a synthetic pentasaccharide (fondaparinux) [54].

The variability in the pharmacodynamic effect is also high. The effect on TG of a fixed level of heparin (UFH and LMWH) added in vitro is highly variable, due to variations in antithrombin (AT) levels, heparin binding proteins, procoagulant factors and platelet activation (giving rise to the shedding of PF4), but also to concomitant medication, etc. [55]. A fixed dose of heparin (LMWHs and UFH alike) induces a highly variable effect on TG in healthy volunteers (CV 25\%) that cannot be attributed to the weight of the subjects [56]. Based on these data it is unlikely that the individual patient will react as the hypothetical "average patient" of the trials [57]. 


\section{Outline of this thesis}

In this thesis the use of TG tests in the management of anticoagulant therapies is described. In chapter 2 we reviewed the clinical applicability of TG tests, such as in bleeding or thrombotic conditions. In chapter 3, 4 and 5 we further describe the use of CAT to evaluate vitamin $\mathrm{K}$ antagonists, together with the effect of these agents on clotting factors and fibrin ultrastructure. Furthermore, we demonstrate the ability of the newly developed whole blood CAT to detect a bleeding risk in patients taking these agents. In chapter 6 we examined the inter-individual variation of the TG parameters after the addition of a fixed dose of both direct and indirect anticoagulants. We focused on the particular, prolonged shape of the TG curve in the presence of direct FXa inhibitors in chapter 7. Chapter 8 reviews the value of TG testing to study the effect of anticoagulants. In chapter 9 the results are summarized and discussed. 


\section{References}

1. King CS, Holley AB, Moores LK. Moving toward a more ideal anticoagulant: the oral direct thrombin and factor Xa inhibitors. Chest. 2013; 143(4): p. 1106-1116.

2. Kleinegris MC, Ten Cate-Hoek AJ, Ten Cate H. Coagulation and the vessel wall in thrombosis and atherosclerosis. Pol Arch Med Wewn. 2012; 122(11): p. 557-566.

3. Dahlback B. Blood coagulation and its regulation by anticoagulant pathways: genetic pathogenesis of bleeding and thrombotic diseases. J Intern Med. 2005; 257(3): p. 209-223.

4. Josso F, Prou-Wartelle O. Interaction of tissue factor and factor VII at the earliest phase of coagulation. Thromb Diath Haemorrh Suppl. 1965; 17: p. 35-44.

5. Hemker HC, Beguin S. Phenotyping the clotting system. Thromb Haemost. 2000; 84(5): p. 747-751.

6. Dahlback B, Villoutreix BO. The anticoagulant protein C pathway. FEBS Lett. 2005; 579(15): p. 3310-3316.

7. Rosing J, Maurissen LF, Tchaikovski SN, Tans G, Hackeng TM. Protein S is a cofactor for tissue factor pathway inhibitor. Thromb Res. 2008; 122 Suppl 1: p. S60-63.

8. Hackeng TM, Rosing J. Protein S as cofactor for TFPI. Arterioscler Thromb Vasc Biol. 2009; 29(12): p. 2015-2020.

9. High KA. Antithrombin III, protein C, and protein S. Naturally occurring anticoagulant proteins. Arch Pathol Lab Med. 1988; 112(1): p. 28-36.

10. Sidelmann JJ, Gram J, Jespersen J, Kluft C. Fibrin clot formation and lysis: basic mechanisms. Semin Thromb Hemost. 2000; 26(6): p. 605-618.

11. Bouma BN, Mosnier LO. Thrombin activatable fibrinolysis inhibitor (TAFI)--how does thrombin regulate fibrinolysis? Ann Med. 2006; 38(6): p. 378-388.

12. Carpenter SL, Mathew P. Alpha2-antiplasmin and its deficiency: fibrinolysis out of balance. Haemophilia. 2008; 14(6): p. 1250-1254.

13. Lippi G, Franchini M, Targher G. Arterial thrombus formation in cardiovascular disease. Nat Rev Cardiol. 2011; 8(9): p. 502-512.

14. Mackman N. Triggers, targets and treatments for thrombosis. Nature. 2008; 451(7181): p. 914-918.

15. Virchow R. Gesammalte abhandlungen zur wissenschaftichen medtzin. Medinger Sohn \& Co, 1856.

16. Gray E, Mulloy B, Barrowcliffe TW. Heparin and low-molecular-weight heparin. Thromb Haemost. 2008; 99(5): p. 807-818. 


\section{Chapter 1}

17. al Dieri R, Alban S, Beguin S, Hemker HC. Thrombin generation for the control of heparin treatment, comparison with the activated partial thromboplastin time. $J$ Thromb Haemost. 2004; 2(8): p. 1395-1401.

18. Bauer KA. New pentasaccharides for prophylaxis of deep vein thrombosis: pharmacology. Chest. 2003; 124(6 Suppl): p. 364S-370S.

19. Eikelboom JW, Hirsh J. Monitoring unfractionated heparin with the aPTT: time for a fresh look. Thromb Haemost. 2006; 96(5): p. 547-552.

20. Liaw PC, Becker DL, Stafford AR, Fredenburgh JC, Weitz JI. Molecular basis for the susceptibility of fibrin-bound thrombin to inactivation by heparin cofactor ii in the presence of dermatan sulfate but not heparin. J Biol Chem. 2001; 276(24): p. 20959-20965.

21. Greaves M. Limitations of the laboratory monitoring of heparin therapy. Scientific and Standardization Committee Communications: on behalf of the Control of Anticoagulation Subcommittee of the Scientific and Standardization Committee of the International Society of Thrombosis and Haemostasis. Thromb Haemost. 2002; 87(1): p. 163-164.

22. Ansell J, Hirsh J, Poller L, Bussey H, Jacobson A, Hylek E. The pharmacology and management of the vitamin $\mathrm{K}$ antagonists: the Seventh ACCP Conference on Antithrombotic and Thrombolytic Therapy. Chest. 2004; 126(3 Suppl): p. 204S233S.

23. Ferland $\mathrm{G}$. The discovery of vitamin $\mathrm{K}$ and its clinical applications. Ann Nutr Metab. 2012; 61(3): p. 213-218.

24. Singer DE, Chang Y, Fang MC, Borowsky LH, Pomernacki NK, Udaltsova N, Go AS. Should patient characteristics influence target anticoagulation intensity for stroke prevention in nonvalvular atrial fibrillation?: the ATRIA study. Circ Cardiovasc Qual Outcomes. 2009; 2(4): p. 297-304.

25. Eisert WG, Hauel N, Stangier J, Wienen W, Clemens A, van Ryn J. Dabigatran: an oral novel potent reversible nonpeptide inhibitor of thrombin. Arterioscler Thromb Vasc Biol. 2010; 30(10): p. 1885-1889.

26. Douxfils J, Mullier F, Robert S, Chatelain C, Chatelain B, Dogne JM. Impact of dabigatran on a large panel of routine or specific coagulation assays. Laboratory recommendations for monitoring of dabigatran etexilate. Thromb Haemost. 2012; 107(5): p. 985-997.

27. Di Nisio M, Middeldorp S, Buller HR. Direct thrombin inhibitors. N Engl J Med. 2005; 353(10): p. 1028-1040. 
28. Crosby JR, Marzec U, Revenko AS, Zhao C, Gao D, Matafonov A, Gailani D, MacLeod AR, Tucker El, Gruber A, Hanson SR, Monia BP. Antithrombotic effect of antisense factor $\mathrm{XI}$ oligonucleotide treatment in primates. Arterioscler Thromb Vasc Biol. 2013; 33(7): p. 1670-1678.

29. Bondarenko M, Curti C, Montana M, Rathelot P, Vanelle P. Efficacy and toxicity of factor Xa inhibitors. J Pharm Pharm Sci. 2013; 16(1): p. 74-88.

30. Douxfils J, Mullier F, Loosen C, Chatelain C, Chatelain B, Dogne JM. Assessment of the impact of rivaroxaban on coagulation assays: laboratory recommendations for the monitoring of rivaroxaban and review of the literature. Thromb Res. 2012; 130(6): p. 956-966.

31. Douxfils J, Chatelain C, Chatelain B, Dogne JM, Mullier F. Impact of apixaban on routine and specific coagulation assays: a practical laboratory guide. Thromb Haemost. 2013; 110(2): p. 283-294.

32. Matafonov A, Leung PY, Gailani AE, Grach SL, Puy C, Cheng Q, Sun MF, McCarty OJ, Tucker El, Kataoka H, Renne T, Morrissey JH, Gruber A, Gailani D. Factor XII inhibition reduces thrombus formation in a primate thrombosis model. Blood. 2014; 123(11): p. 1739-1746.

33. Tucker EI, Marzec UM, White TC, Hurst S, Rugonyi S, McCarty OJ, Gailani D, Gruber A, Hanson SR. Prevention of vascular graft occlusion and thrombusassociated thrombin generation by inhibition of factor XI. Blood. 2009; 113(4): p. 936-944.

34. Hagedorn I, Schmidbauer S, Pleines I, Kleinschnitz C, Kronthaler U, Stoll G, Dickneite G, Nieswandt B. Factor XIla inhibitor recombinant human albumin Infestin-4 abolishes occlusive arterial thrombus formation without affecting bleeding. Circulation. 2010; 121(13): p. 1510-1517.

35. Decrem Y, Rath G, Blasioli V, Cauchie P, Robert S, Beaufays J, Frere JM, Feron O, Dogne JM, Dessy C, Vanhamme L, Godfroid E. Ir-CPI, a coagulation contact phase inhibitor from the tick Ixodes ricinus, inhibits thrombus formation without impairing hemostasis. J Exp Med. 2009; 206(11): p. 2381-2395.

36. Muller F, Gailani D, Renne T. Factor XI and XII as antithrombotic targets. Curr Opin Hematol. 2011; 18(5): p. 349-355.

37. Levi M, Eerenberg E, Kamphuisen PW. Bleeding risk and reversal strategies for old and new anticoagulants and antiplatelet agents. J Thromb Haemost. 2011; 9(9): p. 1705-1712. 
38. Capodanno D, Ferreiro JL, Angiolillo DJ. Antiplatelet therapy: new pharmacological agents and changing paradigms. Journal of thrombosis and haemostasis : JTH. 2013; 11 Suppl 1: p. 316-329.

39. Hemker HC, Giesen P, Al Dieri R, Regnault V, de Smedt E, Wagenvoord R, Lecompte T, Beguin S. Calibrated automated thrombin generation measurement in clotting plasma. Pathophysiol Haemost Thromb. 2003; 33(1): p. 4-15.

40. Castoldi E, Rosing J. Thrombin generation tests. Thromb Res. 2011; 127 Suppl 3: p. S21-25.

41. Al Dieri R, Peyvandi F, Santagostino E, Giansily M, Mannucci PM, Schved JF, Beguin S, Hemker HC. The thrombogram in rare inherited coagulation disorders: its relation to clinical bleeding. Thromb Haemost. 2002; 88(4): p. 576-582.

42. Ninivaggi M, Apitz-Castro R, Dargaud Y, de Laat B, Hemker HC, Lindhout T. Whole-blood thrombin generation monitored with a calibrated automated thrombogram-based assay. Clin Chem. 2012; 58(8): p. 1252-1259.

43. Adams M. Assessment of thrombin generation: useful or hype? Semin Thromb Hemost. 2009; 35(1): p. 104-110.

44. Baglin T. Unraveling the thrombophilia paradox: from hypercoagulability to the prothrombotic state. J Thromb Haemost. 2010; 8(2): p. 228-233.

45. van Veen JJ, Gatt A, Makris M. Thrombin generation testing in routine clinical practice: are we there yet? Br J Haematol. 2008; 142(6): p. 889-903.

46. Bloemen S, Hemker HC, Al Dieri R. Large inter-individual variation of the pharmacodynamic effect of anticoagulant drugs on thrombin generation. Haematologica. 2013; 98(4): p. 549-554.

47. Robert S, Ghiotto J, Pirotte B, David JL, Masereel B, Pochet L, Dogne JM. Is thrombin generation the new rapid, reliable and relevant pharmacological tool for the development of anticoagulant drugs? Pharmacol Res. 2009; 59(3): p. 160-166.

48. Hron G, Kollars M, Binder BR, Eichinger S, Kyrle PA. Identification of patients at low risk for recurrent venous thromboembolism by measuring thrombin generation. Jama. 2006; 296(4): p. 397-402.

49. Reverter JC, Beguin S, Kessels H, Kumar R, Hemker HC, Coller BS. Inhibition of platelet-mediated, tissue factor-induced thrombin generation by the mouse/human chimeric 7E3 antibody. Potential implications for the effect of c7E3 Fab treatment on acute thrombosis and "clinical restenosis". J Clin Invest. 1996; 98(3): p. 863874 . 
50. Bosch Y, Al Dieri R, ten Cate H, Nelemans P, Bloemen S, Hemker C, Weerwind P, Maessen J, Mochtar B. Preoperative thrombin generation is predictive for the risk of blood loss after cardiac surgery: a research article. J Cardiothorac Surg. 2013; 8: p. 154.

51. Coakley M, Hall JE, Evans C, Duff E, Billing V, Yang L, McPherson D, Stephens E, Macartney N, Wilkes AR, Collins PW. Assessment of thrombin generation measured before and after cardiopulmonary bypass surgery and its association with postoperative bleeding. J Thromb Haemost. 2011; 9(2): p. 282-292.

52. Gustafsson D, Elg M. The pharmacodynamics and pharmacokinetics of the oral direct thrombin inhibitor ximelagatran and its active metabolite melagatran: a minireview. Thromb Res. 2003; 109 Suppl 1: p. S9-15.

53. Mueck W, Borris LC, Dahl OE, Haas S, Huisman MV, Kakkar AK, Kalebo P, Muelhofer E, Misselwitz F, Eriksson BI. Population pharmacokinetics and pharmacodynamics of once- and twice-daily rivaroxaban for the prevention of venous thromboembolism in patients undergoing total hip replacement. Thromb Haemost. 2008; 100(3): p. 453-461.

54. Delavenne X, Zufferey P, Baylot D, Nguyen P, Borg JY, Fontenay M, Deygas B, Mismetti P, Laporte S. Population pharmacokinetics of fondaparinux administered at prophylactic doses after major orthopaedic surgery in everyday practice. Thromb Haemost. 2010; 104(2): p. 252-260.

55. Hacquard M, Perrin J, Lelievre N, Vigneron C, Lecompte T. Inter-individual variability of effect of 7 low molecular weight antithrombin-dependent anticoagulants studied in vitro with Calibrated Automated Thrombography. Thromb Res. 2011; 127(1): p. 29-34.

56. Al Dieri R, Alban S, Beguin S, Hemker HC. Fixed dosage of low-molecular-weight heparins causes large individual variation in coagulability, only partly correlated to body weight. J Thromb Haemost. 2006; 4(1): p. 83-89.

57. Rothwell PM. Can overall results of clinical trials be applied to all patients? Lancet. 1995; 345(8965): p. 1616-1619. 



\section{Chapter 2}

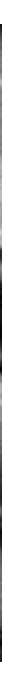

\section{Is there a reason for testing thrombin generation?}

Saartje Bloemen, Bas de Laat, H. Coenraad Hemker, Raed Al Dieri

Journal of Applied Hematology 2012; (3)1: 9-17. 


\section{Abstract}

Thrombin is a focal player in the coagulation system. Thrombin formation and platelet reactions occur concurrently immediately after a wound happens. Thrombin generation (TG) in platelet-rich plasma, therefore, is a close approximation of an integral function test of the hemostatic-thrombotic mechanism. In clotting blood, a transient wave of thrombin appears after a lag time. Clotting occurs at the start of the wave. The duration of the clotting time reflects the function of the initiation mechanism. The function of the production mechanism that is responsible for the burst is reflected in the area under the TG curve (endogenous thrombin potential, ETP). Clotting time and ETP therefore reflect different mechanisms and may or may not be correlated. Calibrated automated thrombinography (CAT) allows quantitative assessment of the TG curve in plateletpoor as well as platelet-rich plasma. All conditions (congenital, acquired, druginduced) that increase TG cause a thrombotic tendency. All conditions (congenital, acquired and drug-induced) that decrease TG prevent thrombosis, but in excess, cause bleeding. Diminution of TG is a common denominator of all antithrombotic treatments, including anti-platelet drugs. Hence, the first law of hemostasis and thrombosis is "The more thrombin the less bleeding but the more thrombosis; the less thrombin the more bleeding but the less thrombosis". Procedures to measure TG at point-of-care are under development. 


\section{Introduction}

Bleeding and thrombosis are life-threatening complications that, together, kill more people than any other cause. Measuring the hemostatic function of blood via the formation of thrombin is important in these pathologies. Insight in thrombin generation (TG), therefore, is essential medical information [1-4].

Until today, clotting times are used to obtain insight into the overall activity of the coagulation system. They enjoy the benefit of being easy to obtain and are familiar. It is a serious hurdle, however, that they correlate poorly with the clinical picture. A thrombotic tendency is not reflected in a shortened clotting time. Mild bleeding disorders hardly prolong a clotting time, and a normal clotting time is no guarantee for the absence of a bleeding tendency. On the other hand, it is of little consequence whether a clotting time is prolonged by 4 or 10 times.

When the coagulation system is triggered, a burst of thrombin occurs after a certain lag time. The clot appears at the very beginning of that burst, so for all practical purposes, the clotting time is the same as the lag time of thrombin formation, and the bulk of thrombin is formed within the clot.

Steadily increasing evidence shows that the amount of thrombin activity that develops is a better marker of the function of the clotting system than is the clotting time, i.e., the time taken before the burst of thrombin starts. The activity is proportional to the concentration of thrombin and to the time that it is active, i.e., to the area under the concentration curve. This area is termed the endogenous thrombin potential [5].

The main message from measuring TG during the last few years is simply: the more thrombin the more thrombosis and the less bleeding; the less thrombin the more bleeding and the less thrombosis.

The magnitude of TG is determined by the concentrations of all the known and unknown clotting factors and inhibitors, together with some plasma proteins that modulate the response. The normal variation in clotting factors is $50-200 \%$ [6], and 


\section{Chapter 2}

the combination of these variations accounts for a large inter-individual variation of the TG parameters. The coefficient of variation is similar to that of body weight in a normal adult population ( $\mathrm{CV} \sim 16 \%)$. In a disease such as hemophilia, where one factor (FVIII) limits the amount of thrombin formed, the amount that is formed in spite of this limitation still varies based on the levels of the other factors. This might explain why the clinical picture corresponds badly with the concentration of the deficient factor [7].

Recent developments have made it possible to measure TG routinely in highthroughput fashion and thus have transformed it from a research tool into a tool for clinical use.

Thus far, it has become clear that measurement of TG is useful in clinical practice for management of venous thrombosis and the hemophilias (Figure 1). The effects of all antithrombotics, as well as that of treatments that do not significantly prolong clotting times, can be monitored with TG. A connection between arterial thrombosis and TG is very likely but has not been proven with the same rigor as with venous thrombosis.

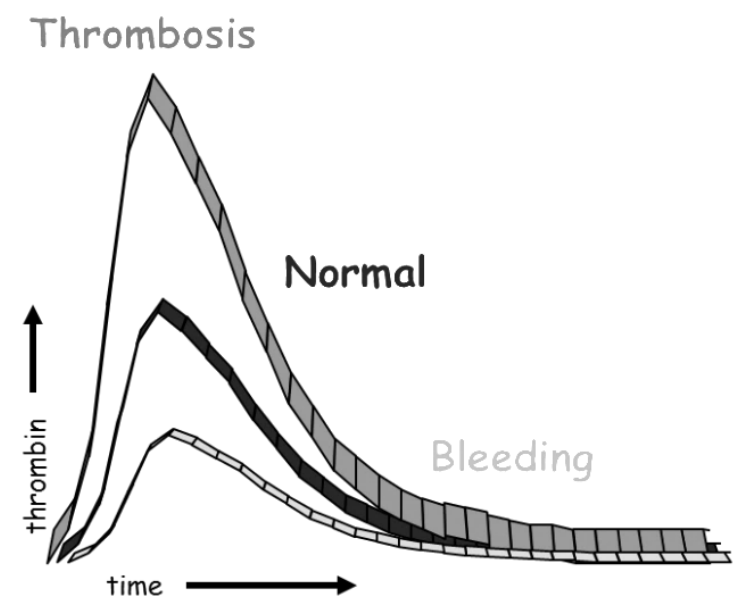

Figure 1: Illustration of thrombin generation in normal, hypo- and hypercoagulable states. 


\section{Why thrombin generation?}

The very term "clotting system", used for the set of reactions that produces thrombin, indicates that the appearance of a clot was thought to be the essence of its function. If it were, the clotting time would be the best possible function test of the clotting system, but for a number of reasons, it is not.

First, it is not always a good indicator of the amount of thrombin that is formed. We can even say that the clotting time is useful only insofar as it does indicate the amount of thrombin formed. The thromboplastin time is (inversely) proportional to the amount of thrombin formed in patients under oral anticoagulation and hence is useful there. The amount of thrombin diminishes during heparin therapy, but the thromboplastin time is not prolonged and therefore is useless. The activated partial thromboplastin time has to be used instead.

These discrepancies between clotting time and TG exist because the mechanism responsible for the clotting time is different from that responsible for bulk thrombin formation. The clotting time is the lag time of thrombin formation. During the lag time, small amounts of thrombin form in a mechanism in which feedback activation plays a limited role. The full TG mechanism is started only when there is sufficient thrombin to feed forward and back on all the thrombin-driven regulation loops. The second reason a clotting time is less than ideal is that it tells only half the story.

The third reason is the awkward dose-response curve of the clotting time. The relation between clotting time and any of the clotting factor concentrations is a hyperbolical one. There is a minimal clotting time that cannot be shortened further no matter how much we increase that clotting factor and that is attained at below $50 \%$ of the clotting factor. On the other hand, it is technically near impossible to distinguish between the very long clotting times that occur when clotting times are $<1 \%$ because measurements are so imprecise. A useful relation between clotting time and clotting factor concentration is limited to a range between $\sim 5 \%$ and $25 \%$ of the clotting factor in plasma. That is why low yet effective doses of e.g. lowmolecular weight heparins (but also other anticoagulants) do not prolong clotting 


\section{Chapter 2}

times (and consequently are sometimes thought not to affect the coagulation system).

The reason that the amount of thrombin is more important than the time before thrombin starts forming is that clotting fibrinogen is far from the only role thrombin plays. Thrombin, by acting on thrombin-activatable fibrinolysis inhibitor (TAFI), determines the resistance of a clot to fibrinolysis. Thrombin also provokes a number of hemostatic effects on different types of tissues and cells [8]. Last but not least, thrombin, by its action on platelets and clotting factors in vivo, provokes further clotting in the neighborhood.

The disadvantages of the clotting time are reflected in similar drawbacks of the lag times of TG and fibrin formation as measured with thrombelastography in its different forms [9-11] and in wave form analysis [12]. The 2 latter procedures display the effects of thrombin on fibrin formation, but they do not reflect TG because fibrin exhausts long before TG ends.

The potency of TG of the plasma (ex vivo TG) is not to be confused with the extent of ongoing thrombin formation in the body (in vivo TG). Prothrombin fragment 1-2 and thrombin-antithrombin (TAT) complexes appear in the circulation when thrombin is being generated in the body. Increased in vivo TG indicates an ongoing pathologic process [13], whereas elevated or decreased ex vivo TG implies that the function of the coagulation process is abnormal (e.g., hyperprothrombinemia [14], hemophilia [15], use of anticoagulants [16]). It does not necessarily indicate ongoing pathology, but indicates an increased risk of thrombosis or bleeding. The difference between the 2 processes appears, for example, in disseminated intravascular coagulation (DIC) with consumption coagulopathy, where the indicators of ongoing coagulation are high but the plasma capacity to generate thrombin is low [17]. In short, TG indicates a fire hazard, while fragment 1-2 and TAT are smoke detectors. 


\section{The TG curve and its variables}

An example of the course of free thrombin in clotting blood (plasma) is shown in figure 2. The main parameters are the lag time, the area under the curve (ETP), and the peak. Additional parameters are the time to peak and the steepness of the rising slope. Of these variables the ETP is the most robust one, because it is determined from the end level of the amount of fluorogenic product that is produced by free thrombin. The peak is more sensitive to variations in the TG mechanism but less robust because it is derived from the first derivative of the product-time curve. The slope steepness of the TG curve is a second derivative of that curve, and again, is less robust and more sensitive.

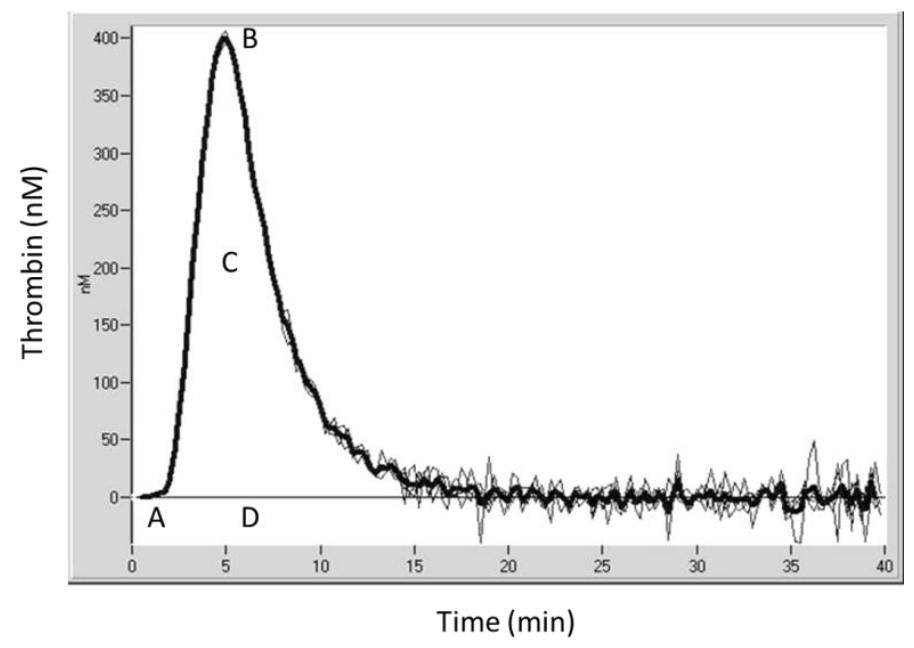

Figure 2: Parameters of the thrombin generation curve measured by calibrated automated thrombinography (CAT). (A) lag time, (B) peak height, (C) endogenous thrombin potential (ETP) and (D) time to peak.

The form of the TG curve can vary in many ways. In platelet poor plasma (PPP) with added procoagulant phospholipids (PPL) and $10 \mathrm{pM}$ tissue factor it is steep and early, in contact-activated plasma it is still steeper but may have a long lag time. In platelet-rich plasma (PRP), bulk TG awaits the feedback activation of the 


\section{Chapter 2}

platelets, as it provides the necessary PPL, and hence has a slow start. With direct reversible FXa inhibitors, a double peak is sometimes seen for as yet unexplained reasons.

\section{Thrombin generation and risk of thrombosis}

Increased formation of thrombin in plasma always induces a risk of venous thrombosis, whether it is due to deficiency of antithrombin, protein $\mathrm{C}$, or protein $\mathrm{S}$, or an excess of prothrombin, APC resistance, blood group non-O, or fibrinogen $\mathrm{y}^{\prime}$ $[14,18-26]$.

The defects in the protein C system, factor $\mathrm{V}$ Leiden included, are most readily recognized when thrombomodulin (TM) is added to the plasma $[27,28]$. The thrombotic tendency stimulated by oral contraceptives can be explained by the increase of TG caused by an acquired resistance to activated protein $\mathrm{C}$, possibly combined with other changes [29-33].

Patients with cancer are associated with a high risk of venous thromboembolism (VTE) [34-38]. It has recently been reported that the development of VTE in cancer was higher in patients with elevated TG compared to those with lower TG [37]. Conversely, a number of epidemiological studies, both retrospective [39-42] and prospective [43, 44], show a strong correlation between high ETP and the occurrence of venous thrombosis.

TG has been described as an excellent method to detect lupus anticoagulant [45]. The antiphospholipid syndrome is known for the association between antiphospholipid antibodies in plasma and vascular thrombosis and/or pregnancy morbidity [46]. These antiphospholipid antibodies can be detected due to their properties of prolonging phospholipid-dependent coagulation times [47]. We have found that certain thrombosis-related antibodies shorten the lag phase of thrombin formation, therefore decreasing clotting times [48]. In this respect, TG is superior compared to classic clotting assays in which hypercoagulability does not result in significant shortening of the clotting time. Furthermore, it was shown that 
antiphospholipid antibodies induce an important resistance to the activity of the protein $\mathrm{C}$ system and hence increase TG in the presence of TM [49].

This, together with the observation that all prevention and therapy diminishes TG, indicates such massive correlation between venous thrombosis and TG that one surmises there is a mechanistic relation.

The role of the plasmatic thrombin generating system is more evident in venous than in arterial disease. High levels of TG (ETP and peak) were associated with an increased risk of acute ischemic stroke, particularly in women, although no significant association was reported between TG and coronary heart disease [50]. There are, however, arguments to assume that thrombin plays a part in arterial thrombosis as well [51-55]. Excess amounts of factors II, VII, and VIII have been found to correlate with the occurrence of myocardial infarction. Additionally, higher than normal levels of VWF increase TG and are a risk factor for arterial thrombosis [56-62]. Both TG in PRP and VWF have been shown to be significantly higher than normal in a sub-population of young stroke patients ( 30\%) [63]. Clinical trials have shown that vitamin $K$ antagonists [64] as well as heparins $[65,66]$ decrease the reoccurrence rate of myocardial infarction. Platelet antagonists derive at least part of their effect by inhibiting TG in PRP [67-69]. In contrast, aspirin has been shown to be beneficial also in venous thrombosis [70]; the conventional view that arterial thrombosis is due to platelets and venous thrombosis to clotting appears to become less evident. Elevated thrombin formation was observed in atherosclerotic disorders such as echogenic carotid plaques [71]. TG was also reported to increase in polycythemia and thrombocythemia [72].

\section{Thrombin generation and bleeding disorders}

The measurement of factor levels with conventional functional assays is often of little value for predicting the presence and severity of a bleeding tendency in clinical practice. In patients with inherited deficiencies of clotting factors, the relation between the outcome of the coagulation screening tests, plasma levels of deficient factors, and bleeding tendency can vary distinctly depending on the 


\section{Chapter 2}

patient and type of deficiency [73]. The properties of the TG were correlated with the levels of clotting factors and the occurrence and severity of bleeding symptoms in well-defined cases of inherited deficiencies of fibrinogen and factors II, V, VII, VIII, IX, X, XI, XII and XIII [15, 73-83].

There is a poor correlation between factor level and clinical severity within a singlefactor deficiency such as hemophilia $A[7,84,85]$. This is also the case when a factor VIII determination is used that allows precise measurement in the $0.1-1 \%$ range [86]. TG in hemophilia $A$ was restored not only by infusion of factor VIII (Figure 3) or administration of DDAVP, but also by inhibitor-bypassing treatment with products containing prothrombin and/or FVIla [87-92]. This shows that bleeding can be treated by restoration of the TG capacity [93].

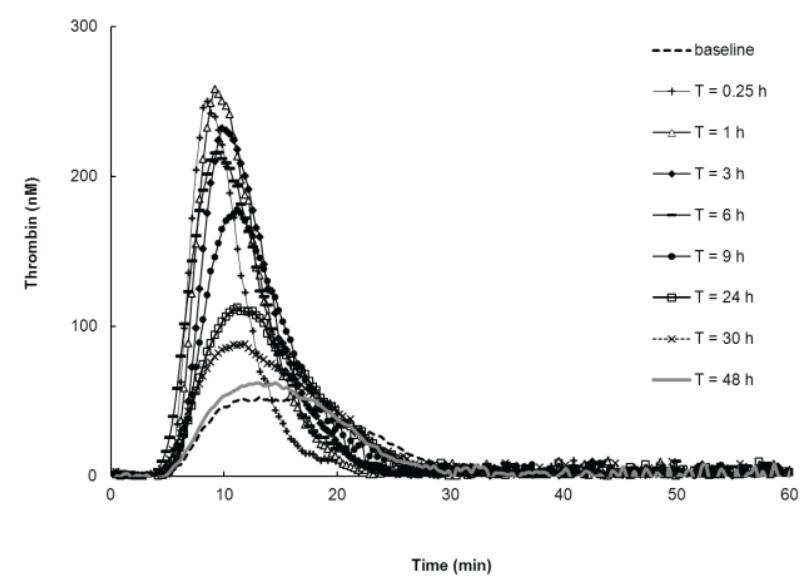

Figure 3: Thrombin generation in platelet poor plasma of severe hemophilia A patient with bleeding episodes before and after infusion of factor VIII concentrate.

It thus appears that a bleeding tendency becomes noticeable as soon as the ETP decreases to less than $20 \%$ of the average normal value [82, 94, 95]. This same threshold can be calculated from studies on oral anticoagulation. Bleeding risk increases at INR values greater than 4, which corresponds to an ETP of $20 \%$ of normal [96]. 
If it can be firmly established that the level of TG indicates the bleeding risk, not only would clinical decision making be much easier, but one could also make more economic use of the very costly factor concentrates.

Without claiming that it is the main cause of bleeding in platelet disease, we note that low TG does accompany platelet dysfunction. Severe thrombopenia causes decreased TG as well as the Glanzmann [70] and Bernard-Soulier [97] thrombopathies. TG in PRP is markedly diminished in von Willebrand's disease. The defect is much more pronounced in PRP than in PPP, which indicates that it cannot be explained by the concomitant deficiency of factor VIII [98].

One of the reasons that a low ETP results in a bleeding tendency is likely due to the fact that the amount of thrombin formed determines the amount of fibrinolysis inhibitor (TAFI) that is generated [99]. Low TG therefore causes increased fibrinolysis. It is likely that this is the explanation for the fibrinolytic character of much of the bleeding in hemophilia, and would explain the beneficial effect of antifibrinolytic agents [100].

\section{Is TG a reliable tool for monitoring antithrombotic therapy?}

Treatment and prevention of venous thrombosis can be achieved by inhibition of the synthesis of prothrombin and related clotting factors (via vitamin $\mathrm{K}$ antagonists), accelerating antithrombin activity (heparins), or by direct inhibition of thrombin or one of the enzymes that contributes to its activation. The common denominator is down-regulation of TG; consequently, measurement of TG is the common test for the anticoagulant effect. Thus, TG is also the only available method to quantify the combined effect of anticoagulants such as heparin and vitamin $\mathrm{K}$ antagonists given at the start of venous thrombosis treatment.

The modern direct reversible inhibitors of FXa (e.g. rivaroxaban) and thrombin (e.g. dabigatran) likewise act on TG [101-110]. 


\section{Chapter 2}

The effect of FXa is directly observable in TG experiments. The FXa inhibitors modify the appearance of the TG curve in that the peak is much more affected than the ETP, and sometimes, a double peak is observed. The reason behind this remains unknown, but we surmise there is inhibition of the feedback inhibition of TF-FVIla by the FXa-TFPI complex. The measurement of direct thrombin inhibitors presents a technical difficulty in that the calibrator in the calibrated automated thrombinography (CAT) procedure is inhibited, as is the TG curve, so that in the end, no net TG would result if the same sample used for TG measurement were used for calibration. The difficulty can be overcome by using normal plasma for calibration. However, this does add $\sim 5 \%$ to the experimental error. Another problem is that at low inhibitor concentrations, a spurious increase of a few percent of the ETP can be observed. The reason behind this phenomenon is known but the practical consequences can be neglected [111]. It is of interest to note that direct inhibition of thrombin also inhibits its anticoagulant function, i.e., the TM-induced limitation of TG [112].

An important question is what, in terms of TG, are the safe limits of anticoagulant treatment. With the use of oral anticoagulation, as with congenital bleeding disorders, bleeding increases at INR $>4$, which corresponds to an ETP of $<20 \%$ [96, 113]. Additionally, doubling the aPTT, however ill defined, has been used as a safe limit for treatment with heparins, which again corresponds to $\sim 80 \%$ inhibition of the ETP [114].

What diminution of the ETP corresponds to adequate anticoagulation is more difficult to say. Moderate increase (100-150\%) of the ETP due to hyperprothrombinaemia already is a risk factor. In addition, a below-average TG capacity is sufficient to produce a 4 times lower risk of recurrent thrombosis than that above average [115]. This suggests that any decrease of the ETP is accompanied by a proportional decrease of thrombosis risk. 


\section{Thrombin generation and blood platelets}

For many years, studies on blood coagulation have been carried out in PFP (platelet free plasma), whereas platelets were studied in anticoagulated blood. This allows the barest observation of interactions between the cellular and humoral components of the hemostatic and thrombotic system. A sharp distinction is often made between primary and secondary hemostasis and between venous and arterial thrombosis. However, recent research stresses the importance of crosstalk between platelets and the clotting system. Furie et al. reported that fibrin is seen approximately 12 seconds after an injury to a microvessel [116]. Given the fact that $\sim 10 \mathrm{nM}$ of thrombin clots fibrinogen in approximately 10 seconds, this means that TG at the injured site must be almost instantaneous. Data on TG in PRP have shown that any defect of platelet function, be it congenital or drug-induced, will inhibit TG [69, 97, 117, 118]. The experiments of Béguin et al. on TG in PRP clearly demonstrate that platelets are essential to provide the procoagulant surface required for the action of prothrombinase and tenase, and in a mechanism that is dependent upon specific platelet receptors [97, 98]. In addition to the inhibition of platelet aggregation, platelet antagonists such as abciximab [69, 117], clopidogrel [118], and aspirin [67] also inhibit TG in PRP. Although it is not their main mode of action, it is an interesting possibility that through decreasing the size of the platelet aggregate, the volume in which thrombin can form undisturbed by flow is also diminished.

\section{How to measure TG}

The first modern experiments (mid-20th century) of TG used the clotting time of diluted bovine plasma as an indicator of the thrombin concentration. The procedure was laborious and required approximately one man-hour of well-trained personnel per individual curve. In order to observe TG directly, a chromogenic thrombin substrate was added directly to the clotting plasma. The substrate, however, was quickly exhausted, so only the very beginning of TG was recorded. Moreover, due to their high affinity for thrombin, substrates strongly inhibited the physiological 


\section{Chapter 2}

feedback reactions of thrombin and thus produced a distorted view of the TG process. We then found substrates that, although specific for thrombin, bound with low affinity and were converted slowly, so they did not unduly inhibit thrombindependent reactions and were not consumed during the TG process. As the formation of product was to be monitored by optical density (OD), clot formation had to be avoided, and TG could only be measured in defibrinated; hence, plateletfree plasma. This problem was overcome by using substrates that yielded a fluorescent product. In an early publication, we did not realize that the velocity of fluorescence increase is not uniquely dependent on the thrombin activity as it is in an OD-based measurement, but also on the level of fluorescence. When we realized that a different calibration factor is required to calculate the concentration of thrombin at every level of fluorescence, we devised a method in which that calibration factor is continuously determined in a parallel experiment in which a constant thrombin activity is present. This is the basis of the present calibrated automated TG (CAT) method (Figure 2) [113].

\section{Prospective advances}

The extensive evidence for a direct role of thrombin in the hemostatic-thrombotic process, both from physiological and clinical studies, leads one to assume that TG is not only the purveyor of useful surrogate parameters for hemostasis and thrombosis, but that it is a function test of an essential element in these processes. This strongly suggests that there is not only a correlation between low TG and bleeding or high TG and thrombosis, but that a direct relation exists. If that is the case, then that function should be measured in a way that is quantitatively correct and under circumstances as near as possible to physiology.

Many measurable qualities of blood change in a manner that is dependent on the formation of thrombin. Many of them depend on clotting, i.e., upon fibrinogen turning into fibrin. This change can be registered by tensile strength (thrombelastography), turbidity (clot dynamics test), viscosity, and a large number 
of other variables. Others depend on the conversion of other quickly exhausted substrates [119]. Such methods probe only the beginning of the TG process.

Methods have also been published and used, by ourselves and others, that require defibrination of plasma [5] or that use inaccurate methods to calculate thrombin concentrations from measured reaction velocities $[115,120]$. Any of these methods will demonstrate correlations between the measured parameters and disturbances of the clotting system and thus, to a certain extent, can be used as a diagnostic tool.

At this moment, only CAT is capable of expressing the thrombin peak in $\mathrm{nM}$ and the ETP in nM.min with acceptable experimental error, especially when accurate thermostation is taken care of [121]. Further developments are in direct measurement from whole blood both under laboratory and under point-of-care conditions. 


\section{Chapter 2}

\section{References}

1. Hemker HC, Beguin S. Phenotyping the clotting system. Thromb Haemost. 2000; 84(5): p. 747-751.

2. Baglin T. The measurement and application of thrombin generation. Br J Haematol. 2005; 130(5): p. 653-661.

3. van Veen JJ, Gatt A, Makris M. Thrombin generation testing in routine clinical practice: are we there yet? Br J Haematol. 2008; 142(6): p. 889-903.

4. Ten Cate H. Thrombin generation in clinical conditions. Thromb Res. 2012; 129(3): p. 367-370.

5. Hemker HC, Wielders S, Kessels H, Beguin S. Continuous registration of thrombin generation in plasma, its use for the determination of the thrombin potential. Thromb Haemost. 1993; 70(4): p. 617-624.

6. Lester RH, Elston RC, Graham JB. Variations in levels of blood clotting factors IX and $\mathrm{X}$ in a population of normal men: possible genetic polymorphisms. Am J Hum Genet. 1972; 24(2): p. 168-180.

7. van den Berg HM, De Groot PH, Fischer K. Phenotypic heterogeneity in severe hemophilia. J Thromb Haemost. 2007; 5 Suppl 1: p. 151-156.

8. Siller-Matula JM, Schwameis M, Blann A, Mannhalter C, Jilma B. Thrombin as a multi-functional enzyme. Focus on in vitro and in vivo effects. Thromb Haemost. 2011; 106(6): p. 1020-1033.

9. Hartert H. Blutgerinnungsstudien mit der thromboelastographie, einemneuen untersuchungsverfahren. Klin Wochenschr. 1948; 26(37-38): p. 577-583.

10. Sorensen B, Johansen $\mathrm{P}$, Christiansen $\mathrm{K}$, Woelke M, Ingerslev J. Whole blood coagulation thrombelastographic profiles employing minimal tissue factor activation. J Thromb Haemost. 2003; 1(3): p. 551-558.

11. O'Donnell J, Riddell A, Owens D, Handa A, Pasi J, Hamilton G, Perry DJ. Role of the Thrombelastograph as an adjunctive test in thrombophilia screening. Blood Coagul Fibrinolysis. 2004; 15(3): p. 207-211.

12. Shima M. Understanding the hemostatic effects of recombinant factor VIla by clot wave form analysis. Semin Hematol. 2004; 41(1 Suppl 1): p. 125-131.

13. van der Poll $\mathrm{T}$, Buller HR, ten Cate $\mathrm{H}$, Wortel $\mathrm{CH}$, Bauer KA, van Deventer SJ, Hack CE, Sauerwein HP, Rosenberg RD, ten Cate JW. Activation of coagulation after administration of tumor necrosis factor to normal subjects. $N$ Engl $J$ Med. 1990; 322(23): p. 1622-1627. 
14. Kyrle PA, Mannhalter C, Beguin S, Stumpflen A, Hirschl M, Weltermann A, Stain M, Brenner B, Speiser W, Pabinger I, Lechner K, Eichinger S. Clinical studies and thrombin generation in patients homozygous or heterozygous for the G20210A mutation in the prothrombin gene. Arterioscler Thromb Vasc Biol. 1998; 18(8): p. 1287-1291.

15. Siegemund T, Petros S, Siegemund A, Scholz U, Engelmann L. Thrombin generation in severe haemophilia $A$ and $B$ : the endogenous thrombin potential in platelet-rich plasma. Thromb Haemost. 2003; 90(5): p. 781-786.

16. Kakkar VV, Hoppenstead DA, Fareed J, Kadziola Z, Scully M, Nakov R, Breddin HK. Randomized trial of different regimens of heparins and in vivo thrombin generation in acute deep vein thrombosis. Blood. 2002; 99(6): p. 1965-1970.

17. Seo JW, Kim HK, Kim JE, Park S, Cho HI. Prognostic values of the factor Xaactivated clotting time and endogenous thrombin potential in patients suspected of having disseminated intravascular coagulation. Thromb Res. 2009; 123(4): p. 565572.

18. Wielders S, Mukherjee M, Michiels J, Rijkers DT, Cambus JP, Knebel RW, Kakkar $\mathrm{V}$, Hemker HC, Beguin S. The routine determination of the endogenous thrombin potential, first results in different forms of hyper- and hypocoagulability. Thromb Haemost. 1997; 77(4): p. 629-636.

19. Egeberg O. Inherited Antithrombin Deficiency Causing Thrombophilia. Thromb Diath Haemorrh. 1965; 13: p. 516-530.

20. Griffin JH, Evatt B, Zimmerman TS, Kleiss AJ, Wideman C. Deficiency of protein C in congenital thrombotic disease. J Clin Invest. 1981; 68(5): p. 1370-1373.

21. Schwarz HP, Fischer M, Hopmeier P, Batard MA, Griffin JH. Plasma protein S deficiency in familial thrombotic disease. Blood. 1984; 64(6): p. 1297-1300.

22. Poort SR, Rosendaal FR, Reitsma PH, Bertina RM. A common genetic variation in the 3 -untranslated region of the prothrombin gene is associated with elevated plasma prothrombin levels and an increase in venous thrombosis. Blood. 1996; 88(10): p. 3698-3703.

23. Bertina RM, Koeleman BP, Koster T, Rosendaal FR, Dirven RJ, de Ronde H, van der Velden PA, Reitsma PH. Mutation in blood coagulation factor $\mathrm{V}$ associated with resistance to activated protein C. Nature. 1994; 369(6475): p. 64-67.

24. Dahlback B, Carlsson M, Svensson PJ. Familial thrombophilia due to a previously unrecognized mechanism characterized by poor anticoagulant response to 
activated protein C: prediction of a cofactor to activated protein C. Proc Natl Acad Sci U S A. 1993; 90(3): p. 1004-1008.

25. Jick H, Slone D, Westerholm B, Inman WH, Vessey MP, Shapiro S, Lewis GP, Worcester J. Venous thromboembolic disease and ABO blood type. A cooperative study. Lancet. 1969; 1(7594): p. 539-542.

26. Uitte de Willige S, de Visser MC, Houwing-Duistermaat JJ, Rosendaal FR, Vos HL, Bertina RM. Genetic variation in the fibrinogen gamma gene increases the risk for deep venous thrombosis by reducing plasma fibrinogen gamma' levels. Blood. 2005; 106(13): p. 4176-4183.

27. Duchemin J, Pittet JL, Tartary M, Beguin S, Gaussem P, Alhenc-Gelas M, Aiach M. A new assay based on thrombin generation inhibition to detect both protein $\mathrm{C}$ and protein S deficiencies in plasma. Thromb Haemost. 1994; 71(3): p. 331-338.

28. Curvers J, Thomassen MC, Rimmer J, Hamulyak K, van der Meer J, Tans G, Preston FE, Rosing J. Effects of hereditary and acquired risk factors of venous thrombosis on a thrombin generation-based APC resistance test. Thromb Haemost. 2002; 88(1): p. 5-11.

29. Nicolaes GA, Thomassen MC, Tans G, Rosing J, Hemker HC. Effect of activated protein $\mathrm{C}$ on thrombin generation and on the thrombin potential in plasma of normal and APC-resistant individuals. Blood Coagul Fibrinolysis. 1997; 8(1): p. 28-38.

30. Rosing J, Tans G, Nicolaes GA, Thomassen MC, van Oerle R, van der Ploeg PM, Heijnen P, Hamulyak K, Hemker HC. Oral contraceptives and venous thrombosis: different sensitivities to activated protein $C$ in women using second- and thirdgeneration oral contraceptives. Br J Haematol. 1997; 97(1): p. 233-238.

31. Rotteveel RC, Roozendaal KJ, Eijsman L, Hemker HC. The influence of oral contraceptives on the time-integral of thrombin generation (thrombin potential). Thromb Haemost. 1993; 70(6): p. 959-962.

32. Schubert L, Gibelli A, De Nicola P. Blood coagulation and fibrinolysis in patients treated with an anovulatory drug with estroprogestational action. Ann Ostet Ginecol Med Perinat. 1968; 90(1): p. 48-58.

33. van Deijk WA, van Dam-Mieras MC, Muller AD, Hemker HC. Evaluation of a coagulation assay determining the activity state of factor VII in plasma. Haemostasis. 1983; 13(3): p. 192-197.

34. Rickles FR, Patierno S, Fernandez PM. Tissue factor, thrombin, and cancer. Chest. 2003; 124(3 Suppl): p. 58S-68S. 
35. Orbe J, Zudaire M, Serrano R, Coma-Canella I, Martinez de Sizarrondo S, Rodriguez JA, Paramo JA. Increased thrombin generation after acute versus chronic coronary disease as assessed by the thrombin generation test. Thromb Haemost. 2008; 99(2): p. 382-387.

36. Falanga A, Panova-Noeva M, Russo L. Procoagulant mechanisms in tumour cells. Best Pract Res Clin Haematol. 2009; 22(1): p. 49-60.

37. Ay C, Dunkler D, Simanek R, Thaler J, Koder S, Marosi C, Zielinski C, Pabinger I. Prediction of venous thromboembolism in patients with cancer by measuring thrombin generation: results from the Vienna Cancer and Thrombosis Study. J Clin Oncol. 2011; 29(15): p. 2099-2103.

38. Ferroni P, Martini F, Portarena I, Grenga I, Riondino S, La Farina F, Laudisi A, Roselli M, Guadagni F. An activated protein C-dependent thrombin generation assay predicts chemotherapy-associated venous thromboembolism in cancer patients. Thromb Haemost. 2011; 105(5): p. 931-932.

39. Dargaud Y, Trzeciak MC, Bordet JC, Ninet J, Negrier C. Use of calibrated automated thrombinography +/- thrombomodulin to recognise the prothrombotic phenotype. Thromb Haemost. 2006; 96(5): p. 562-567.

40. ten Cate-Hoek AJ, Dielis AW, Spronk HM, van Oerle R, Hamulyak K, Prins MH, ten Cate $\mathrm{H}$. Thrombin generation in patients after acute deep-vein thrombosis. Thromb Haemost. 2008; 100(2): p. 240-245.

41. Tripodi A, Martinelli I, Chantarangkul V, Battaglioli T, Clerici M, Mannucci PM. The endogenous thrombin potential and the risk of venous thromboembolism. Thromb Res. 2007; $121(3)$ : p. 353-359.

42. van Hylckama Vlieg A, Christiansen SC, Luddington R, Cannegieter SC, Rosendaal FR, Baglin TP. Elevated endogenous thrombin potential is associated with an increased risk of a first deep venous thrombosis but not with the risk of recurrence. Br J Haematol. 2007; 138(6): p. 769-774.

43. Besser M, Baglin C, Luddington R, van Hylckama Vlieg A, Baglin T. High rate of unprovoked recurrent venous thrombosis is associated with high thrombingenerating potential in a prospective cohort study. J Thromb Haemost. 2008; 6(10): p. $1720-1725$.

44. Tripodi A. The history of phenotypic testing in thrombosis and hemostasis. Semin Thromb Hemost. 2008; 34(7): p. 585-592. 


\section{Chapter 2}

45. Devreese K, Peerlinck K, Arnout J, Hoylaerts MF. Laboratory detection of the antiphospholipid syndrome via calibrated automated thrombography. Thromb Haemost. 2009; 101(1): p. 185-196.

46. de Laat B, Mertens K, de Groot PG. Mechanisms of disease: antiphospholipid antibodies-from clinical association to pathologic mechanism. Nat Clin Pract Rheumatol. 2008; 4(4): p. 192-199.

47. de Laat B, Derksen RH, Reber G, Musial J, Swadzba J, Bozic B, Cucnik S, Regnault V, Forastiero R, Woodhams BJ, De Groot PG. An international multicentre-laboratory evaluation of a new assay to detect specifically lupus anticoagulants dependent on the presence of anti-beta2-glycoprotein autoantibodies. J Thromb Haemost. 2011; 9(1): p. 149-153.

48. de Laat B, van Os G, Ninivaggi M, Agar C, de Groot P, Hemker HC, Lindhout T, Meijers J. Anti-domain I antibodies have a prothrombotic character on coagulation by inhibiting the anticoagulant effect of beta2GPI. J Thromb Haemost. 2010; 9(suppl. 02): p. (abstract).

49. Regnault V, Beguin S, Wahl D, de Maistre E, Coenraad Hemker H, Lecompte T. Thrombinography shows acquired resistance to activated protein $\mathrm{C}$ in patients with lupus anticoagulants. Thromb Haemost. 2003; 89(2): p. 208-212.

50. Carcaillon L, Alhenc-Gelas M, Bejot Y, Spaft C, Ducimetiere P, Ritchie K, Dartigues $\mathrm{JF}$, Scarabin PY. Increased thrombin generation is associated with acute ischemic stroke but not with coronary heart disease in the elderly: the Three-City cohort study. Arterioscler Thromb Vasc Biol. 2011; 31(6): p. 1445-1451.

51. Gast A, Tschopp TB, Baumgartner HR. Thrombin plays a key role in late platelet thrombus growth and/or stability. Effect of a specific thrombin inhibitor on thrombogenesis induced by aortic subendothelium exposed to flowing rabbit blood. Arterioscler Thromb. 1994; 14(9): p. 1466-1474.

52. Badimon L, Badimon JJ, Lassila R, Heras M, Chesebro JH, Fuster V. Thrombin regulation of platelet interaction with damaged vessel wall and isolated collagen type I at arterial flow conditions in a porcine model: effects of hirudins, heparin, and calcium chelation. Blood. 1991; 78(2): p. 423-434.

53. Badimon L, Badimon JJ, Fuster V. Thrombogenesis and inhibition of platelet aggregation. Experimental aspects and future approaches. Z Kardiol. 1990; 79 Suppl 3: p. 133-145.

54. Heras M, Chesebro JH, Webster MW, Mruk JS, Grill DE, Penny WJ, Bowie EJ, Badimon L, Fuster V. Hirudin, heparin, and placebo during deep arterial injury in 
the pig. The in vivo role of thrombin in platelet-mediated thrombosis. Circulation. 1990; 82(4): p. 1476-1484.

55. Ulrich-Mockel NV, Riehle M, Vollert J, Heller G, Jr., Stork T, Riess H, Muller C, Frei $\mathrm{U}$, Mockel M. Thrombin activity throughout the acute phase of acute ST-elevation myocardial infarction and the relation to outcome. Biomarkers. 2009; 14(5): p. 311 316.

56. Giroud M, Dutrillaux F, Lemesle M, Volot F, Lorenzini JL, Becker F, Dumas R. Coagulation abnormalities in lacunar and cortical ischemic stroke are quite different. Neurol Res. 1998; 20(1): p. 15-18.

57. Gurfinkel E, Altman R, Scazziota A, Rouvier J, Mautner B. Importance of thrombosis and thrombolysis in silent ischaemia: comparison of patients with acute myocardial infarction and unstable angina. Br Heart J. 1994; 71(2): p. 151-155.

58. Haider AW, Andreotti F, Thompson GR, Kluft C, Maseri A, Davies GJ. Serum lipoprotein(a) level is related to thrombin generation and spontaneous intermittent coronary occlusion in patients with acute myocardial infarction. Circulation. 1996; 94(9): p. 2072-2076.

59. Martinez-Sales V, Vila V, Reganon E, Goberna MA, Ferrando F, Palencia MA, Aznar J. Elevated thrombotic activity after myocardial infarction: A 2-year follow-up study. Haemostasis. 1998; 28(6): p. 301-306.

60. Soskin P, Wiesel ML, Mossard JM, Grunebaum L, Arbogast R, Roul G, Bareiss P, Sacrez A, Cherrier F, Cazenave JP. Potential thrombogenicity of coronary angioplasty compared with coronary angiography. Blood Coagul Fibrinolysis. 1994; 5(6): p. 965-966.

61. Tanaka M, Suzuki A. Hemostatic abnormalities in acute myocardial infarction as detected by specific blood markers. Thromb Res. 1994; 76(3): p. 289-298.

62. Soskin P, Mossard JM, Arbogast R, Wiesel ML, Grunebaum L, Roul G, Bareiss P, Moulichon ME, Cazenave JP, Sacrez A. Variation in von Willebrand's Factor according to the treatment of acute myocardial infarction: physiopathological and clinical implications. Eur Heart J. 1994; 15(4): p. 479-482.

63. Faber CG, Lodder J, Kessels F, Troost J. Thrombin generation in platelet-rich plasma as a tool for the detection of hypercoagulability in young stroke patients. Pathophysiol Haemost Thromb. 2003; 33(1): p. 52-58.

64. A double-blind trial to assess long-term oral anticoagulant therapy in elderly patients after myocardial infarction. Report of the Sixty Plus Reinfarction Study Research Group. Lancet. 1980; 2(8202): p. 989-994. 


\section{Chapter 2}

65. Neri Serneri GG, Modesti PA, Gensini GF, Branzi A, Melandri G, Poggesi L, Rostagno C, Tamburini C, Carnovali M, Magnani B. Randomised comparison of subcutaneous heparin, intravenous heparin, and aspirin in unstable angina. Studio Epoorine Sottocutanea nell'Angina Instobile (SESAIR) Refrattorie Group. Lancet. 1995; 345(8959): p. 1201-1204.

66. Neri Serneri GG, Rovelli F, Gensini GF, Pirelli S, Carnovali M, Fortini A. Effectiveness of low-dose heparin in prevention of myocardial reinfarction. Lancet. 1987; 1(8539): p. 937-942.

67. Kessels H, Beguin S, Andree H, Hemker HC. Measurement of thrombin generation in whole blood--the effect of heparin and aspirin. Thromb Haemost. 1994; 72(1): p. 78-83.

68. Musial J, Radwan J, Szczeklik A. Aspirin delays thrombin generation in vitro through interaction with platelet phospholipids. Thromb Res. 1997; 85(4): p. 367368.

69. Reverter JC, Beguin S, Kessels H, Kumar R, Hemker HC, Coller BS. Inhibition of platelet-mediated, tissue factor-induced thrombin generation by the mouse/human chimeric 7E3 antibody. Potential implications for the effect of c7E3 Fab treatment on acute thrombosis and "clinical restenosis". J Clin Invest. 1996; 98(3): p. 863874.

70. Prevention of pulmonary embolism and deep vein thrombosis with low dose aspirin: Pulmonary Embolism Prevention (PEP) trial. Lancet. 2000; 355(9212): p. 12951302.

71. With Noto AT, Mathiesen EB, Osterud B, Amiral J, Vissac AM, Hansen JB. Increased thrombin generation in persons with echogenic carotid plaques. Thromb Haemost. 2008; 99(3): p. 602-608.

72. Panova-Noeva M, Marchetti M, Spronk HM, Russo L, Diani E, Finazzi G, Salmoiraghi S, Rambaldi A, Barbui T, Ten Cate H, Falanga A. Platelet-induced thrombin generation by the calibrated automated thrombogram assay is increased in patients with essential thrombocythemia and polycythemia vera. Am J Hematol. 2011; 86(4): p. 337-342.

73. Peyvandi F, Mannucci PM. Rare coagulation disorders. Thromb Haemost. 1999; 82(4): p. 1207-1214.

74. Gilmore R, Harmon S, Gannon C, Byrne M, O'Donnell JS, Jenkins PV. Thrombin generation in haemophilia A patients with mutations causing factor VIII assay discrepancy. Haemophilia. 2010; 16(4): p. 671-674. 
75. Santagostino E, Mancuso ME, Tripodi A, Chantarangkul V, Clerici M, Garagiola I, Mannucci PM. Severe hemophilia with mild bleeding phenotype: molecular characterization and global coagulation profile. J Thromb Haemost. 2010; 8(4): p. 737-743.

76. van Veen JJ, Gatt A, Bowyer AE, Cooper PC, Kitchen S, Makris M. Calibrated automated thrombin generation and modified thromboelastometry in haemophilia A. Thromb Res. 2009; 123(6): p. 895-901.

77. Gatt A, van Veen JJ, Woolley AM, Kitchen S, Cooper P, Makris M. Thrombin generation assays are superior to traditional tests in assessing anticoagulation reversal in vitro. Thromb Haemost. 2008; 100(2): p. 350-355.

78. van Veen JJ, Gatt A, Bowyer AE, Cooper PC, Kitchen S, Makris M. The effect of tissue factor concentration on calibrated automated thrombography in the presence of inhibitor bypass agents. Int J Lab Hematol. 2009; 31(2): p. 189-198.

79. Trossaert M, Regnault V, Sigaud M, Boisseau P, Fressinaud E, Lecompte T. Mild hemophilia A with factor VIII assay discrepancy: using thrombin generation assay to assess the bleeding phenotype. J Thromb Haemost. 2008; 6(3): p. 486-493.

80. Lewis SJ, Stephens E, Florou G, Macartney NJ, Hathaway LS, Knipping J, Collins $\mathrm{PW}$. Measurement of global haemostasis in severe haemophilia A following factor VIII infusion. Br J Haematol. 2007; 138(6): p. 775-782.

81. Beltran-Miranda CP, Khan A, Jaloma-Cruz AR, Laffan MA. Thrombin generation and phenotypic correlation in haemophilia A. Haemophilia. 2005; 11(4): p. 326-334.

82. Dargaud Y, Beguin S, Lienhart A, Al Dieri R, Trzeciak C, Bordet JC, Hemker HC, Negrier C. Evaluation of thrombin generating capacity in plasma from patients with haemophilia A and B. Thromb Haemost. 2005; 93(3): p. 475-480.

83. Chantarangkul V, Clerici M, Bressi C, Giesen PL, Tripodi A. Thrombin generation assessed as endogenous thrombin potential in patients with hyper- or hypocoagulability. Haematologica. 2003; 88(5): p. 547-554.

84. van Dijk K, van der Bom JG, Fischer K, Grobbee DE, van den Berg HM. Do prothrombotic factors influence clinical phenotype of severe haemophilia? A review of the literature. Thromb Haemost. 2004; 92(2): p. 305-310.

85. van Dijk K, van der Bom JG, Fischer K, de Groot PG, van den Berg HM. Phenotype of severe hemophilia $A$ and plasma levels of risk factors for thrombosis. $J$ Thromb Haemost. 2007; 5(5): p. 1062-1064. 
86. Ninivaggi $M$, Dargaud $Y$, van Oerle $R$, de Laat $B$, Hemker HC, Lindhout $T$. Thrombin generation assay using factor IXa as a trigger to quantify accurately factor VIII levels in haemophilia A. J Thromb Haemost. 2011; 9(8): p. 1549-1555.

87. Keularts IM, Hamulyak K, Hemker HC, Beguin S. The effect of DDAVP infusion on thrombin generation in platelet-rich plasma of von Willebrand type 1 and in mild haemophilia A patients. Thromb Haemost. 2000; 84(4): p. 638-642.

88. Dargaud $Y$, Lienhart A, Meunier S, Hequet $O$, Chavanne $H$, Chamouard V, Marin $S$, Negrier C. Major surgery in a severe haemophilia $A$ patient with high titre inhibitor: use of the thrombin generation test in the therapeutic decision. Haemophilia. 2005; 11(5): p. 552-558.

89. Hedner U. Dosing with recombinant factor viia based on current evidence. Semin Hematol. 2004; 41(1 Suppl 1): p. 35-39.

90. Hedner U. Mechanism of action of recombinant activated factor VII: an update. Semin Hematol. 2006; 43(1 Suppl 1): p. S105-107.

91. Turecek PL, Varadi K, Keil B, Negrier C, Berntorp E, Astermark J, Bordet JC, Morfini M, Linari S, Schwarz HP. Factor VIII inhibitor-bypassing agents act by inducing thrombin generation and can be monitored by a thrombin generation assay. Pathophysiol Haemost Thromb. 2003; 33(1): p. 16-22.

92. Turecek PL, Varadi K, Schwarz HP. Update on the mechanism of action and future of activated prothrombin complex concentrates. Curr Hematol Rep. 2004; 3(5): p. 331-337.

93. Luporsi P, Chopard R, Janin S, Racadot E, Bernard Y, Ecarnot F, Seronde MF, Briand F, Guignier A, Descotes-Genon V, Meneveau N, Schiele F. Use of recombinant factor VIla (NovoSeven $((\mathrm{R}))$ ) in 8 patients with ongoing lifethreatening bleeding treated with fondaparinux. Acute Card Care. 2011; 13(2): p. 93-98.

94. Al Dieri R, Peyvandi F, Santagostino E, Giansily M, Mannucci PM, Schved JF, Beguin S, Hemker HC. The thrombogram in rare inherited coagulation disorders: its relation to clinical bleeding. Thromb Haemost. 2002; 88(4): p. 576-582.

95. Keularts IM, Zivelin A, Seligsohn U, Hemker HC, Beguin S. The role of factor XI in thrombin generation induced by low concentrations of tissue factor. Thromb Haemost. 2001; 85(6): p. 1060-1065.

96. Azar AJ, Cannegieter SC, Deckers JW, Briet E, van Bergen PF, Jonker JJ, Rosendaal FR. Optimal intensity of oral anticoagulant therapy after myocardial infarction. J Am Coll Cardiol. 1996; 27(6): p. 1349-1355. 
97. Beguin S, Keularts I, Al Dieri R, Bellucci S, Caen J, Hemker HC. Fibrin polymerization is crucial for thrombin generation in platelet-rich plasma in a VWFGPlb-dependent process, defective in Bernard-Soulier syndrome. J Thromb Haemost. 2004; 2(1): p. 170-176.

98. Beguin S, Kumar R, Keularts I, Seligsohn U, Coller BS, Hemker HC. Fibrindependent platelet procoagulant activity requires GPlb receptors and von Willebrand factor. Blood. 1999; 93(2): p. 564-570.

99. Lisman T, Mosnier LO, Lambert T, Mauser-Bunschoten EP, Meijers JC, Nieuwenhuis HK, de Groot PG. Inhibition of fibrinolysis by recombinant factor VIla in plasma from patients with severe hemophilia A. Blood. 2002; 99(1): p. 175-179.

100. Lee AP, Boyle CA, Savidge GF, Fiske J. Effectiveness in controlling haemorrhage after dental scaling in people with haemophilia by using tranexamic acid mouthwash. Br Dent J. 2005; 198(1): p. 33-38; discussion 26.

101. Gulseth MP, Michaud J, Nutescu EA. Rivaroxaban: an oral direct inhibitor of factor Xa. Am J Health Syst Pharm. 2008; 65(16): p. 1520-1529.

102. Perzborn E, Kubitza D, Misselwitz F. Rivaroxaban. A novel, oral, direct factor Xa inhibitor in clinical development for the prevention and treatment of thromboembolic disorders. Hamostaseologie. 2007; 27(4): p. 282-289.

103. Graff J, von Hentig N, Misselwitz F, Kubitza D, Becka M, Breddin HK, Harder S. Effects of the oral, direct factor xa inhibitor rivaroxaban on platelet-induced thrombin generation and prothrombinase activity. J Clin Pharmacol. 2007; 47(11): p. 1398-1407.

104. Borris LC. Rivaroxaban, a new, oral, direct factor Xa inhibitor for thromboprophylaxis after major joint arthroplasty. Expert Opin Pharmacother. 2009; 10(6): p. 1083-1088.

105. Green L, Lawrie AS, Patel R, Stephens RC, Mackie IJ, Chitolie A, Haddad FS, Machin SJ. The effect of total hip/knee replacement surgery and prophylactic dabigatran on thrombin generation and coagulation parameters. Thromb Res. 2012; 130(5): p. 775-779.

106. Serebruany V, Sani Y, Lynch D, Schevchuck A, Svetlov S, Fong A, Thevathasan L, Hanley D. Effects of dabigatran in vitro on thrombin biomarkers by Calibrated Automated Thrombography in patients after ischemic stroke. J Thromb Thrombolysis. 2012; 33(1): p. 22-27.

107. Freyburger G, Macouillard G, Labrouche S, Sztark F. Coagulation parameters in patients receiving dabigatran etexilate or rivaroxaban: two observational studies in 
patients undergoing total hip or total knee replacement. Thromb Res. 2011; 127(5): p. 457-465.

108. Ammollo CT, Semeraro F, Incampo F, Semeraro N, Colucci M. Dabigatran enhances clot susceptibility to fibrinolysis by mechanisms dependent on and independent of thrombin-activatable fibrinolysis inhibitor. J Thromb Haemost. 2010; 8(4): p. 790-798.

109. Stangier J, Clemens A. Pharmacology, pharmacokinetics, and pharmacodynamics of dabigatran etexilate, an oral direct thrombin inhibitor. Clin Appl Thromb Hemost. 2009; 15 Suppl 1: p. 9S-16S.

110. Wienen W, Stassen JM, Priepke H, Ries UJ, Hauel N. In-vitro profile and ex-vivo anticoagulant activity of the direct thrombin inhibitor dabigatran and its orally active prodrug, dabigatran etexilate. Thromb Haemost. 2007; 98(1): p. 155-162.

111. Wagenvoord RJ, Deinum J, Elg M, Hemker HC. The paradoxical stimulation by a reversible thrombin inhibitor of thrombin generation in plasma measured with thrombinography is caused by alpha-macroglobulin-thrombin. $J$ Thromb Haemost. 2010; 8(6): p. 1281-1289.

112. Furugohri T, Sugiyama N, Morishima Y, Shibano T. Antithrombin-independent thrombin inhibitors, but not direct factor $\mathrm{Xa}$ inhibitors, enhance thrombin generation in plasma through inhibition of thrombin-thrombomodulin-protein C system. Thromb Haemost. 2011; 106(6): p. 1076-1083.

113. Hemker HC, Giesen P, Al Dieri R, Regnault V, de Smedt E, Wagenvoord R, Lecompte T, Beguin S. Calibrated automated thrombin generation measurement in clotting plasma. Pathophysiol Haemost Thromb. 2003; 33(1): p. 4-15.

114. Al Dieri R, Wagenvoord R, van Dedem GW, Beguin S, Hemker HC. The inhibition of blood coagulation by heparins of different molecular weight is caused by a common functional motif--the C-domain. J Thromb Haemost. 2003; 1(5): p. 907914.

115. Hron G, Kollars M, Binder BR, Eichinger S, Kyrle PA. Identification of patients at low risk for recurrent venous thromboembolism by measuring thrombin generation. Jama. 2006; 296(4): p. 397-402.

116. Furie B, Furie BC. Mechanisms of thrombus formation. N Engl J Med. 2008; 359(9): p. 938-949.

117. Al Dieri R, Beguin S, Hemker HC. The ionic contrast medium ioxaglate interferes with thrombin-mediated feedback activation of factor V, factor VIII and platelets. $J$ Thromb Haemost. 2003; 1(2): p. 269-274. 
118. Herault JP, Dol F, Gaich C, Bernat A, Herbert JM. Effect of clopidogrel on thrombin generation in platelet-rich plasma in the rat. Thromb Haemost. 1999; 81(6): p. 957960.

119. Calatzis A, Reininger A, Spannagl M, Schramm W. Rapid and automated quantification of the kinetics of thrombin formation using the Thrombin Dynamics Test (TDT). J Thromb Haemost. 2003; 1: p. 1589 (abstract).

120. Hemker HC, Giesen PL, Ramjee M, Wagenvoord R, Beguin S. The thrombogram: monitoring thrombin generation in platelet-rich plasma. Thromb Haemost. 2000; 83(4): p. 589-591.

121. De Smedt E, Hemker HC. Thrombin generation is extremely sensitive to preheating conditions. J Thromb Haemost. 2011; 9(1): p. 233-234. 



\section{Chapter 3}

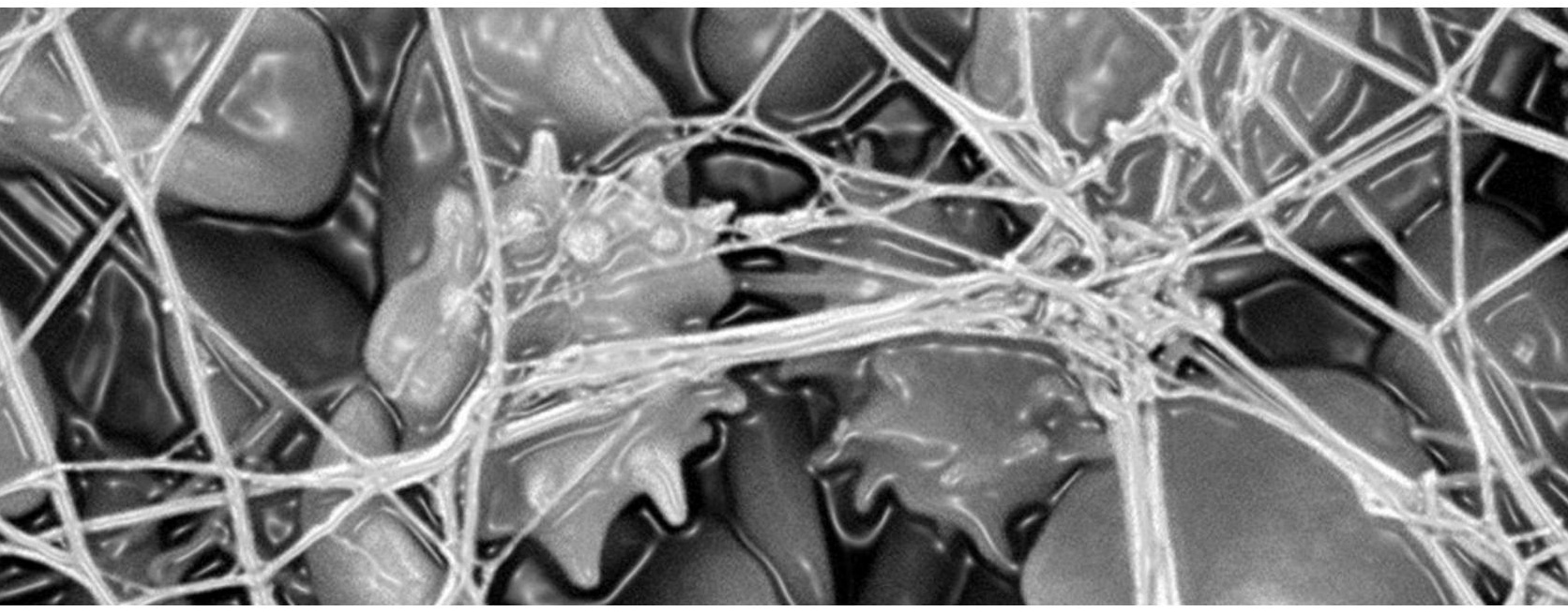

\section{Procoagulant effect of vitamin $\mathrm{K}$ antagonists?}

Raed Al Dieri, Arina ten Cate-Hoek, Saartje Bloemen, Hugo ten Cate, H. Coenraad Hemker

Journal of Thrombosis Haemostasis 2011; 9(12):2511-2512 


\section{Chapter 3}

Current monitoring of vitamin $\mathrm{K}$ antagonist (VKA) treatment is carried out with the international normalized ratio (INR), which assesses the procoagulant clotting factors II, VII and X but not the anticoagulant proteins $\mathrm{C}$ and $\mathrm{S}$, which are also vitamin $\mathrm{K}$ dependent. Diminished function of proteins $\mathrm{S}$ or $\mathrm{C}$ provokes a thrombotic tendency, as can be seen in inherited deficiency and in acquired decrease of function [1-3]. Such conditions show a higher than normal amount of thrombin being formed in the presence of thrombomodulin (TM). This suggests that the state of the coagulation system is better reflected by measuring in the presence of TM than in its absence. Because natural TM is a surface bound protein [4] one cannot define a physiological concentration and it remains uncertain what amount of TM added in vitro best represents the situation in vivo. Arbitrarily we choose concentrations that in our hands clearly reveal the defects in the conditions with dysfunction of the protein $\mathrm{C}$ system mentioned above, that is 10 and $20 \mathrm{nM}$ of TM. They roughly inhibit thrombin generation (TG) in normal pooled plasma by $20 \%$ and $50 \%$, respectively, when triggered with $5 \mathrm{pM}$ tissue factor (TF). TF likewise is a surface bound protein; here we choose $5 \mathrm{pM}$ because at this and higher concentration factor IX does not play a role so that the reaction mechanism of thrombin formation is comparable to that in the determination of the INR.

We measured TG at 5 pM TF and 0, 10 and 20 nM TM in the platelet-poor plasmas from 134 patients that were on VKA treatment for over 3 months and under control at the local anticoagulation clinic. The results were expressed in absolute values and as a percentage of the activity of normal pooled plasma measured under the same conditions (Figure 1). The normal pooled plasma was prepared as described previously [5]. A series of 44 normal volunteers tested against this plasma showed an activity of $94 \pm 16 \%$ of this normal plasma.

It is evident that the attenuation of TG in the presence of TM is much less than in its absence and that there are conditions in which certain patients on VKA treatment even generate more thrombin than normal subjects do.

Whether such conditions occur in vivo is not clear because an experiment in which elements of the structures that surround the blood, that is TF and TM, are added in 
soluble form is obviously a model, the applicability of which remains unknown. It is clear, however, that the presence of TM reveals prothrombotic conditions that remain hidden when $\mathrm{TM}$ is not present and therefore is a more representative model than tests executed in the presence of TF alone.
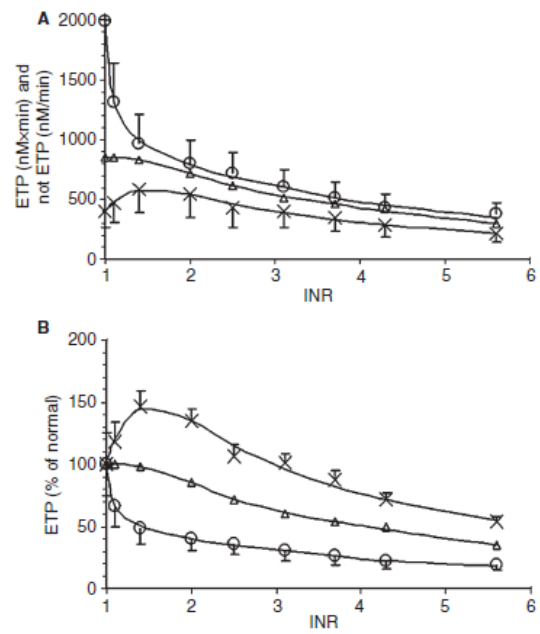

Figure 1: Effect of VKA therapy on amount of thrombin activity formed ex-vivo in the presence and absence of thrombomodulin (TM). Thrombin generation (TG) was measured in samples collected from patients treated with VKA (acenocoumarol). TG was determined at $5 \mathrm{pM}$ TF and $4 \mu \mathrm{M}$ phospholipids in the absence (o) and presence of $10 \mathrm{nM}(\Delta)$ and $20 \mathrm{nM}(\mathrm{X})$ soluble TM, as described previously by Hemker et al. Venous blood was collected into BD Vacutainer tubes (1 volume trisodium citrate $0.105 \mathrm{M}$ to 9 volumes blood) in the absence of corn trypsin inhibitor (Becton Dickinson,UK). Informed consent was obtained from all patients for blood sampling. Platelet poor plasma (PPP) was obtained by centrifuging the blood twice at $2,900 \mathrm{~g}$ for $10 \mathrm{~min}$ at room temperature. All reagents used were of analytical grade or higher. Recombinant relipidated human tissue factor (TF) not containing polybrene or $\mathrm{Ca}^{2+}$ was a kind gift from Dade Behring (Marburg, Germany). Synthetic procoagulant phospholipids (PL) were obtained from Avanti Polar Lipids Inc., (Alabaster, AL, USA) and added in the form of vesicles consisting of phosphatidylserine, phosphatidylethanolamine and phosphatidylcholine, 1:1:3, mol:mol. As a TM preparation we used recombinant human TM, a kind gift of Asahi (Japan). Prothrombin times (PT) were performed with an automated coagulation analyzer using innovin (Dade Behring, Marburg, Germany) as a thromboplastin reagent and the values of the INR were calculated accordingly. Panel A represents the absolute values of the endogenous thrombin potential (ETP). In panel B the ETP-data are expressed as \% of normal plasma tested under the same conditions. ETP is expressed as mean \pm SD. Error bars at $10 \mathrm{nM}$ TM are not shown in order to maintain clarity of the figure. 


\section{Chapter 3}

Persistent TG at INR in the lower areas of the INR 1-2 interval may account for the hypercoagulant state reported at the beginning of VKA treatment [6]. Interestingly, our patients were on treatment for over 3 months, showing that this hypercoagulability is not restricted to initial treatment states. The results are also in accordance with the finding of increased in vivo prothrombin turnover at lowintensity VKA treatment [7], as well as with the observation that low INR values have been shown to be inadequate for the prevention of myocardial infarction [8] whereas they may or may not have an effect in venous thrombosis [9]. This might suggest that the role of TM differs with the underlying pathology.

TM binds to thrombin and this thrombin is no longer available for procoagulant functions but still does convert the fluorogenic substrate added. Whether this contributes to the endogenous thrombin potential (ETP) that is measured depends upon the action of natural antithrombins on the bound thrombin. If TM, like $\alpha_{2^{-}}$ macroglobulin, protects thrombin from inactivation, then its effect is eliminated by the calculation procedures. If it does not influence the decay of thrombin, then a spurious increase of the ETP will occur that we calculated to be $<2 \%$ of the normal ETP.

We conclude that the effect of VKA treatment on TG is overestimated if no TM is present, although we cannot estimate to what extent. This has its consequences for the comparison between different forms of anticoagulation. All anticoagulants diminish TG, independent of their mode of action [10]. One can surmise that an identical decrease of TG will have an identical preventive effect, independent of the way in which it is obtained (e.g. by heparins, direct inhibitors of thrombin or factor $\mathrm{Xa}$ ). This is the more tempting because, on the basis of clinical observation, the 'preventive window' of VKA treatment has been very well defined in terms of INR, so that the effect of other anticoagulants in this way can be compared with a wellestablished standard. From the present results it follows that in such a comparison the effects on proteins $\mathrm{C}$ and $\mathrm{S}$ should not be neglected (i.e. that for this purpose TG should be measured in the presence of TM). How much TM should be added is not clear at the moment but will emerge from the correlation between clinical events and laboratory measurements. 


\section{References}

1. Bucciarelli P, Rosendaal FR, Tripodi A, Mannucci PM, De Stefano V, Palareti G, Finazzi G, Baudo F, Quintavalla R. Risk of venous thromboembolism and clinical manifestations in carriers of antithrombin, protein $\mathrm{C}$, protein $\mathrm{S}$ deficiency, or activated protein $\mathrm{C}$ resistance: a multicenter collaborative family study. Arterioscler Thromb Vasc Biol. 1999; 19(4): p. 1026-1033.

2. Vandenbroucke JP, Rosing J, Bloemenkamp KW, Middeldorp S, Helmerhorst FM, Bouma BN, Rosendaal FR. Oral contraceptives and the risk of venous thrombosis. N Engl J Med. 2001; 344(20): p. 1527-1535.

3. van Vliet HA, Bertina RM, Dahm AE, Rosendaal FR, Rosing J, Sandset PM, Helmerhorst FM. Different effects of oral contraceptives containing different progestogens on protein $S$ and tissue factor pathway inhibitor. $J$ Thromb Haemost. 2008; 6(2): p. 346-351.

4. Esmon NL, Owen WG, Esmon CT. Isolation of a membrane-bound cofactor for thrombin-catalyzed activation of protein C. J Biol Chem. 1982; 257(2): p. 859-864.

5. Hemker HC, Giesen P, Al Dieri R, Regnault V, de Smedt E, Wagenvoord R, Lecompte T, Beguin S. Calibrated automated thrombin generation measurement in clotting plasma. Pathophysiol Haemost Thromb. 2003; 33(1): p. 4-15.

6. Ansell J, Hirsh J, Poller L, Bussey H, Jacobson A, Hylek E. The pharmacology and management of the vitamin $\mathrm{K}$ antagonists: the Seventh ACCP Conference on Antithrombotic and Thrombolytic Therapy. Chest. 2004; 126(3 Suppl): p. 204S233 S.

7. Zeuthen EL, Lassen JF, Husted SE. Is there a hypercoagulable phase during initiation of antithrombotic therapy with oral anticoagulants in patients with atrial fibrillation? Thromb Res. 2003; 109(5-6): p. 241-246.

8. Azar AJ, Cannegieter SC, Deckers JW, Briet E, van Bergen PF, Jonker JJ, Rosendaal FR. Optimal intensity of oral anticoagulant therapy after myocardial infarction. J Am Coll Cardiol. 1996; 27(6): p. 1349-1355.

9. Schafer Al. Warfarin for venous thromboembolism - walking the dosing tightrope. $N$ Engl J Med. 2003; 348(15): p. 1478-1480.

10. Hemker HC, Al Dieri R, De Smedt E, Beguin S. Thrombin generation, a function test of the haemostatic-thrombotic system. Thromb Haemost. 2006; 96(5): p. 553561. 



\section{Chapter 4}

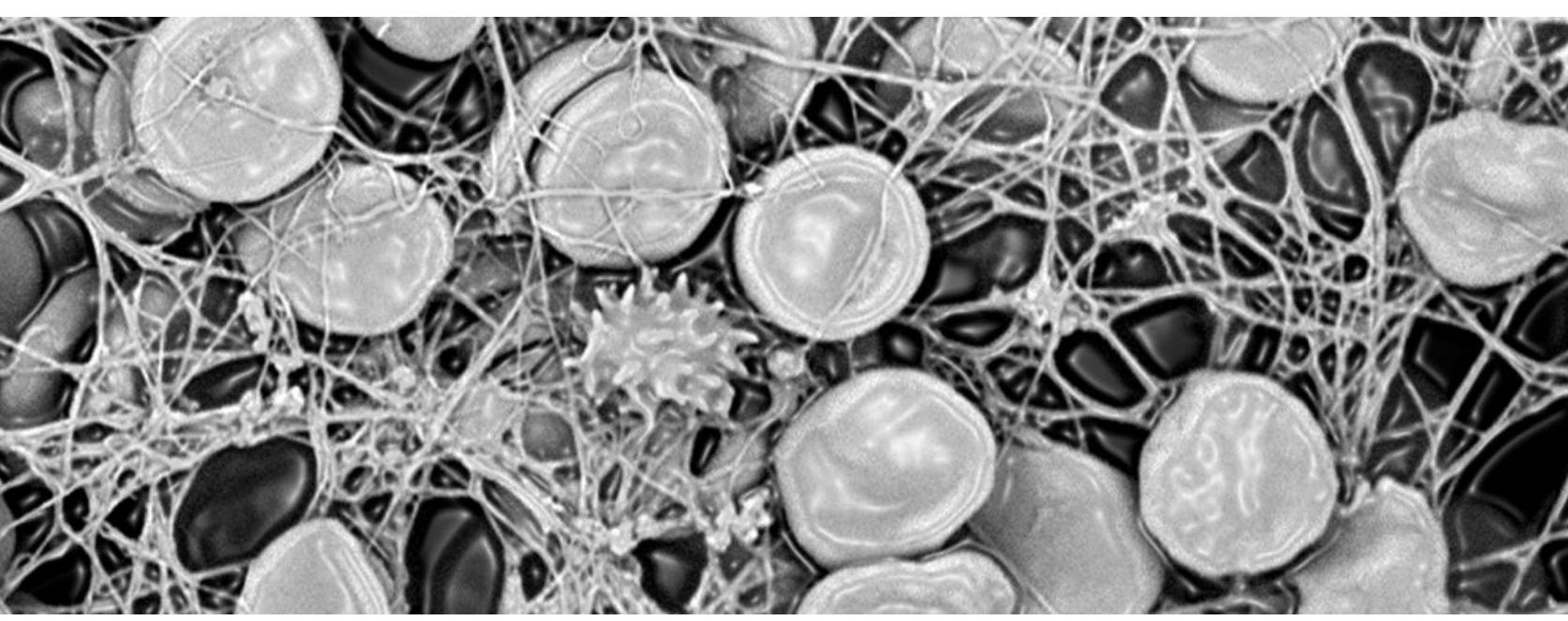

Vitamin $\mathrm{K}$ antagonist therapy can be evaluated by whole blood CAT and results in high plasma levels of factor VIII as well as fibrinogen

Saartje Bloemen, Marieke de Laat, Arina ten Cate-Hoek, Rinaldo van Meel, Hugo ten Cate, Bas de Laat, H. Coenraad Hemker, Raed Al Dieri

In preparation 


\section{Abstract}

Background: Vitamin $\mathrm{K}$ antagonists (VKAs) attenuate coagulation factors ( $\mathrm{F}$ ) II, VII, IX and X, as well as the anticoagulants protein C (PC) and protein S (PS). The prothrombin time (PT) used for monitoring the effect of VKAs only evaluates II, VII and $X$. Thrombin generation (TG) evaluates processes in the full coagulation system and recently TG in whole blood (WB) was developed. In this study we investigated thrombin generation in WB of patients taking VKAs. We also studied the clotting factors levels and determined the thickness of fibrin fibers.

Materials \& methods: Blood samples were collected from 150 consenting patients on VKA (of which 21 were excluded) and from 20 consenting healthy volunteers. TG was measured in WB, platelet rich plasma (PRP) and platelet poor plasma (PPP). The international normalized ratio (INR) and the levels of FII, V, VII, VIII, IX, and $X$ were assessed as well as antithrombin (ATIII), fibrinogen, PC and PS levels. Fibrin formed on paper disks during TG in WB was fixated for scanning electron microscopy (SEM) and the fibrin thickness was determined.

Results: All TG parameters in WB correlated significantly $(p<0.01)$ with the parameters in plasma. The endogenous thrombin potential (ETP) and peak from WB, PRP and PPP of the patients correlated significantly to the inverse of the INR ( $p$-value $<0.01$ ). Lag time and time to peak (ttpeak) correlated linearly with the INR ( $p$-value $<0.01$ ). Vitamin $\mathrm{K}$ dependent clotting factor levels decreased as the INR increased. Interestingly, patients had significantly higher levels of FVIII (184\% vs. $118 \%, p<0.01)$ and of fibrinogen $(4.0 \mathrm{~g} / \mathrm{l}$ vs. $3.2 \mathrm{~g} / \mathrm{l}, \mathrm{p}<0.01)$ compared to healthy donors. The fibrin fibers were thicker in the donors as compared to the patients.

Conclusion: Thrombin generation data in whole blood correlate well with plasma TG parameters. The fibrin fibers of patients were thinner than those of the donors, although less thrombin was formed in patients. This observation can be explained by the finding of higher fibrinogen levels in patients. The elevated levels of FVIII and fibrinogen might be a risk factor for recurrent thrombosis after cessation of therapy. 


\section{Introduction}

Vitamin $\mathrm{K}$ antagonists (VKAs) have been the most widely used oral anticoagulants for over 60 years. They exert their effect by inhibiting vitamin $\mathrm{K}$ epoxide reductase, thereby diminishing the $\mathrm{Y}$-carboxylation of vitamin $\mathrm{K}$ dependent proteins. The inhibition of the procoagulant factors II, VII, IX and $X$ is responsible for the antithrombotic effect of the VKAs. However, also the anticoagulant factors protein $\mathrm{C}$ and protein $\mathrm{S}$ are affected. This implies a procoagulant action of the VKAs, but this is overruled by the antithrombotic effect under normal circumstances [1-3].

The prothrombin time (PT) is the indicated test for monitoring the effect of VKAs and is standardized by using the International normalized ratio (INR). Studies have shown that an INR below 2.0 is associated with an increased thrombotic risk and levels above 3.5 are related to a higher risk of bleeding complications [4]. For most indications the therapeutic range is situated between 2.0 and 3.0 (2.0 and 3.5 in the Netherlands). The actual amount of time spent in this range (time within therapeutic range, TTR) is also associated with the occurrence of adverse outcomes (stroke, myocardial infarction and bleeding) [5].

The PT only encompasses a small part of coagulation. It only measures the time until the plasma starts clotting. At this point only $5 \%$ of the total thrombin is generated. Moreover thrombin has several functions beyond catalyzing fibrin formation. Thrombin activates platelets, which also have an important role in hemostasis. In addition, thrombin acts on thrombin activatable fibrinolysis inhibitor (TAFI), which influences clot strength [6].

In calibrated automated thrombinography (CAT) the amount of thrombin formed is measured instead of the time until formation of the fibrin clot. Thrombin generation testing has been used in the past to assess the effect of VKAs in plasma. An INR range of 2.0-3.0 is approximately covered by an endogenous thrombin potential (ETP) between 500-700 nM.min [7]. An ETP below 350 nM.min (<20\% of normal) results in an increased bleeding risk and corresponds to an INR $>4.0[8,9]$. Thrombin generation testing, up to this point, has been mostly performed in 


\section{Chapter 4}

plasma, but recently CAT in whole blood was developed. This technique excludes the need for centrifugation and renders a view of coagulation in which all blood cells are included. The red blood cells introduce an extra procoagulant phospholipid surface, which cannot be evaluated by using the conventional CAT method in plasma [10]. The effect of VKAs in the whole blood CAT technique has not been tested so far.

The addition of thrombomodulin (TM) to the thrombin generation test might also provide a more complete assessment of coagulation. Since TM is an endothelial membrane protein that is not present in the circulating blood, it has to be added to the test. In the presence of TM the inhibitory effect of protein $\mathrm{C}$ and protein $\mathrm{S}$ can be investigated. Protein $\mathrm{C}$ and $\mathrm{S}$ are also vitamin $\mathrm{K}$ dependent factors and as such affected by VKAs. In an earlier study we have shown that adding TM to the thrombin generation test gives a more precise assessment of the state of the clotting system in patients on VKAs [11]. The aim of this study was to investigate the whole blood CAT in samples from patients taking VKAs. In addition we determined the concentrations of several clotting factors and measured the thickness of the fibrin fibers.

\section{Materials and methods}

\section{Reagents}

Z-Gly-Gly-Arg-aminomethylcoumarine (ZGGR-AMC) was purchased from Bachem (Basel, Switzerland). Recombinant tissue factor was Innovin (Dade-Behring, Marburg, Germany). Rhodamine substrate $\left(\mathrm{P}_{2} \mathrm{Rho}\right)$ was a gift of Diagnostica Stago (Asnières sur Seine, France). Synthetic phospholipids were from Avanti Polar Lipids Inc. (Alabaster, AL, USA). The calibrator, $a_{2}$-macroglobulin-thrombin complex, was prepared as described previously [12]. Hepes buffers containing 5 $\mathrm{mg} / \mathrm{ml}$ or $60 \mathrm{mg} / \mathrm{ml}$ bovine serum albumin were composed for dilution of the reagents or the substrate, respectively, as described by Hemker et al. [13]. Recombinant human TM was a kind gift of Asahi Kasei Pharma (Japan). 


\section{Study population}

A total of 150 patients taking vitamin $\mathrm{K}$ antagonists (VKAs) were included in this study. Patients were eligible for inclusion in this study when they were on VKAs for over 3 months and were undergoing a venipuncture in order to determine their International Normalized Ratio (INR) value at the local thrombosis service. Patients were excluded if they were younger than 18 years. Twenty healthy donors were included aged between 18 and 65 years. Donors were excluded if they were taking any medication that affects clotting (anticoagulants, anti-platelet agents, nonsteroidal anti-inflammatory drugs and oral contraceptives). Having experienced an episode of bleeding or thrombosis was also an exclusion criterion. All patients and donors gave written informed consent and the study was approved by the local ethical committee (METC aZM/UM).

\section{Blood samples}

Blood was obtained through antecubital venipuncture using BD vacutainer tubes (1 volume of trisodium citrate $3.2 \%$ to 9 volumes of blood) (BD Vacutainer system, Roborough, Plymouth, UK). Platelet rich plasma (PRP) was obtained by centrifuging the blood at $250 \mathrm{~g}$ for $15 \mathrm{~min}$. Platelet poor plasma (PPP) was prepared by double centrifugation of the remaining PRP at $1,000 \mathrm{~g}$ for $10 \mathrm{~min}$. The residual PPP was stored at $-80^{\circ} \mathrm{C}$ until further use. Cell counts in whole blood and PRP were performed with a Coulter Counter analyzer (Beckman Coulter, Woerden, the Netherlands).

\section{Calibrated automated thrombinography}

Calibrated automated thrombinography was executed as described before [12]. In short, for the measurement in PPP $10 \mu \mathrm{l}$ of tissue factor (TF)/phospholipid mixture was added to a well with either $10 \mu$ of BSA5 buffer or TM. The final concentrations were 1 or $5 \mathrm{pM}$ TF and $4 \mu \mathrm{M}$ phospholipids. In case of PRP the same protocol was implicated, however no phospholipids were added to the TF 


\section{Chapter 4}

solution. The final TF concentration was $1 \mathrm{pM}$. The reaction in plasma was started by addition of $20 \mu \mathrm{l}$ of Fluca (ZGGR-AMC at $2.5 \mathrm{mM}$ and $\mathrm{CaCl}_{2}$ at $100 \mathrm{mM}$ in BSA60 buffer) to the wells. Normal pooled plasma was used as a control during each measurement. The data were acquired by specialized software from Thrombinoscope (Maastricht, the Netherlands). The final concentrations of TM were $20 \mathrm{nM}$ for PRP as well as PPP at $5 \mathrm{pM}$ TF and $2.5 \mathrm{nM}$ for PPP at $1 \mathrm{pM}$ TF. Concentrations were determined to be around the $\mathrm{IC}_{50}$ levels in normal pooled plasma.

The whole blood CAT technique was performed according to our group's earlier specifications [10]. Thirty microliters of blood was mixed with $10 \mu$ of $P_{2} R$ ho substrate (1.8 mM), $10 \mu \mathrm{TF} / \mathrm{CaCl}_{2}$ solution ( $3 \mathrm{pM} \mathrm{TF}$ and $50 \mathrm{mM} \mathrm{CaCl}$ ), thereby triggering thrombin generation, and $10 \mu$ of BSA5 buffer with or without TM (final concentration: $20 \mathrm{nM})$. In the calibration wells, the $20 \mu \mathrm{l}$ of reagents were replaced with calibrator $(300 \mathrm{nM})$. Instantly after the activation, $5 \mu$ l of the mixture was pipetted on paper disks (Whatman 589/1, Whatman GmbH, Dassel, Germany) in a flat bottom 96-well polystyrene plate and covered with $40 \mu \mathrm{l}$ of mineral oil (Affymetrix, USB, Cleveland, Ohio, USA). For this technique, the final tissue factor concentration was also $1 \mathrm{pM}$. Fluorescent signals were measured at excitation/emission wavelengths of $485 / 538 \mathrm{~nm}$ using the Fluoroskan Ascent software (Thermo Labsystems, Helsinki, Finland). Measurements were performed in triplicate. The fluorescent signals were transformed into thrombin concentration as described by Hemker and Kremers [14].

\section{Scanning electron microscopy}

After thrombin generation was determined in whole blood in a flat bottom 96-well plate, the clots were prepared for visualization by scanning electron microscopy (SEM). The clots were fixated by adding $2.5 \%$ glutaraldehyde (grade I, Sigma Aldrich, St. Louis, Missouri) in phosphate buffered saline (PBS) (Sorensen's, pH 7.2) (Electron Microscopy Sciences, Hatfield, PA, USA) for 1 hour at room temperature and overnight at $4^{\circ} \mathrm{C}$. The following day, the glutaraldehyde solution 
was removed and the samples were washed 5 times in PBS. As a secondary fixation, the samples were placed in osmiumtetroxide (OsO4, 1\%) diluted in sodium cacodylate (200 mM, pH 7.4) (Electron Microscopy Sciences, Hatfield, PA, USA) for 1 hour at room temperature. Consecutively, the clots were dehydrated in ethanol (30\%, 50\%, $70 \%, 90 \%$ and 3 times at $100 \%)$ for 3 minutes. The samples were then treated with a hexamethyldisilazane (HMDS)/ethanol solution for 3 minutes and in HMDS for 10 minutes (Sigma Aldrich, St. Louis, MO, USA). The samples were removed from the wells, left to dry and coated with gold. Analysis was performed on a desktop SEM (Phenom-World, Eindhoven, the Netherlands). The thickness of fibrin fibers was determined using ImageJ software (version $1.48 \mathrm{v})$. Per picture at least 100 measurements were performed. For the analysis of these data we calculated the median of the fiber measurements that were derived from one picture and used this for further analysis.

\section{Additional determinations}

Levels of clotting factors were determined using the STA-R Evolution analyzer (Stago, Asnières sur Seine, France). Factor II, V, VII, VIII, IX, X levels were determined with clotting assays triggered by either a thromboplastin based reagent (FII, FV, FVII, FX) or a kaolin based reagent (FVIII and FIX). Protein C activity was determined by an aPTT based assay, activated by Agkistrodon c. contortrix venom. Protein $S$ was tested in a clotting assay in which the activity of protein $S$ as a cofactor of protein $C$ is measured by its effect on factor Va. Fibrinogen levels were measured using the Clauss method. Antithrombin (ATIII) was determined by a chromogenic measurement.

The prothrombin time was determined in citrated plasma with an automated coagulation analyzer (Sysmex CA 1500, Siemens Diagnostics, the Netherlands) using Innovin ${ }^{\circledR}$ (Dade-Behring) as the thromboplastin reagent. The INR value was expressed as the ratio of the subject's PT to a normal (control) sample raised to the power of the International Sensitivity Index (ISI); $\left(\mathrm{PT}_{\text {test }} / \mathrm{PT}_{\text {normal }}\right)^{|S|}$. 


\section{Chapter 4}

\section{Statistics}

For statistical analysis of the data SPSS version 20 (SPSS Inc., Chicago, Illinois, USA) was used. Correlation analysis was performed using the Pearson correlation test in case of a linear correlation or Spearman in case of a non-linear correlation. Differences between two groups were evaluated by an independent samples t-test. Differences between three or more unmatched groups were analyzed with the oneway ANOVA test and the Bonferroni test was used as a post hoc test. The analysis of the fibermetrics data were analyzed by using the Mann Whitney $U$ test.

\section{Results}

\section{Patient characteristics}

One hundred and fifty patients were enrolled in the study of which 21 had to be excluded. Two patients were excluded because of failed blood collection, six due to technical problems during measurements, three due to not fulfilling the inclusion criterion of using VKAs for more than 3 months and 10 patients participated more than once. The remaining 129 patients had an average age of 68.11 years $( \pm$ 11.04 ) and an average INR of 2.95 ( \pm 0.92 ); $21.71 \%$ were female and $95.35 \%$ were taking acenocoumarol. Of this population only $45 \%$ of patients were in the INR target area corresponding to their indication. Of the total study population $3 \%$ forgot to take the tablets shortly before inclusion and $3.9 \%$ temporarily stopped the VKA due to a surgical or medical procedure. Additionally, as control group twenty healthy donors (12 females and 8 males) were included with an average age of 35.8 years.

\section{Thrombin generation parameters in whole blood}

This is the first study investigating the effect of treatment with VKAs measured by the whole blood CAT. We therefore compared the measurement results of CAT in whole blood to the measurement results of CAT in plasma and explored the association with the INR. The four thrombin generation parameters (ETP, peak 
height, lag time and time to peak) in plasma and whole blood were compared to the corresponding INR values of the patients. With increasing INR values, the ETP and peak height decreased. Both in plasma and whole blood, there was a significant inverse correlation which displayed a hyperbolical shape $(p<0.01)$. The lag time and time to peak correlated linearly to the INR $(p<0.01)$ (Table 1). The TG parameters determined by the whole blood CAT technique correlated significantly to the parameters in plasma $(p<0.01)$ (Table 2$)$. Although the INR correlated with the TG parameters there was still a large inter-individual variation in the TG parameters that is not reflected by the INR. When choosing one INR value within the therapeutic range (INR 3.1), there was a variation of more than $20 \%$ in the ETP and peak of the patients even though they had the same INR value.

Table 1: Correlation of INR values with the TG parameters.

\begin{tabular}{|c|cccc}
\hline \multicolumn{5}{|c}{ Correlation of INR with TG parameters } \\
\hline R-value & ETP & Peak & Lag time & Ttpeak \\
\hline WB & -0.456 & -0.720 & 0.504 & 0.662 \\
PRP & -0.626 & -0.653 & 0.581 & 0.605 \\
PPP (5 pM TF) & -0.748 & -0.782 & 0.466 & 0.489 \\
PPP (1 pM TF) & -0.784 & -0.768 & 0.384 & 0.377 \\
\hline
\end{tabular}

For the linear correlation of the INR with lag time and Ttpeak the Pearson correlation coefficient was used, for the hyperbolic correlation with ETP and peak the Spearman correlation coefficient is depicted. All values are statistically significant $(p<0.01)$. INR, international normalized ratio; ETP, endogenous thrombin potential; Ttpeak, time to peak; WB, whole blood; PRP, platelet rich plasma; PPP, platelet poor plasma; TF, tissue factor.

Table 2: Correlation of whole blood TG with TG in plasma.

\begin{tabular}{|c|cccc}
\hline \multicolumn{5}{|c}{ Correlation of TG parameters in WB with plasma } \\
\hline R-value & ETP & Peak & Lag time & Ttpeak \\
\hline PRP & 0.593 & 0.651 & 0.300 & 0.449 \\
PPP (5 pM TF) & 0.675 & 0.815 & 0.426 & 0.510 \\
PPP (1 pM TF) & 0.613 & 0.767 & 0.252 & 0.506 \\
\hline
\end{tabular}

All values are statistically significant $(p<0.01)$. Abbreviations are as stated in Table 1 . 


\section{Chapter 4}

Addition of thrombomodulin to the CAT assay

In a previous study [11] it was demonstrated that adding TM to TG tests gives a more complete view of the coagulation system. Addition of a fixed concentration of TM (20 nM, which we opted to keep constant for all the experiments) to the thrombin generation assay resulted in different levels of inhibition in different groups stratified according to the INR values (Table 3). For PPP the level of inhibition decreased as the INR increased. However in whole blood and PRP the INR level did not seem to affect the inhibition by TM. In whole blood and PRP more TM was necessary to reach $50 \%$ inhibition (around 35 and $25 \mathrm{nM}$, respectively) (data not shown).

Table 3: Level of inhibition of ETP and peak in 5 groups stratified on INR levels.

\begin{tabular}{|l|rrrrrr}
\hline \multicolumn{3}{|c}{ Inhibition (\%) after addition of TM } \\
\hline & \multicolumn{3}{c}{ ETP } & \multicolumn{3}{c}{ Peak } \\
\hline & WB & PRP & PPP & WB & PRP & PPP \\
\hline INR 1.0-1.5 $(\mathrm{n}=4)$ & 35.2 & 55.0 & 67.6 & 34.3 & 64.5 & 66.0 \\
\hline INR 1.5-2.5 $(\mathrm{n}=39)$ & 32.6 & 32.6 & 45.6 & 27.6 & 38.7 & 35.3 \\
\hline INR 2.5-3.5 $(\mathrm{n}=52)$ & 32.8 & 29.9 & 40.4 & 28.7 & 42.2 & 26.5 \\
\hline INR 3.5-4.5 $(\mathrm{n}=26)$ & 31.1 & 42.9 & 38.0 & 28.8 & 42.2 & 26.5 \\
\hline INR 4.5-6.0 $(\mathrm{n}=8)$ & 27.8 & 28.6 & 44.6 & 27.6 & 38.2 & 29.3 \\
\hline
\end{tabular}

Abbreviations are as stated in Table 1.

\section{Clotting factors}

Levels of clotting factors were determined in the healthy donors as well as the patients (Figure 1). The vitamin $\mathrm{K}$ dependent clotting factors (FII, FVII, FIX, FX, protein $\mathrm{C}$ and protein $\mathrm{S}$ ) were significantly lower in the patient group. Factor $\mathrm{V}$ and ATIII had similar levels in both groups. Factor VIII and fibrinogen were found to be significantly increased in the patients $(184.5 \%$ and $4.0 \mathrm{~g} / \mathrm{l})$ as compared to the healthy donors $(118.3 \%$ and $3.2 \mathrm{~g} / \mathrm{l} ; \mathrm{p}<0.001)$. The increase in these clotting factor levels was independent of the INR value. The patients were divided into 3 groups based on the INR values, one group which comprised the therapeutic range, the other two groups above and below the therapeutic range, respectively 
(INR 1.0 to $2.5,2.5$ to 3.5 and 3.5 to 6.0 ). For both FVIII and fibrinogen no significant difference between these three groups was found (data not shown).

The inter-individual variability between the clotting factor concentrations was quite high for most of the clotting factors in our population of healthy donors. The CV's ranged between 7.8 and $31.1 \%$.

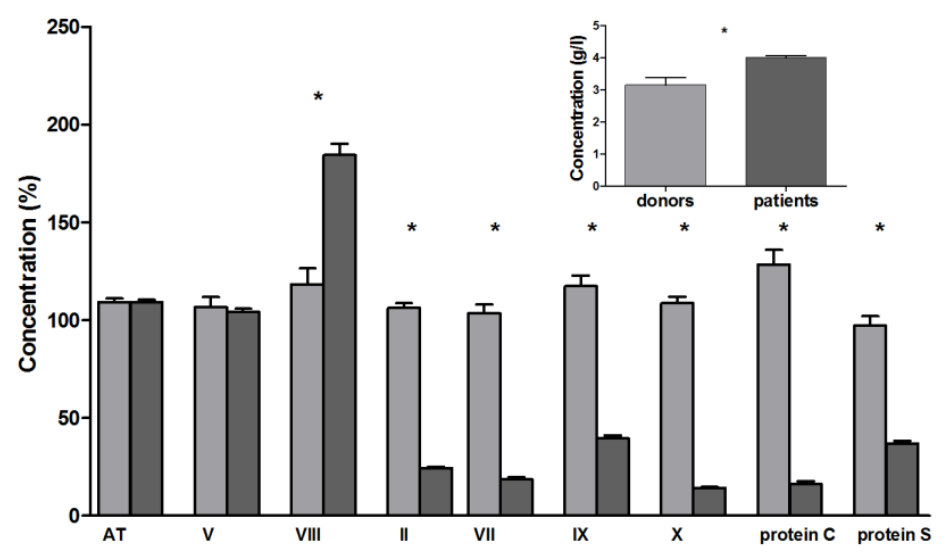

Figure 1: Levels of clotting factors in healthy donors and patients taking vitamin $\mathrm{K}$ antagonists. Values are represented as mean with standard error of mean. The inserted figure represents the fibrinogen levels. ${ }^{*} p<0.01$

\section{Fibrin ultrastructure}

It is known that thrombin and fibrinogen concentrations can affect the structure of fibrin fibers, so we decided to analyze the fibrin ultrastructure via SEM. Whole blood TG was performed on paper disks in the presence of 1 pM TF. The mineral oil that was used to prevent evaporation was removed and the fibrin that was formed during this process was fixated for visualization with SEM (17 donors and 32 patients). The thickness of the fibrin fibers was analyzed and the fibers of the patients were significantly thinner than those of the healthy donors (160 nm vs. 212 $n m ; p<0.01$ ) (Figure 2). 

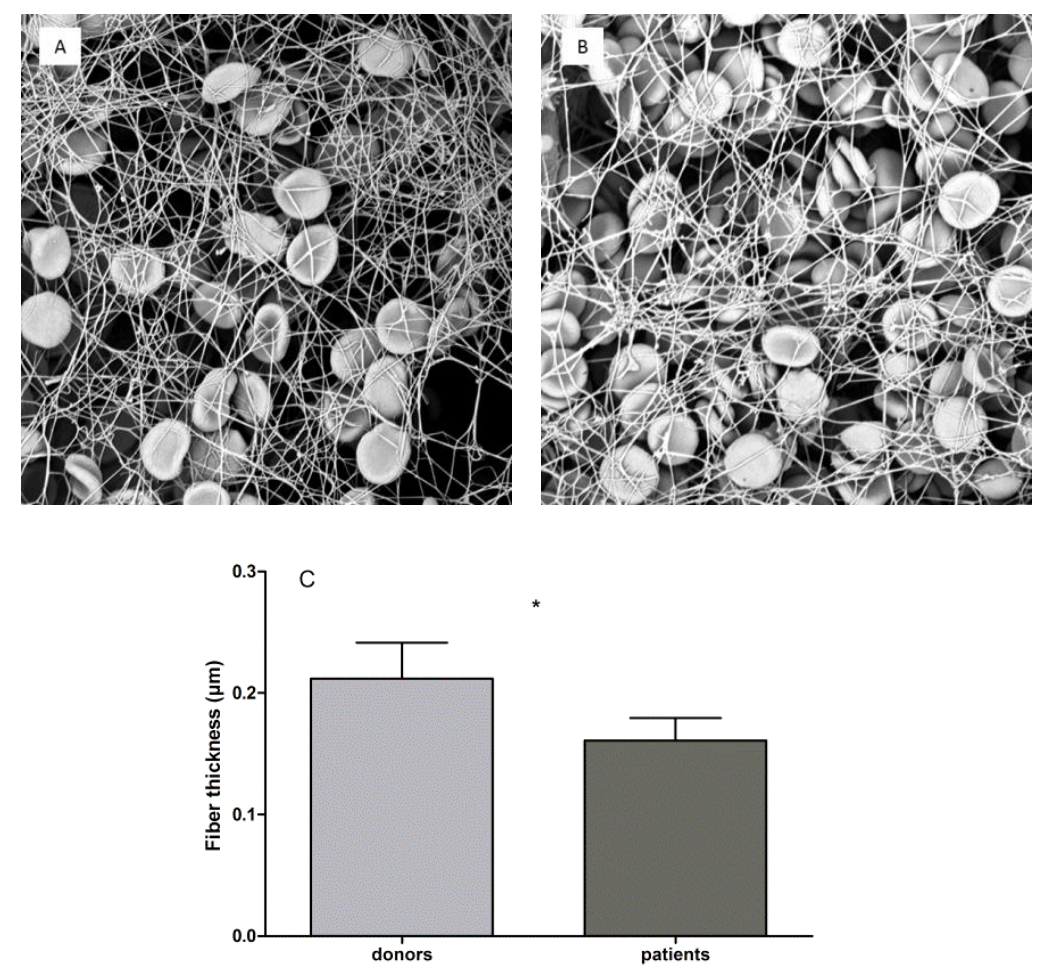

Figure 2: Fibrin ultrastructure in patients and donors. Whole blood TG was performed on paper disks and the fibrin was fixated for analysis with SEM. Pictures were taken at 5000x magnification. A) Patient sample, B) Donor sample, C) The thickness of the fibrin was determined. The median of the fibrin measurements per picture was determined. Values are represented as mean with standard deviation. ${ }^{*} p<0.01$

\section{Discussion}

This is the first study validating the whole blood CAT assay in a clinical setting and more specifically in patients taking VKAs. A highly significant correlation was found between the plasma CAT parameters and those of whole blood CAT. This indicates that in these settings whole blood CAT can be used to determine the effect of VKA treatment on thrombin generation. Although the whole blood CAT was published using $0.5 \mathrm{pM}$ TF as a standard condition for a sensitive assay [10], in this study we could hardly detect a signal at this concentration of TF, especially 
at high INR values, so $1 \mathrm{pM}$ TF was used as a final concentration. The whole blood CAT parameters correlate to the INR in the same way as the parameters in plasma. A linear correlation was found with the time dependent parameters (lag time and time to peak) representing the nature of the clotting time as measured by the PT. A negative hyperbolical correlation was detected between the INR and the functional parameters, ETP and peak. In plasma, these types of correlations were reported previously by Gerotziafas et al. [15]. Furthermore, this group reported that the ETP reached a plateau when the INR values exceeded 5 . In our population in PPP activated with $5 \mathrm{pM}$ TF this plateau was reached at an INR of 4 and in whole blood it is even reached sooner at INR values around 3. The same correlations and plateaus were found for the peak (data not shown). Since CAT uses TF concentrations that are closer to physiology as compared to PT and additionally measures the thrombin concentration in time, it has been described as a more suitable test to distinguish between patients who might bleed or suffer from thrombosis while on anticoagulation [16]. As was indicated by Dargaud et al. there is a significant variability in the TG parameters of patients on VKAs that is not reflected in the INR. This was explained in their study by variations in FIX levels that are not detected by the PT [17].

The addition of TM to the CAT assay was previously shown to be a better representation of the in vivo clotting system [11]. Here we also found that the attenuation of $T G$ is less in the presence of TM compared to the healthy donors. Vitamin $\mathrm{K}$ antagonists not only affect the procoagulant factors II, VII, IX and X, but also affect the anticoagulant factors protein $C$ and protein $S$ indicating that the effect of VKAs is partly procoagulant. When thrombin forms a complex with TM it will, together with cofactor protein S, activate protein C into APC [18]. Hence, in order to investigate the effect of the protein $C$ pathway, TM must be added to the TG test. We compared the addition of $20 \mathrm{nM}$ TM to thrombin generation in PPP (5 pM TF), PRP and whole blood. In plasma the addition of TM represents the physiological situation with a high response (55-70\%) in the group with an INR between 1.0 and 1.5. When the INR values increase this response is reduced to $25-45 \%$ representing the lower protein $\mathrm{C}$ and protein $\mathrm{S}$ concentrations that are 


\section{Chapter 4}

available in patients on VKAs, inducing a resistance to TM. However, in whole blood this effect is not noticeable, which leads us to conclude that this test does not represent the physiological action of natural anticoagulants (protein $C$ and $S$ ) as well as the tests in plasma.

The levels of clotting factors were also investigated and as expected significant decreases were found in the vitamin $\mathrm{K}$ dependent clotting factors (FII, FVII, FIX, $\mathrm{FX}$, protein $\mathrm{C}$ and protein $\mathrm{S}$ ) when comparing the healthy donors to the patient population. Protein C, FX and FVII were the factors that were most affected. As for levels of the vitamin $\mathrm{K}$ independent factors AT and FV, they were similar between the donors and patients. Fibrinogen and FVIII levels, on the other hand, were significantly increased in the patients compared to the donors. The rise in FVIII levels has been described previously by different groups [19, 20]. From this study we cannot conclude with certainty that the elevated fibrinogen levels related to a compensatory effect for the anticoagulant treatment. Both proteins may also have been elevated in response to the underlying cardiovascular disease, including atherosclerosis.

An argument against a response to chronic inflammation may be that AT, which has been reported to show a negative acute phase response to inflammation, was not different from the level in healthy donors [21]. This together with the observation by Brummel et al. that the increase in FVIII was correlated with the time an individual was on VKA therapy [20], provide circumstantial evidence for a compensatory reaction to the treatment with VKAs. On the other hand, one can argue that the increased FVIII and fibrinogen levels could be due to the difference in age between the patient group and the healthy donors. It has been shown previously that FV levels are also elevated in the elderly [22] and in this study we did not detect a difference in these levels.

When examining the clot structure of the whole blood samples, the patients had thinner fibrin fibers than the donors. This observation was unexpected, yet when linking the increased fibrinogen concentrations and the FVIII levels, this could 
possibly explain the thinner fibrin structure. Previously it was shown that with increasing fibrinogen concentrations, the fibrin fibers become thinner [23].

The resistance to TM can be an indirect effect of APC resistance and thus can be due not only to decreased protein $C$ and S levels, but also to increased FVIII levels [24]. The higher FVIII levels might therefore be an additional explanatory factor for the observations that were mentioned earlier. High FVIII and fibrinogen levels have been associated with an increased risk of thrombosis [25, 26]. These increased levels might play a role in the prothrombotic rebound effect that is seen shortly after patients withdraw from therapy. The rebound effect can be described as a transient increase in thromboembolic events after withdrawal from a drug [27] and has been observed after withdrawal of VKAs [28, 29].

\section{Acknowledgments}

The authors would like to thank Leonie Pelkmans for her technical assistance and the employees of the thrombosis service in the Maastricht University Medical Centre for their assistance with patient inclusion and blood collection. We would also like to thank Patty Nelemans for the advice on statistical analysis. 


\section{Chapter 4}

\section{References}

1. Ansell J, Hirsh J, Poller L, Bussey H, Jacobson A, Hylek E. The pharmacology and management of the vitamin $\mathrm{K}$ antagonists: the Seventh ACCP Conference on Antithrombotic and Thrombolytic Therapy. Chest. 2004; 126(3 Suppl): p. 204S2335 .

2. Ferland G. The discovery of vitamin $\mathrm{K}$ and its clinical applications. Ann Nutr Metab. 2012; 61(3): p. 213-218.

3. Mackman N. Triggers, targets and treatments for thrombosis. Nature. 2008; 451(7181): p. 914-918.

4. Singer DE, Chang Y, Fang MC, Borowsky LH, Pomernacki NK, Udaltsova N, Go AS. Should patient characteristics influence target anticoagulation intensity for stroke prevention in nonvalvular atrial fibrillation?: the ATRIA study. Circ Cardiovasc Qual Outcomes. 2009; 2(4): p. 297-304.

5. White HD, Gruber M, Feyzi J, Kaatz S, Tse HF, Husted S, Albers GW. Comparison of outcomes among patients randomized to warfarin therapy according to anticoagulant control: results from SPORTIF III and V. Arch Intern Med. 2007; 167(3): p. 239-245.

6. Al Dieri R, de Laat B, Hemker HC. Thrombin generation: what have we learned? Blood Rev. 2012; 26(5): p. 197-203.

7. Hemker HC, Beguin S. Phenotyping the clotting system. Thromb Haemost. 2000; 84(5): p. 747-751.

8. Al Dieri R, Peyvandi F, Santagostino E, Giansily M, Mannucci PM, Schved JF, Beguin S, Hemker HC. The thrombogram in rare inherited coagulation disorders: its relation to clinical bleeding. Thromb Haemost. 2002; 88(4): p. 576-582.

9. Azar AJ, Koudstaal PJ, Wintzen AR, van Bergen PF, Jonker JJ, Deckers JW. Risk of stroke during long-term anticoagulant therapy in patients after myocardial infarction. Ann Neurol. 1996; 39(3): p. 301-307.

10. Ninivaggi M, Apitz-Castro R, Dargaud Y, de Laat B, Hemker HC, Lindhout T. Whole-blood thrombin generation monitored with a calibrated automated thrombogram-based assay. Clin Chem. 2012; 58(8): p. 1252-1259.

11. Al Dieri R, Ten Cate-Hoek A, Bloemen S, Ten Cate H, Hemker HC. Procoagulant effect of vitamin $\mathrm{K}$ antagonists? J Thromb Haemost. 2011; 9(12): p. 2511-2512.

12. Hemker HC, Giesen P, Al Dieri R, Regnault V, de Smedt E, Wagenvoord R, Lecompte $\mathrm{T}$, Beguin S. Calibrated automated thrombin generation measurement in clotting plasma. Pathophysiol Haemost Thromb. 2003; 33(1): p. 4-15. 
13. Hemker HC, Hemker PW, Al Dieri R. The technique of measuring thrombin generation with fluorescent substrates: 4. The H-transform, a mathematical procedure to obtain thrombin concentrations without external calibration. Thromb Haemost. 2009; 101(1): p. 171-177.

14. Hemker HC, Kremers R. Data management in thrombin generation. Thromb Res. 2013; 131(1): p. 3-11.

15. Gerotziafas GT, Dupont C, Spyropoulos AC, Hatmi M, Samama MM, Kiskinis D, Elalamy I. Differential inhibition of thrombin generation by vitamin $\mathrm{K}$ antagonists alone and associated with low-molecular-weight heparin. Thromb Haemost. 2009; 102(1): p. 42-48.

16. Gatt A, van Veen JJ, Bowyer A, Woolley AM, Cooper P, Kitchen S, Makris M. Wide variation in thrombin generation in patients with atrial fibrillation and therapeutic International Normalized Ratio is not due to inflammation. $\mathrm{Br} J$ Haematol. 2008; 142(6): p. 946-952.

17. Dargaud Y, Hoffman M, Lefrapper L, Lin FC, Genty A, Chatard B, Marin S, Negrier $\mathrm{C}$, Monroe DM. Bleeding risk in warfarinized patients with a therapeutic international normalized ratio: the effect of low factor IX levels. Journal of thrombosis and haemostasis : JTH. 2013; 11(6): p. 1043-1052.

18. Dahlback B. Blood coagulation and its regulation by anticoagulant pathways: genetic pathogenesis of bleeding and thrombotic diseases. J Intern Med. 2005; 257(3): p. 209-223.

19. Passamonti SM, Bucciarelli P, Bader R, Martinelli I. Influence of anticoagulant therapy with vitamin $\mathrm{K}$ antagonists on plasma levels of coagulation factor VIII. Thromb Res. 2010; 126(3): p. 243-245.

20. Brummel KE, Paradis SG, Branda RF, Mann KG. Oral anticoagulation thresholds. Circulation. 2001; 104(19): p. 2311-2317.

21. Niessen RW, Lamping RJ, Jansen PM, Prins MH, Peters M, Taylor FB, Jr., de Vijlder JJ, ten Cate JW, Hack CE, Sturk A. Antithrombin acts as a negative acute phase protein as established with studies on HepG2 cells and in baboons. Thromb Haemost. 1997; 78(3): p. 1088-1092.

22. Hamilton PJ, Allardyce M, Ogston D, Dawson AA, Douglas AS. The effect of age upon the coagulation system. J Clin Pathol. 1974; 27(12): p. 980-982.

23. Ryan EA, Mockros LF, Weisel JW, Lorand L. Structural origins of fibrin clot rheology. Biophys J. 1999; 77(5): p. 2813-2826. 


\section{Chapter 4}

24. Castoldi E, Rosing J. APC resistance: biological basis and acquired influences. $J$ Thromb Haemost. 2010; 8(3): p. 445-453.

25. Koster T, Blann AD, Briet E, Vandenbroucke JP, Rosendaal FR. Role of clotting factor VIII in effect of von Willebrand factor on occurrence of deep-vein thrombosis. Lancet. 1995; 345(8943): p. 152-155.

26. Koster T, Rosendaal FR, Reitsma PH, van der Velden PA, Briet E, Vandenbroucke JP. Factor VII and fibrinogen levels as risk factors for venous thrombosis. A casecontrol study of plasma levels and DNA polymorphisms--the Leiden Thrombophilia Study (LETS). Thromb Haemost. 1994; 71(6): p. 719-722.

27. Hermans C, Claeys D. Review of the rebound phenomenon in new anticoagulant treatments. Curr Med Res Opin. 2006; 22(3): p. 471-481.

28. Grip L, Blomback M, Schulman S. Hypercoagulable state and thromboembolism following warfarin withdrawal in post-myocardial-infarction patients. Eur Heart $\mathrm{J}$. $1991 ; 12(11)$ : p. 1225-1233.

29. Ascani A, lorio A, Agnelli G. Withdrawal of warfarin after deep vein thrombosis: effects of a low fixed dose on rebound thrombin generation. Blood Coagul Fibrinolysis. 1999; 10(5): p. 291-295. 


\section{Chapter 5}

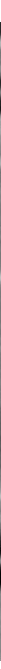

Detection of bleeding risk in patients taking vitamin $\mathrm{K}$ antagonists

Saartje Bloemen, Arina ten Cate-Hoek, Hugo ten Cate, Bas de Laat

Submitted 


\section{Abstract}

Vitamin $\mathrm{K}$ antagonists (VKAs) are widely used oral anticoagulants and are monitored by the prothrombin time (PT). Thrombin generation (TG) tests have been proposed as a useful functional assay and can be executed in whole blood (WB). Using this method, patients on VKAs that suffered from any clinically relevant bleeding had a significantly lower TG than those that did not bleed. Our findings indicate that WB TG can be used to detect patients with a bleeding phenotype. 
For the past 50 years VKAs have been widely used for the primary prevention of thromboembolism in patients with atrial fibrillation, or for the secondary prevention in patients with a history of venous thromboembolism [1]. Warfarin is the most widely used VKA followed by acenocoumarol and phenprocoumon. The most prevalent adverse effect of anticoagulant therapy is an increased risk of bleeding which can lead to serious morbidity and mortality. Annually approximately $1-4 \%$ of patients treated with VKAs suffer from episodes of major bleeding [2]. The risk of bleeding increases with age. Patients over 75 years of age suffer from bleeding more frequently than younger patients $(5.1 \%$ and $1 \%$ per year, respectively) [3]. This risk of bleeding increases even more when VKAs are combined with antiplatelet therapy [4].

In the past several attempts have been made to predict patients at risk for bleeding when treated with VKAs. One of the commonly used clinical methods at this moment is the HAS-BLED score, which is a clinical decision score [5]. The HASBLED score has a better predictive value compared to other bleeding scores, yet the accuracy of this score differs based on the cohort that was used for validation [6]. Up to this point there are no laboratory methods to predict patients at risk for bleeding. Thrombin generation, a method that detects the enzymatic activity of thrombin, has been shown to be able to detect both prothrombotic and bleeding phenotypes based on changes in the coagulation system [7]. In addition, thrombin generation has the capacity to detect the anticoagulant effect of many if not all anticoagulants, including VKAs [8, 9]. Until recently this method was only applicable in plasma due to quenching of the fluorescent signal by sedimentation of erythrocytes. Introduction of a matrix preventing sedimentation of erythrocytes and using a different thrombin-sensitive substrate enabled studying thrombin generation in whole blood [10].

We investigated whether thrombin generation either in plasma or whole blood can be used to predict bleeding episodes in 129 patients taking VKAs for over 3 months (a detailed version of materials \& methods can be found in chapter 4). Thrombin generation was determined in whole blood, platelet rich plasma and platelet poor plasma by means of calibrated automated thrombinography (CAT) 


\section{Chapter 5}

[11]. Tissue factor was used as a trigger at a final concentration of $1 \mathrm{pM}$ in whole blood and platelet rich plasma and at both $1 \mathrm{pM}$ and $5 \mathrm{pM}$ in platelet poor plasma. Hematocrit, hemoglobin concentration and INR were also determined.

In our study we found that 26 patients $(20.2 \%)$ suffered from 44 clinically relevant bleeding episodes during a mean follow-up of 15.5 months. Patient demographics can be found in table 1 .

Table 1: Characteristics of the patient population.

\begin{tabular}{|c|c|}
\hline \multicolumn{2}{|c|}{ Demographics } \\
\hline Number of patients & 129 \\
\hline Age (mean $\pm S D)$ & $68.11 \pm 11.04$ \\
\hline Female sex (\%) & 21.71 \\
\hline INR $($ mean $\pm S D)$ & $2.95 \pm 0.92$ \\
\hline VKA Acenocoumarol (\%) & 95.35 \\
\hline \multicolumn{2}{|l|}{ Indications (\%) } \\
\hline$A F$ & 72.09 \\
\hline prosthetic valve & 13.18 \\
\hline lung embolism & 3.88 \\
\hline thrombosis & 3.10 \\
\hline$C A B G$ & 1.55 \\
\hline peripheral atherosclerosis & 1.55 \\
\hline cardiomyopathy & 0.78 \\
\hline cerebrovascular insufficiency & 0.78 \\
\hline cerebral embolism & 0.78 \\
\hline arterial embolism & 0.78 \\
\hline other rare indications & 1.55 \\
\hline
\end{tabular}

SD, standard deviation; AF, atrial fibrillation; CABG, coronary artery bypass graft.

Applying thrombin generation in plasma we found no difference in either endogenous thrombin potential (ETP), an indication for the total amount of 
thrombin that can be converted, nor peak height, which represents the highest amount of active thrombin present during coagulation. Interestingly, when we applied whole blood thrombin generation we found a significantly lower ETP ( $p<$ $0.01)$ and peak $(p<0.05)$ in the patients that suffered from bleeding (median (interquartile range): 182.5 (157.2 - 284.7) $\mathrm{nM}$.min and $23.9(19.6-41.8) \mathrm{nM}$ ) compared to patients that did not have this adverse effect (256.2 (194.9 - 344.2) nM.min and 39.1 (24.9 - 53.2) nM) (Figure 1 a). When examining the INR, hematocrit and hemoglobin levels, no significant differences could be detected (Figure $1 b)$. A receiver operating curve (ROC) was constructed for the ETP and peak (Figure 1c). By determining the area under the curve (AUC) of the ROC we found that the ETP and peak were significantly $(p<0.05)$ associated with the tendency to bleed (ETP, AUC: 0.700; peak, AUC: 0.642). This compares favorably with the AUC reported for the HAS-BLED score related to clinically relevant bleeding in patients on VKAs $(0.60)$ [12].

In our study TG measured in whole blood proved to be the first laboratory test that was able to detect patients at risk of bleeding when treated with VKAs. The INR and plasma CAT, on the other hand, did not discriminate between the bleeding and non-bleeding patients. In a different study it was demonstrated that platelet function tests and determination of von Willebrand factor levels could also not discriminate between bleeding and non-bleeding patients [13]. For whole blood TG, based on the AUC of the ROC, the ETP and peak in whole blood had a predictive value for bleeding in patients taking VKAs. Previously it was shown that TG tests in plasma give a more complete assessment of the coagulation system than clotting tests (such as the PT) do [8]. The thrombin generation test in whole blood was only recently developed and this is the first study implementing it to test patients using VKAs. In contrast to plasma CAT, in whole blood CAT the effect of the red blood cells is included and in particular the phospholipid surface of these cells. Possibly there is an interplay between the coagulation system and the red blood cells which explains the ability of the test to discriminate between bleeding and non-bleeding patients. It was shown that a sub-fraction of red blood cells expresses phosphatidylserine, which might serve as a surface for thrombin and 


\section{Chapter 5}

other phospholipid bound coagulation factors [14]. However this will have to be elucidated by further studies.

A
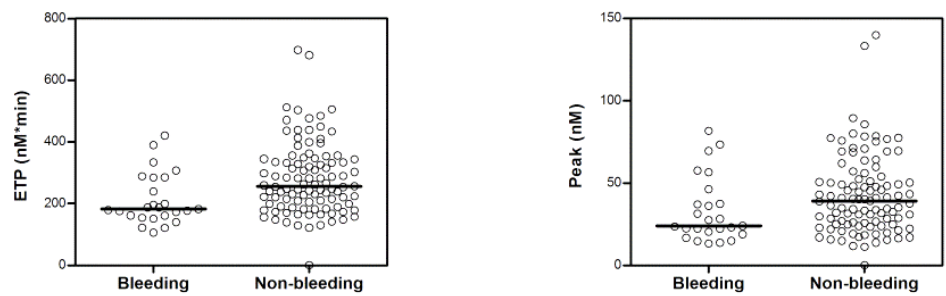

B
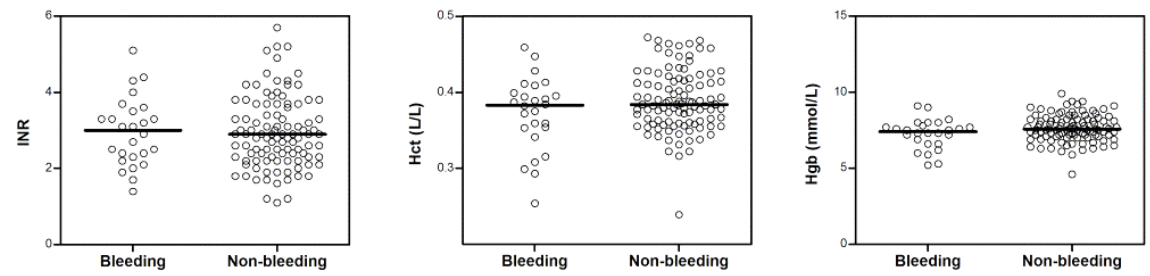

C

ETP WB

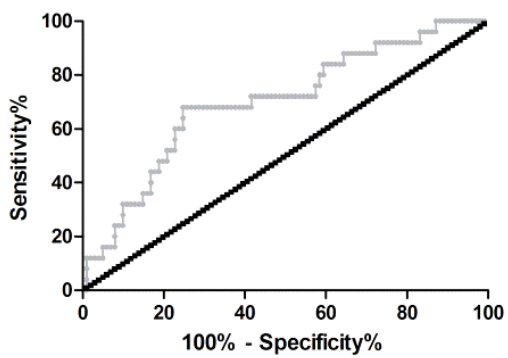

Peak WB

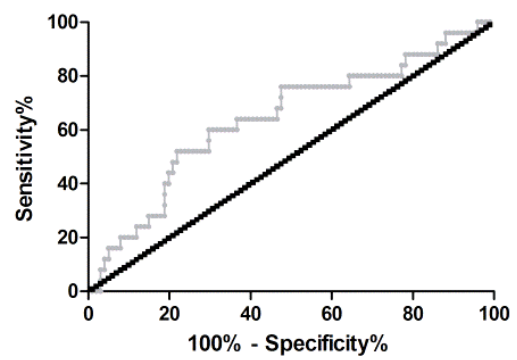

Figure 1: Analysis of patients with and without bleeding symptoms. A) Difference in endogenous thrombin potential (ETP) $(p<0.01)$ and peak $(p<0.05)$ in patients with and without bleeding. Medians are indicated by lines. B) International normalized ratio (INR) values, hematocrit (Hct) and hemoglobin $(\mathrm{Hgb})$ levels in bleeding and non-bleeding patients. No statistically significant differences could be detected for these parameters. Medians are indicated by lines. C) Receiver operating curves (ROC) of the ETP and peak in whole blood (WB) thrombin generation. The area under the curve was 0.700 and 0.642 , respectively $(p<0.05)$. 


\section{Acknowledgments}

The authors would like to thank Leonie Pelkmans for her assistance on the statistical analysis 


\section{Chapter 5}

\section{References}

1. Ansell J, Hirsh J, Poller L, Bussey H, Jacobson A, Hylek E. The pharmacology and management of the vitamin $\mathrm{K}$ antagonists: the Seventh ACCP Conference on Antithrombotic and Thrombolytic Therapy. Chest. 2004; 126(3 Suppl): p. 204S2335 .

2. Halbritter K, Beyer-Westendorf J, Nowotny J, Pannach S, Kuhlisch E, Schellong SM. Hospitalization for vitamin-K-antagonist-related bleeding: treatment patterns and outcome. J Thromb Haemost. 2013; 11(4): p. 651-659.

3. Levine MN, Raskob G, Beyth RJ, Kearon C, Schulman S. Hemorrhagic complications of anticoagulant treatment: the Seventh ACCP Conference on Antithrombotic and Thrombolytic Therapy. Chest. 2004; 126(3 Suppl): p. 287S310 S.

4. Hallas J, Dall M, Andries A, Andersen BS, Aalykke C, Hansen JM, Andersen M, Lassen AT. Use of single and combined antithrombotic therapy and risk of serious upper gastrointestinal bleeding: population based case-control study. Bmj. 2006; 333(7571): p. 726.

5. Gallego P, Roldan V, Torregrosa JM, Galvez J, Valdes M, Vicente V, Marin F, Lip GY. Relation of the HAS-BLED bleeding risk score to major bleeding, cardiovascular events, and mortality in anticoagulated patients with atrial fibrillation. Circ Arrhythm Electrophysiol. 2012; 5(2): p. 312-318.

6. Lane DA, Lip GY. Use of the CHA(2)DS(2)-VASc and HAS-BLED scores to aid decision making for thromboprophylaxis in nonvalvular atrial fibrillation. Circulation. 2012; 126(7): p. 860-865.

7. Hemker HC, Giesen P, AIDieri R, Regnault V, de Smed E, Wagenvoord R, Lecompte T, Beguin S. The calibrated automated thrombogram (CAT): a universal routine test for hyper- and hypocoagulability. Pathophysiol Haemost Thromb. 2002; 32(5-6): p. 249-253.

8. Al Dieri R, de Laat B, Hemker HC. Thrombin generation: what have we learned? Blood Rev. 2012; 26(5): p. 197-203.

9. Bloemen S, Hemker HC, Al Dieri R. Large inter-individual variation of the pharmacodynamic effect of anticoagulant drugs on thrombin generation. Haematologica. 2013; 98(4): p. 549-554.

10. Ninivaggi M, Apitz-Castro R, Dargaud Y, de Laat B, Hemker HC, Lindhout T. Whole-blood thrombin generation monitored with a calibrated automated thrombogram-based assay. Clin Chem. 2012; 58(8): p. 1252-1259. 
11. Hemker HC, Giesen P, Al Dieri R, Regnault V, de Smedt E, Wagenvoord R, Lecompte T, Beguin S. Calibrated automated thrombin generation measurement in clotting plasma. Pathophysiol Haemost Thromb. 2003; 33(1): p. 4-15.

12. Apostolakis S, Lane DA, Buller H, Lip GY. Comparison of the CHADS2, CHA2DS2VASc and HAS-BLED scores for the prediction of clinically relevant bleeding in anticoagulated patients with atrial fibrillation: the AMADEUS trial. Thromb Haemost. 2013; 110(5): p. 1074-1079.

13. van der Meijden PE, Bouman AC, Feijge MA, van Oerle R, Spronk HM, Hamulyak $\mathrm{K}$, ten Cate-Hoek AJ, ten Cate $\mathrm{H}$, Heemskerk JW. Platelet dysfunction in thrombosis patients treated with vitamin $\mathrm{K}$ antagonists and recurrent bleeding. PLoS One. 2013; 8(5): p. e64112.

14. Whelihan MF, Mann KG. The role of the red cell membrane in thrombin generation. Thromb Res. 2013; 131(5): p. 377-382. 



\section{Chapter 6}

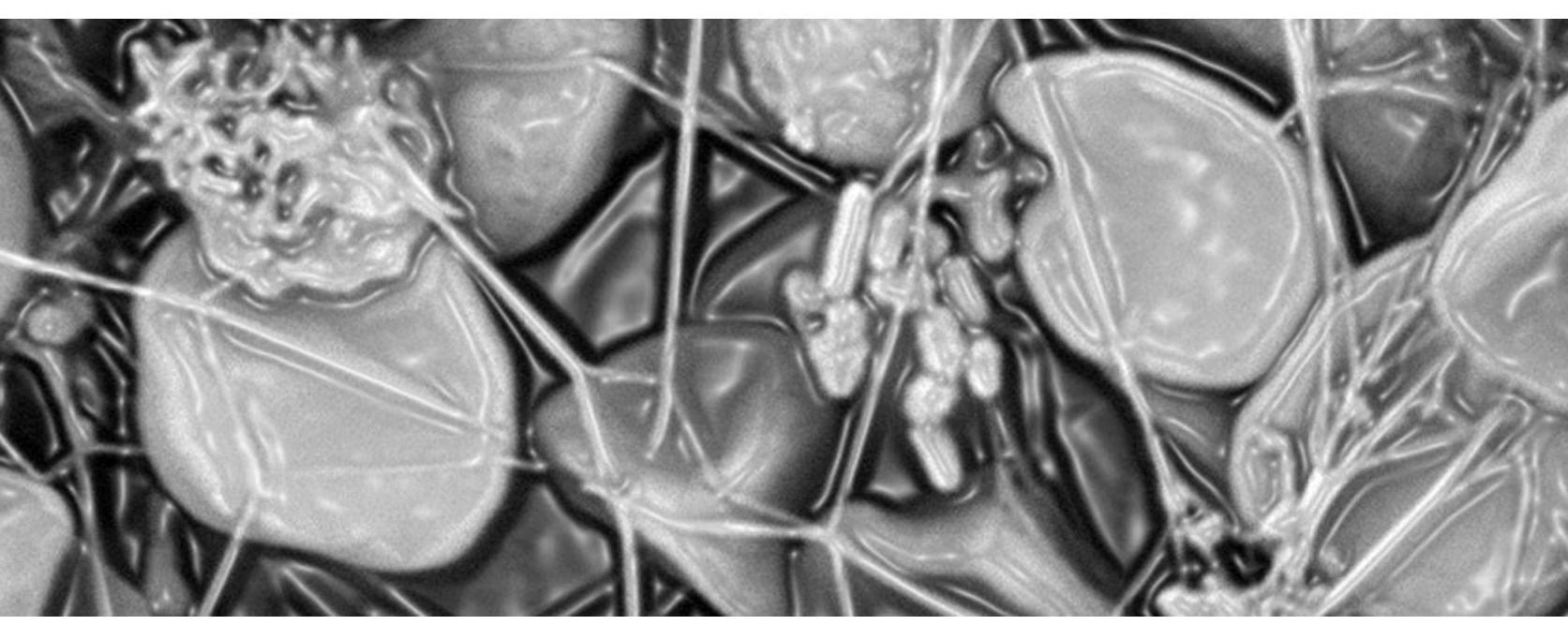

Large inter-individual variation of the pharmacodynamic effect of anticoagulant drugs on thrombin generation

Saartje Bloemen, H. Coenraad Hemker, Raed Al Dieri

Haematologica 2013; 98(4): 549-554. 


\section{Abstract}

Background: Anticoagulation by a standard dosage of an inhibitor of thrombin generation presupposes predictable pharmacokinetics and pharmacodynamics of the anticoagulant. We determined the inter-individual variation of the effect on thrombin generation of a fixed concentration of direct and antithrombin-mediated inhibitors of thrombin and factor $X$ a.

Materials \& methods: Thrombin generation was determined by calibrated automated thrombinography in platelet-poor plasma from 44 apparently healthy subjects which was spiked with fixed concentrations of otamixaban, melagatran, unfractionated heparin, dermatan sulfate and pentasaccharide.

Results: The variability of the inhibitory effect of the different anticoagulants within the population was determined using the coefficient of variation, i.e. the standard deviation expressed as a percentage of the mean. The inter-individual coefficients of variation of the endogenous thrombin potential and peak height before inhibition were $18 \%$ and $16 \%$, respectively and became $20 \%-24 \%$ and $24 \%-43 \%$ after inhibition. The average inhibition of endogenous thrombin potential (ETP) and peak height brought about by the anticoagulants was respectively: otamixaban $(27 \%$, $83 \%)$, melagatran $(56 \%, 63 \%)$, unfractionated heparin $(43 \%, 58 \%)$, dermatan sulfate $(68 \%, 57 \%)$ and pentasaccharide $(25 \%, 67 \%)$.

Conclusion: This study demonstrates that the addition of a fixed concentration of any type of anticoagulant tested causes an inhibition that is highly variable from one individual to another. In this respect there is no difference between direct inhibitors of thrombin and factor Xa and heparin(-like) inhibitors acting on the same factors. 


\section{Introduction}

Selective inhibitors of factor (F) Xa and thrombin are in clinical development for the prevention and treatment of thrombosis [1]. There would be many practical advantages from an antithrombotic that could be taken at a fixed dosage and that would not require its effect to be controlled. Trials showing that direct inhibitors of thrombin or coagulation FXa, when given in fixed doses, are not inferior to adjusted dose treatment with vitamin $\mathrm{K}$ antagonists are, therefore, hailed with enthusiasm [2-5].

Bleeding and thrombosis in patients receiving anticoagulant treatment have a local cause but are influenced by the coagulability of the blood, i.e. by the systematic component that determines the response to the local cause. There is a large body of evidence indicating that the thrombin-generating capacity of plasma is an important element in this systematic component and that it is the function that is diminished by antithrombotics [6, 7]. The effect of antithrombotic treatment is, therefore, likely due to its effect on the thrombin-generating capacity of blood. This determines the therapeutic results of the treatment, which are measured as the rates of thrombosis and bleeding in the treated group in comparison to a reference group.

The anticoagulant effect itself is a combination of how much of the drug reaches the target organ, i.e. the plasma (pharmacokinetics) and how the function of the target organ, i.e. the coagulability of plasma, is influenced by the drug (pharmacodynamics). The pharmacokinetics of the new drugs have been reported to be predictable and stable [8-10]. For a fixed-dose treatment to be safe and effective one would like the pharmacodynamics response to be predictable and stable within the population as well. We, therefore, measured the response of thrombin generation to a fixed concentration of different anticoagulants in a series of individual normal plasmas $(n=44)$. We tested unfractionated heparin (UFH), known to enhance the anti-thrombin and anti-FXa activities of plasma antithrombin [11]; dermatan sulfate, which enhances the anti-thrombin activity of heparin cofactor II [12]; pentasaccharide, which specifically enhances the anti-FXa action 


\section{Chapter 6}

of plasma antithrombin [13]; otamixaban, a direct and reversible inhibitor of FXa [14]; and melagatran, a direct and reversible inhibitor of thrombin [15]. Of each of these drugs we used a concentration that inhibits around $50 \%$ of either the thrombin generation peak or the endogenous thrombin potential (ETP: area under the thrombin generation curve).

\section{Materials and methods}

\section{Preparation of platelet-poor plasma}

Blood was acquired from apparently healthy subjects by antecubital venipuncture and was collected into BD vacutainer tubes (1 volume of trisodium citrate $0.105 \mathrm{M}$ to 9 volumes of blood) in the absence of corn trypsin inhibitor (BD Vacutainer System, Roborough, Plymouth, UK). Platelet-poor plasma was obtained by centrifuging the blood at $2,900 \mathrm{~g}$ for $10 \mathrm{~min}$ at room temperature. Plasma was aspirated and the procedure was repeated. Aliquots of $2 \mathrm{ml}$ were prepared and stored at $-80^{\circ} \mathrm{C}$ until use.

The platelet-poor plasma from the 44 individual donors was pooled (equal volumes from each donor) and is referred to as the 'pool' in this article. Normal pooled plasma (NPP) was prepared previously as described above, from at least 24 apparently healthy donors, different from those already mentioned and was used as a reference plasma. All enrolled volunteers gave their full informed consent according to the Helsinki Declaration and its amendments. The study fulfilled all institutional ethical requirements and was approved by the Medical Ethical Committee of Maastricht University Medical Center.

\section{Reagents}

Synthetic procoagulant phospholipids were obtained from Avanti Polar Lipids Inc. (Alabaster, AL, USA) and added in the form of vesicles consisting of phosphatidylserine, phosphatidylethanolamine and phosphatidylcholine (1:1:3, mol:mol:mol). The recombinant tissue factor used was Innovin (Dade-Behring, 96 
Marburg, Germany). The fluorogenic substrate Z-Gly-Gly-Arg aminomethylcoumarine (ZGGR-AMC) was purchased from Bachem (Basel, Switzerland). A calibrator was prepared as described by Hemker et al. [16]. Hepes buffers containing $5 \mathrm{mg} / \mathrm{ml}$ or $60 \mathrm{mg} / \mathrm{ml}$ bovine serum albumin (BSA5 and BSA60, respectively) were prepared as described previously [17].

The anticoagulants were obtained from different sources: otamixaban (a direct FXa inhibitor) was a gift from Sanofi-Aventis (Frankfurt, Germany), melagatran (a direct thrombin inhibitor) was provided by AstraZeneca (Zoetermeer, the Netherlands), UFH (Liquemin ${ }^{\circledR} N$ ) was from Hoffman-La Roche AG (Basel, Switzerland), dermatan sulfate (Mistral) was a gift from Mediolanum Farmaceutici S.p.A. (Milan, Italy) and the synthetic pentasaccharide (Org31540/SR90107A, currently known as fondaparinux) was a gift from Dr. Petitou (Sanofi-Recherche, Toulouse, France).

\section{Calibrated automated thrombinography}

Calibrated automated thrombinography (CAT) was performed as described previously by Hemker et al. [16]. Ten microliters of tissue factor/phospholipid mixture in BSA5 buffer was added to a well with $10 \mu$ of BSA5 buffer with or without the anticoagulant (anticoagulants were not added to calibrator wells). The final concentrations of recombinant tissue factor and phospholipids were $5 \mathrm{pM}$ and $4 \mu \mathrm{M}$, respectively. Thrombin generation was initiated by adding $20 \mu \mathrm{l}$ of ZGGRAMC $(2.5 \mathrm{mM})$ and $\mathrm{CaCl}_{2}(100 \mathrm{mM})$ in BSA60 buffer. NPP served as a control in each measurement. All experiments were performed in triplicate and the prewarmed plate was placed in the fluorometer at $37^{\circ} \mathrm{C}$ for $10 \mathrm{~min}$ before initializing the measurement.

Experiments were constructed in such a manner as to measure the effect of all the different anticoagulants on the platelet-poor plasma of one (or more) donor(s) in one run. The experimental error in thrombin generation without any addition, as determined in NPP under these conditions, was $6.5 \%$ for the ETP and $4.7 \%$ for the peak $(n=37)$. The experimental error after addition of an anticoagulant to NPP was calculated with data of 14 measurements. 


\section{Chapter 6}

The thrombin generation curves and their parameters were derived from the fluorescence curves using the dedicated software provided with the CAT method (Thrombinoscope BV, Maastricht, the Netherlands).

\section{Anticoagulant concentrations}

Dose-response curves were constructed in order to select the $\mathrm{IC}_{50}$ concentrations for each anticoagulant. However, the parameters of the CAT assay (ETP, peak height, time to peak and lag time) were affected diversely, which made it impossible to compare the effects of the different agents by considering only one parameter. Since the ETP and peak height were the most informative parameters, we chose a fixed concentration of the anticoagulants at which the sum of the inhibitions of ETP and peak was between 80 and $120 \%$. Consequently, the following concentrations were utilized: otamixaban $200 \mathrm{nM}$, melagatran $400 \mathrm{nM}$, dermatan sulfate $20 \mu \mathrm{g} / \mathrm{ml}$, pentasaccharide $0.9 \mu \mathrm{g} / \mathrm{ml}$, and UFH $0.08 \mathrm{U} / \mathrm{ml}$ (with around $30 \%$ high-affinity material [18]). The concentrations of the new anticoagulants used here are comparable to plasma concentrations effective invivo. A study in healthy male subjects used predicted target concentrations of otamixaban of $100 \mathrm{ng} / \mathrm{mL}$; i.e. about $210 \mathrm{nM}$ (200 nM used here) [19]. For melagatran, the proposed therapeutic plasma concentration is $<500 \mathrm{nM}$, (400 nM used here) [15]. Therapeutic doses of fondaparinux lead to a concentration of approximately $1.4 \mu \mathrm{g} / \mathrm{ml}$ [20]. The concentration of pentasaccharide in the present study is deliberately lower, because the aim was not to measure within the plateau region, which would obscure inter-individual differences.

\section{Data analysis}

To quantify the variability of the inhibitory effect of the different antithrombotics within the 44 normal plasma samples we used the coefficient of variation (CV), i.e. the standard deviation expressed as a percentage of the average. The total CV is caused by random experimental error $\left(\mathrm{CV}_{\text {error }}\right)$ and by inter-individual variation $\left(\mathrm{CV}_{\mathrm{ii}}\right)$. The experimental error was derived from the measurements in NPP, which 
served as a reference plasma during each run. The coefficient of inter-individual variation was calculated as:

$$
\mathrm{CV}_{\mathrm{ii}}=\text { square root }\left(\mathrm{CV}_{\text {total }}^{2}-\mathrm{CV}_{\text {error }}^{2}\right)[21]
$$

The same formula was used to calculate the variation in susceptibility to inhibition $\left(\mathrm{CV}_{\text {susc }}\right.$, i.e. how much extra variation is induced by adding an anticoagulant) from the total CV of ETP and peak found in the absolute values of the inhibited $\left(\mathrm{CV}_{\mathrm{inh}}\right)$ plasmas and in the uninhibited plasmas $\left(\mathrm{CV}_{\text {uninh }}\right)$ :

$$
\mathrm{CV}_{\text {susc }}=\text { square root }\left(\mathrm{CV}_{\text {inh }}^{2}-\mathrm{CV}_{\text {uninh }}{ }^{2}\right)
$$

The inhibition of thrombin-generating capacity was calculated as follows: 100((ETP after addition of an anticoagulant/ETP before addition of an anticoagulant) $x$ 100).

\section{Results}

\section{Inhibition of normal pooled plasma}

Important qualitative differences in the type of inhibition were observed (Figure 1). The direct inhibitors (otamixaban, melagatran) had a stronger effect on the lag time than the heparin(-like) inhibitors. Inhibition of factor $\mathrm{Xa}$ (otamixaban, pentasaccharide) primarily affected the peak and tended to protract thrombin generation so that the ETP was much less affected than the peak. In order to find concentrations that caused around $50 \%$ inhibition, we constructed dose-response curves in NPP (Figure 2). Inhibition of FXa systematically inhibited the peak more than the ETP, inhibition of thrombin affected both ETP and peak to a similar extent, whereas UFH produced an intermediate position. Because of these differences an unequivocal $\mathrm{IC}_{50}$ could not be defined, as mentioned before, and arbitrarily we chose that concentration at which the sum of the inhibitions of ETP and peak was between 80 and $120 \%$. 


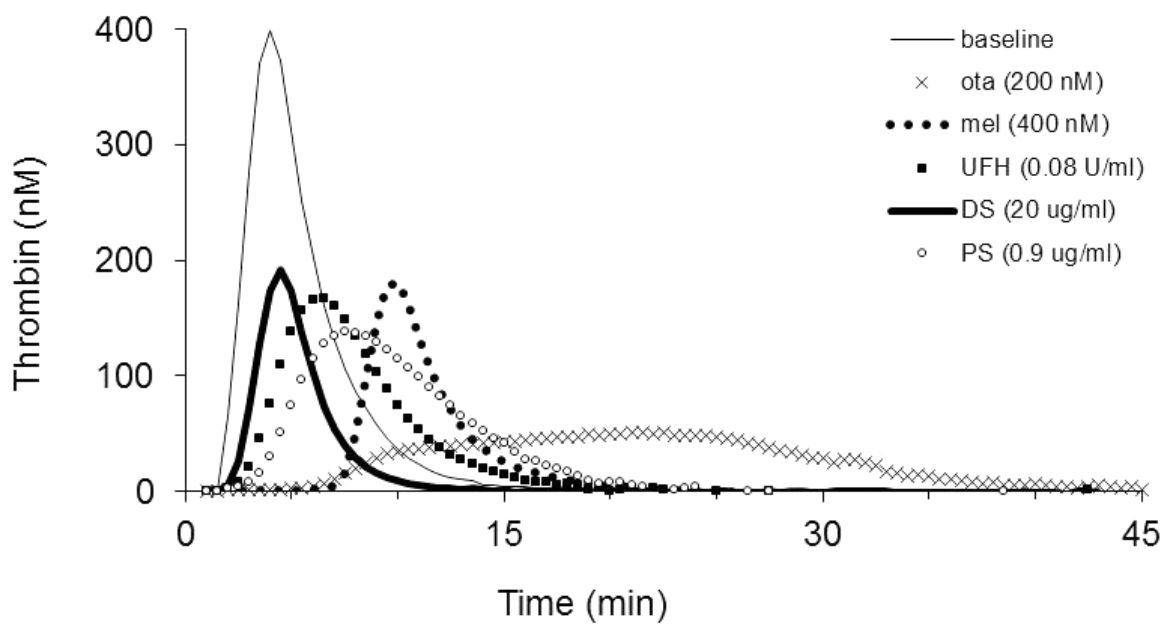

Figure 1: Effect of anticoagulants on thrombin generation in normal pooled plasma. Thin black line: no anticoagulant added, line of Xs: $200 \mathrm{nM}$ otamixaban, closed dots: $400 \mathrm{nM}$ melagatran, squares: $0.08 \mathrm{U} / \mathrm{ml}$ unfractionated heparin, bold black line: $20 \mu \mathrm{g} / \mathrm{ml}$ dermatan sulfate, open dots: $0.9 \mu \mathrm{g} / \mathrm{ml}$ pentasaccharide.

In order to determine the inter-assay CV of thrombin generation, we tested the effect of the above-mentioned concentrations in NPP in 14 fold. The inter-assay $\mathrm{CV}$ of the inhibition of the peak was $2-5 \%$, except for UFH (8.5\%). The CV of the inhibition of the ETP varied between $2-6 \%$, while otamixaban and pentasaccharide had a higher CV of $16 \%$ and $15 \%$, respectively. 

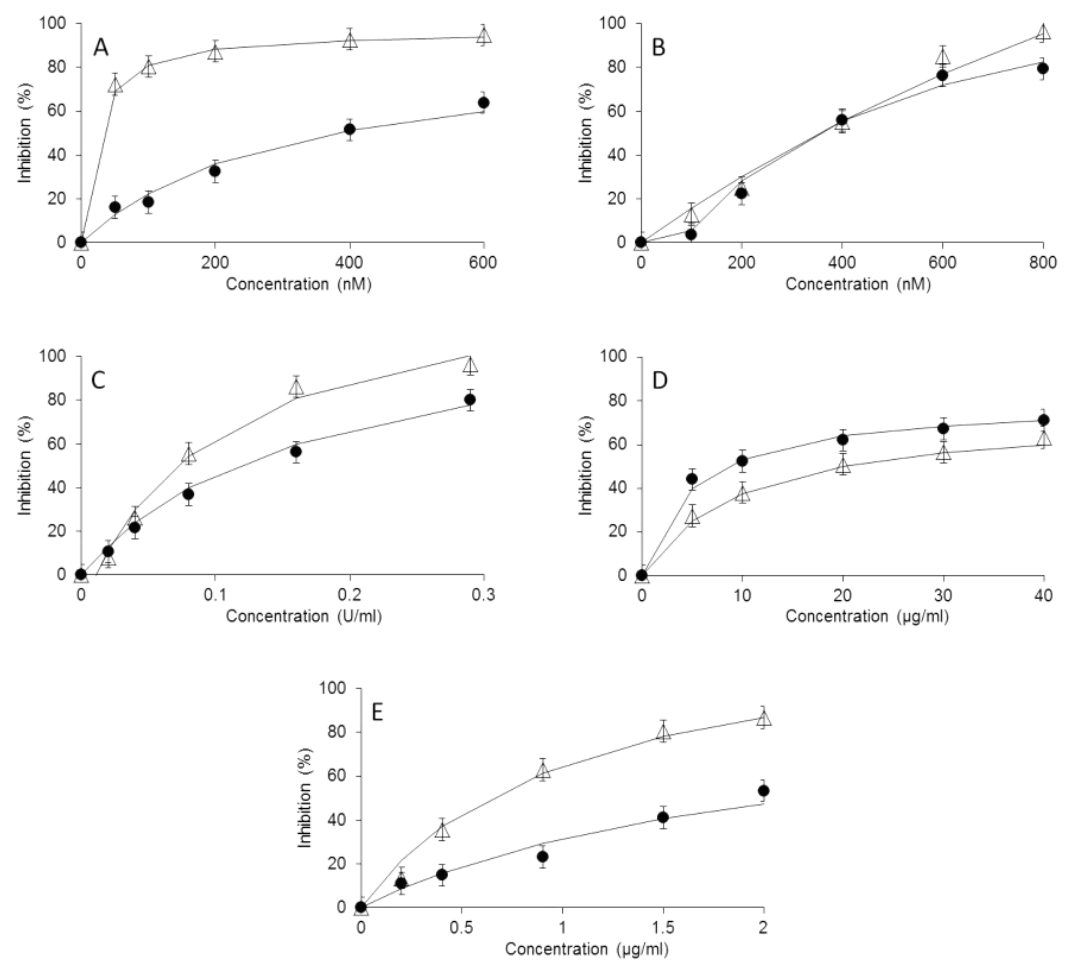

Figure 2: Dose-response curves of ETP and peak height in normal pooled plasma. Open triangles: $\%$ inhibition of peak height; closed dots: \% inhibition of endogenous thrombin potential (ETP) (with $5 \%$ error bars). (A) otamixaban (B) melagatran (C) unfractionated heparin (D) dermatan sulfate (E) pentasaccharide.

\section{Inhibition of individual plasma specimens}

The qualitative differences that were observed in NPP were also seen in the individual plasma samples. Table 1 shows that the direct inhibitors had a strong effect on the lag time whereas the effect of the inhibitors requiring plasma cofactors was much less. The variation between individual samples was between $18-30 \%$ after correction for experimental errors. Similar effects on time-to-peak were seen, with variations between 13 and $37 \%$ in inhibited plasma samples and a CV of $14 \%$ in uninhibited plasma after correction for the CV from experimental errors. 


\section{Chapter 6}

Table 1: Influence of anticoagulants on lag time.

\begin{tabular}{|l|ccccc}
\hline & \multicolumn{5}{|c}{ Lag time (min) } \\
& Mean & $\mathrm{SD}$ & $\mathrm{CV}_{\text {error }}$ & $\mathrm{CV}_{\text {ii }}$ & $\mathrm{CV}_{\text {susc }}$ \\
\hline No anticoagulant added & 2.2 & 0.5 & 11.0 & 21.7 & - \\
\hline Otamixaban & 7.1 & 1.4 & 8.1 & 18.1 & $/$ \\
\hline Melagatran & 7.9 & 2.2 & 12.8 & 25.5 & 13.5 \\
\hline UFH & 3.2 & 0.8 & 7.4 & 23.2 & 8.2 \\
\hline Dermatan sulfate & 2.8 & 0.7 & 7.0 & 22.9 & 7.5 \\
\hline Pentasaccharide & 4.1 & 1.3 & 6.1 & 30.2 & 21.0 \\
\hline
\end{tabular}

$\mathrm{n}=44$; for $\mathrm{CV}_{\text {error }}$ (without and with addition of anticoagulant): $\mathrm{n}=37$ and 14, respectively. Experimental error was calculated by means of measurements in NPP. SD, standard deviation; $\mathrm{CV}_{\text {error, }}$ experimental error; $\mathrm{CV}_{\mathrm{ii}}$, inter-individual coefficient of variation (corrected for $\mathrm{CV}_{\text {error }}$ ); $\mathrm{CV}_{\text {susc }}$, coefficient of variation in susceptibility to inhibition. CV's are represented in \%. Since the $\mathrm{CV}_{\mathrm{ii}}$ after addition of otamixaban is lower than before, the $\mathrm{CV}_{\text {susc }}$ cannot be calculated.

Table 2 summarizes the effect of the antithrombotics on ETP and peak at fixed concentrations in the 44 individual plasma samples. The CV's have been corrected for the experimental error. It can be seen that addition of the anticoagulant induced an extra variation superimposed on the interindividual variation of the uninhibited values. The uninhibited peak variation was $16.0 \%$ and the $\mathrm{CV}$ values became larger after adding antithrombotic agents (24.0 to $43.3 \%)$. The variation in ETP without addition of an antithrombotic was 18.4\% which increased to between 20.2 and $24.3 \%$ after addition of anticoagulants.

\section{Susceptibility to inhibition}

The larger CV after inhibition compared to before suggests that the plasma of some individuals is more susceptible to inhibition than that of others. It is possible that this susceptibility is dependent on the activity of thrombin generation in the uninhibited plasma. We therefore investigated whether the degree of inhibition is dependent on the value of uninhibited ("basal") thrombin generation, i.e. whether individuals with a high basal thrombin generation would be more prone to inhibition than those with a lower one. Plots of the degree of inhibition against the basal ETP 
or peak did not show any consistent correlation (data not shown). It can, therefore, be assumed that the variation in inhibition superimposes independently upon the variation of the basal values.

Table 2: Variation in inhibition by anticoagulants in individual plasma samples.

\begin{tabular}{|c|c|c|c|c|c|c|c|c|c|c|}
\hline & \multicolumn{5}{|c|}{ ETP (nM.min) } & \multicolumn{5}{|c|}{ Peak (nM) } \\
\hline & Mean & SD & $\mathrm{CV}_{\text {error }}$ & $\mathrm{CV}_{\mathrm{ii}}$ & $\mathrm{CV}_{\text {susc }}$ & Mean & SD & $\mathrm{CV}_{\text {error }}$ & $\mathrm{CV}_{\mathrm{ii}}$ & $\mathrm{CV}_{\text {susc }}$ \\
\hline No anticoagulant added & 1555 & 303 & 6.5 & 18.4 & - & 330 & 55 & 4.7 & 16.0 & - \\
\hline Otamixaban & 1149 & 247 & 8.2 & 20.5 & 7.6 & 61 & 17 & 15.1 & 27.4 & 17.0 \\
\hline Melagatran & 685 & 164 & 6.7 & 23.0 & 13.7 & 126 & 55 & 9.8 & 43.3 & 39.3 \\
\hline UFH & 920 & 232 & 5.9 & 24.3 & 16.2 & 145 & 56 & 15.2 & 38.7 & 32.1 \\
\hline Dermatan sulfate & 497 & 107 & 3.8 & 20.4 & 10.3 & 144 & 35 & 5.1 & 24.0 & 17.8 \\
\hline Pentasaccharide & 1153 & 244 & 10.3 & 20.2 & 2.3 & 118 & 45 & 16.2 & 37.6 & 30.3 \\
\hline
\end{tabular}

ETP, endogenous thrombin potential; other abbreviations and details are as stated in Table 1.

The variation in the susceptibility to the anticoagulants (i.e. how much extra variation is induced by the addition of the anticoagulant) was calculated from the variation in the absolute values obtained before and after inhibition. These values varied between 17.0 and $39.3 \%$ for peak height and between $2.3 \%$ and $16.2 \%$ for the ETP, without apparent differences between direct and heparin(-like) inhibitors (Table 2). The variation in susceptibility was also calculated for the lag time, as indicated in Table 1.

The average inhibition by the anticoagulants was $25-68 \%$ for the ETP and $57-83 \%$ for peak height (Table 3). The level of inhibition was also determined in the pool prepared from the 44 individual plasmas. It was comparable to the mean inhibition obtained from the 44 individual plasma samples (within a range of $5 \%$ ) for all anticoagulants, with the exception of pentasaccharide. 


\section{Chapter 6}

Table 3: Inhibition (\%) of the individual plasma samples (with the variation) and their pool after addition of anticoagulants.

\begin{tabular}{|c|c|c|c|}
\hline & & \multicolumn{2}{|c|}{ Inhibition (\%) } \\
\hline & & ETP & Peak \\
\hline \multirow[t]{5}{*}{ Otamixaban } & Pool & 29.2 & 84.3 \\
\hline & Mean & 26.5 & 83.0 \\
\hline & SD & 9.1 & 3.5 \\
\hline & $\mathrm{CV}_{\text {error }}$ & 16.0 & 2.3 \\
\hline & $\mathrm{CV}_{\mathrm{ii}}$ & 30.2 & 3.5 \\
\hline \multirow[t]{5}{*}{ Melagatran } & Pool & 52.7 & 58.2 \\
\hline & Mean & 56.2 & 63.3 \\
\hline & SD & 4.8 & 12.3 \\
\hline & $\mathrm{CV}_{\text {error }}$ & 5.8 & 5.5 \\
\hline & $\mathrm{CV}_{\mathrm{ii}}$ & 6.2 & 18.6 \\
\hline \multirow[t]{5}{*}{ UFH } & Pool & 42.1 & 55.2 \\
\hline & Mean & 43.2 & 57.6 \\
\hline & SD & 5.3 & 13.9 \\
\hline & $\mathrm{CV}_{\text {error }}$ & 4.7 & 8.5 \\
\hline & $\mathrm{CV}_{\mathrm{ii}}$ & 11.4 & 22.7 \\
\hline \multirow[t]{5}{*}{ Dermatan sulfate } & Pool & 69.6 & 55.3 \\
\hline & Mean & 67.6 & 56.9 \\
\hline & SD & 6.3 & 6.4 \\
\hline & $\mathrm{CV}_{\text {error }}$ & 2.1 & 4.8 \\
\hline & $\mathrm{CV}_{\mathrm{ii}}$ & 9.1 & 10.1 \\
\hline \multirow[t]{5}{*}{ Pentasaccharide } & Pool & 36.4 & 76.0 \\
\hline & Mean & 25.4 & 67.0 \\
\hline & SD & 12.8 & 11.3 \\
\hline & $\mathrm{CV}_{\text {error }}$ & 15.0 & 4.6 \\
\hline & $\mathrm{CV}_{\mathrm{ii}}$ & 48.0 & 16.3 \\
\hline
\end{tabular}

Abbreviations and details are as stated in Tables $1 \& 2$.

\section{Discussion}

In clinical trials, direct inhibitors of thrombin or of FXa are not inferior to prophylaxis with traditional vitamin $\mathrm{K}$ antagonists [2-5]. It has been surmised, however, that certain patients could benefit from dose adaptation [22, 23]. This raises the question of whether dose adaptation should be restricted to certain categories or 
whether it could improve the results with direct inhibitors so that these become better than the - admittedly not ideal - results of prophylaxis with vitamin $\mathrm{K}$ antagonists. This article deals with a partial problem pertaining to this question, viz. will the plasma of different individuals react similarly to a fixed dose of an antithrombotic agent?

We start from the a priori assumption - supported by a wealth of literature $[16,20$, 24-30] - that thrombin generation is a sensitive surrogate variable for bleeding or, conversely, thrombotic tendency. All known drugs that diminish thrombin generation have an antithrombotic action, independently of their mode of action. It is, therefore, a reasonable assumption that antithrombotic drugs, such as those tested in this study, act because they diminish thrombin generation and that their action can be quantified by measuring to what degree they diminish it. In contrast, clotting times (activated partial thromboplastin time, prothrombin time, lag time of thrombin generation) may or may not be prolonged, depending on the nature of the antithrombotic agent and/or the condition of the assay [24, 31, 32] (Figure 1 and Table 1).

It is known that the capacity to form thrombin varies widely between individuals. In a normal adult population the coefficient of variation is $\sim 16 \%$ [16]. Our results show that adding a fixed amount of any anticoagulant causes a variable inhibitory effect with a CV of $6-48 \%$ for ETP and 3-23\% for peak height, which adds to the variation already present in the population. The variability of effect of the modern antithrombotics, otamixaban, melagatran and pentasaccharide, is just the same as that of UFH or dermatan sulfate. From the literature it is known that low molecular weight heparins do no better either [20].

There must be a range of thrombin generation values that minimizes the risk of thrombosis without causing undue bleeding risk. What this "prophylactic window" is, cannot be determined with any accuracy at the moment. It has only been defined for vitamin $\mathrm{K}$ antagonist treatment, which however affects the protein $\mathrm{C}$ system as well as the procoagulant system [33] and is not, therefore, directly comparable to the materials tested here. After a first idiopathic venous thrombosis, 


\section{Chapter 6}

people with above average thrombin generation have a four times higher risk of recurrence than those with below average thrombin generation [34]. This would mean that moderate anticoagulation resulting in below average thrombin generation would already have a beneficial effect.

The evident limit is set by the risk of bleeding. Thrombin generation below $\sim 20 \%$ of normal, i.e. an ETP of below 350 nM.min in congenital factor deficiencies, is associated with a definite bleeding risk [35], as is an international normalized ratio $>4$ [36], which corresponds to an ETP of 300 nM.min. From this it follows that treatment which keeps a trial population under the average ETP of a normal population, i.e. 1800 nM.min [16], and above the threshold limit for bleeding, i.e. an ETP >300 nM.min, will show a beneficial effect. This is a very large window, which explains the positive outcome of clinical trials despite the large inter-individual variation. An optimal beneficial effect, however, is to be expected within a significantly narrower range. An international normalized ratio of $2-3$, which has been proven to be adequate in oral anticoagulation, corresponds roughly to an ETP in the range of 500-700 nM.min [37]. Due to the effect of vitamin $\mathrm{K}$ antagonists on proteins $\mathrm{S}$ and $\mathrm{C}$, the optimal range for other antithrombotics may be at higher levels of the ETP, but there is no reason to assume that it would cover a wider range. The large variation of the susceptibility of the target organ to inhibition, together with the variation in individual properties that influence the pharmacokinetics (e.g. weight) will, in all probability, not allow a (trial) population to be kept within narrow limits of optimal prophylaxis unless the dose is tuned to the needs of the individuals.

Previous studies have shown that variations in blood coagulation proteins vary from $50 \%$ to $150 \%$ of the mean values and can be associated with thrombotic events. However, the most important factors affecting thrombin generation are prothrombin and antithrombin [38-40].

Our results are in accordance with previous work by Hacquard et al. on low molecular weight heparins (LMWH) that also showed inter-individual variances of around $20 \%$ for the inhibition of ETP [20]. In an earlier study by our group on 
thrombin generation in healthy subjects who received fixed doses of UFH and $\mathrm{LMWH}$, variances in the inhibitory effect were found to be $32 \%$ and $13-21 \%$, respectively [41]. Freyburger et al. concluded that there is also a high interindividual variability in response to dabigatran and rivaroxaban [42]. Pharmacokinetic variation played a role in both these latter two studies.

Some interesting considerations can be made from a more detailed examination of the results.

- Inhibition of FXa by otamixaban causes a strong inhibition of the peak but a significant protraction of the thrombin generation process, so that the ETP is much less inhibited than the peak. We surmise that this is due to inhibition of the direct positive feedback action of FXa on FVII [43], which will cause a prolongation of the lag time and a slow start of prothrombinase formation, together with inhibition of the negative feedback on the tissue factor-FVIla complex by the tissue factor pathway inhibitor-FXa complex which prevents shutting off of the extrinsic pathway.

- The inhibition by dermatan sulfate appears to reach a plateau rather than tending to complete inhibition. This may be due to the fact that there is less heparin cofactor II in the plasma $(\sim 1 \mu \mathrm{M})$ than prothrombin $(\sim 2 \mu \mathrm{M})$ so that even complete activation of heparin cofactor II by dermatan sulfate would not lead to complete inhibition of thrombin generation. This implies that dermatan sulfate would be an antithrombotic that cannot be overdosed.

- The fact that dermatan sulfate and UFH only slightly prolong the lag time, in contrast to melagatran, indicates that the positive feedback mechanism of factor $\mathrm{V}$ activation by thrombin is only accessible to a direct inhibitor, probably because it is membrane-bound and involves meizothrombin rather than thrombin. A similar difference is seen between otamixaban and pentasaccharide. Probably, the feedback activation of FVII by FXa is membrane-bound and therefore inaccessible to inhibition by the pentasaccharide-antithrombin complex [44, 45]. 


\section{Chapter 6}

These two examples together show that the relation between lag time $(\approx$ clotting time) and thrombin generation is mechanism-dependent, so that clotting time measurements cannot be used as a universal indicator of the effect of antithrombotics on thrombin generation. Effects of melagatran on thrombin generation were previously studied by Beilfuss et al. and this group also found a strong effect on the lag time as well as a dose-dependent decrease in ETP [25]. Samama et al. who investigated the effect of rivaroxaban and fondaparinux (indirect FXa inhibitor) observed qualitative differences between the two, similar to those reported here $[46,47]$.

Our results suggest that the results of direct inhibitors could be improved by tuning the dose to the needs of the individual patient. However, due to the large 'prophylactic window', fine tuning is probably not required; differentiation between high, middle and low responders might suffice. However, further in vivo investigation of this facet is warranted.

\section{Acknowledgments}

The authors would like to thank Bas de Laat for carefully reading the manuscript and providing us with helpful comments. We would also like to thank Leonie Pelkmans for technical assistance. 


\section{References}

1. Bauer KA. New anticoagulants: anti lla vs anti Xa--is one better? $J$ Thromb Thrombolysis. 2006; 21(1): p. 67-72.

2. Schulman S, Kearon C, Kakkar AK, Mismetti P, Schellong S, Eriksson H, Baanstra D, Schnee J, Goldhaber SZ. Dabigatran versus warfarin in the treatment of acute venous thromboembolism. N Engl J Med. 2009; 361(24): p. 2342-2352.

3. Patel MR, Mahaffey KW, Garg J, Pan G, Singer DE, Hacke W, Breithardt G, Halperin JL, Hankey GJ, Piccini JP, Becker RC, Nessel CC, Paolini JF, Berkowitz $\mathrm{SD}$, Fox KA, Califf RM. Rivaroxaban versus warfarin in nonvalvular atrial fibrillation. N Engl J Med. 2011; 365(10): p. 883-891.

4. Connolly SJ, Ezekowitz MD, Yusuf S, Eikelboom J, Oldgren J, Parekh A, Pogue J, Reilly PA, Themeles E, Varrone J, Wang S, Alings M, Xavier D, Zhu J, Diaz R, Lewis BS, Darius H, Diener HC, Joyner CD, Wallentin L. Dabigatran versus warfarin in patients with atrial fibrillation. $N$ Engl $J$ Med. 2009; 361(12): p. 11391151.

5. Granger CB, Alexander JH, McMurray JJ, Lopes RD, Hylek EM, Hanna M, AlKhalidi HR, Ansell J, Atar D, Avezum A, Bahit MC, Diaz R, Easton JD, Ezekowitz JA, Flaker G, Garcia D, Geraldes M, Gersh BJ, Golitsyn S, Goto S, Hermosillo AG, Hohnloser SH, Horowitz J, Mohan P, Jansky P, Lewis BS, Lopez-Sendon JL, Pais P, Parkhomenko A, Verheugt FW, Zhu J, Wallentin L. Apixaban versus warfarin in patients with atrial fibrillation. N Engl J Med. 2011; 365(11): p. 981-992.

6. Adams M. Assessment of thrombin generation: useful or hype? Semin Thromb Hemost. 2009; 35(1): p. 104-110.

7. Eerenberg ES, van Es J, Sijpkens MK, Buller HR, Kamphuisen PW. New anticoagulants: Moving on from scientific results to clinical implementation. Ann Med. 2011; 43(8): 606-616.

8. Ho SJ, Brighton TA. Ximelagatran: direct thrombin inhibitor. Vasc Health Risk Manag. 2006; 2(1): p. 49-58.

9. Gomez-Outes A, Suarez-Gea ML, Lecumberri R, Rocha E, Pozo-Hernandez C, Vargas-Castrillon E. New parenteral anticoagulants in development. Ther $A d v$ Cardiovasc Dis. 2011; 5(1): p. 33-59.

10. Stangier J. Clinical pharmacokinetics and pharmacodynamics of the oral direct thrombin inhibitor dabigatran etexilate. Clin Pharmacokinet. 2008; 47(5): p. 285295. 


\section{Chapter 6}

11. Petitou M, Casu B, Lindahl U. 1976-1983, a critical period in the history of heparin: the discovery of the antithrombin binding site. Biochimie. 2003; 85(1-2): p. 83-89.

12. Tollefsen DM, Pestka CA, Monafo WJ. Activation of heparin cofactor II by dermatan sulfate. J Biol Chem. 1983; 258(11): p. 6713-6716.

13. Boneu B, Necciari J, Cariou R, Sie P, Gabaig AM, Kieffer G, Dickinson J, Lamond $\mathrm{G}$, Moelker $\mathrm{H}$, Mant $\mathrm{T}$, et al. Pharmacokinetics and tolerance of the natural pentasaccharide (SR90107/Org31540) with high affinity to antithrombin III in man. Thromb Haemost. 1995; 74(6): p. 1468-1473.

14. Chu V, Brown K, Colussi D, Gao J, Bostwick J, Kasiewski C, Bentley R, Morgan S, Guertin K, Pauls HW, Gong Y, Zulli A, Perrone MH, Dunwiddie CT, Leadley RJ. Pharmacological characterization of a novel factor Xa inhibitor, FXV673. Thromb Res. 2001; 103(4): p. 309-324.

15. Gustafsson D, Antonsson T, Bylund R, Eriksson U, Gyzander E, Nilsson I, Elg M, Mattsson C, Deinum J, Pehrsson S, Karlsson O, Nilsson A, Sorensen H. Effects of melagatran, a new low-molecular-weight thrombin inhibitor, on thrombin and fibrinolytic enzymes. Thromb Haemost. 1998; 79(1): p. 110-118.

16. Hemker HC, Giesen P, Al Dieri R, Regnault V, de Smedt E, Wagenvoord R, Lecompte $\mathrm{T}$, Beguin $\mathrm{S}$. Calibrated automated thrombin generation measurement in clotting plasma. Pathophysiol Haemost Thromb. 2003; 33(1): p. 4-15.

17. Hemker HC, Hemker PW, Al Dieri R. The technique of measuring thrombin generation with fluorescent substrates: 4. The H-transform, a mathematical procedure to obtain thrombin concentrations without external calibration. Thromb Haemost. 2009; 101(1): p. 171-177.

18. Beguin S, Wielders S, Lormeau JC, Hemker HC. The mode of action of CY216 and CY222 in plasma. Thromb Haemost. 1992; 67(1): p. 33-41.

19. Paccaly A, Frick A, Rohatagi S, Liu J, Shukla U, Rosenburg R, Hinder M, Jensen BK. Pharmacokinetics of otamixaban, a direct factor $\mathrm{Xa}$ inhibitor, in healthy male subjects: pharmacokinetic model development for phase $2 / 3$ simulation of exposure. J Clin Pharmacol. 2006; 46(1): p. 37-44.

20. Hacquard $M$, Perrin J, Lelievre N, Vigneron C, Lecompte T. Inter-individual variability of effect of 7 low molecular weight antithrombin-dependent anticoagulants studied in vitro with Calibrated Automated Thrombography. Thromb Res. 2011; 127(1): p. 29-34.

21. Fuchs G, Mathematik für Mediziner und Biologen. Springer Verlag, 1969, 71. 
22. Mismetti $\mathrm{P}$, Laporte $\mathrm{S}$. New oral antithrombotics: a need for laboratory monitoring. For. J Thromb Haemost. 2010; 8(4): p. 621-626.

23. Bounameaux H, Reber G. New oral antithrombotics: a need for laboratory monitoring. Against. J Thromb Haemost. 2010; 8(4): p. 627-630.

24. al Dieri R, Alban S, Beguin S, Hemker HC. Thrombin generation for the control of heparin treatment, comparison with the activated partial thromboplastin time. $J$ Thromb Haemost. 2004; 2(8): p. 1395-1401.

25. Beilfuss A, Grandoch M, Wenzel F, Hohlfeld T, Schror K, Weber AA. Differential effects of factor lla inhibitors on the endogenous thrombin potential. Ther Drug Monit. 2008; 30(6): p. 740-743.

26. Castoldi E, Rosing J. Thrombin generation tests. Thromb Res. 2011; 127 Suppl 3: p. S21-25.

27. Hemker HC, Al Dieri R, De Smedt E, Beguin S. Thrombin generation, a function test of the haemostatic-thrombotic system. Thromb Haemost. 2006; 96(5): p. 553561.

28. Hemker HC, Giesen P, AlDieri R, Regnault V, de Smed E, Wagenvoord R, Lecompte T, Beguin S. The calibrated automated thrombogram (CAT): a universal routine test for hyper- and hypocoagulability. Pathophysiol Haemost Thromb. 2002; 32(5-6): p. 249-253.

29. van Veen JJ, Gatt A, Makris M. Thrombin generation testing in routine clinical practice: are we there yet? Br J Haematol. 2008; 142(6): p. 889-903.

30. Petros S, Siegemund T, Siegemund A, Engelmann L. The effect of different anticoagulants on thrombin generation. Blood Coagul Fibrinolysis. 2006; 17(2): p. 131-137.

31. Tripodi A, van den Besselaar A. Laboratory monitoring of anticoagulation: where do we stand? Semin Thromb Hemost. 2009; 35(1): p. 34-41.

32. Erkens PM, Prins MH. Fixed dose subcutaneous low molecular weight heparins versus adjusted dose unfractionated heparin for venous thromboembolism. Cochrane Database Syst Rev. 2010(9): p. CD001100.

33. Ansell J, Hirsh J, Poller L, Bussey H, Jacobson A, Hylek E. The pharmacology and management of the vitamin $\mathrm{K}$ antagonists: the Seventh ACCP Conference on Antithrombotic and Thrombolytic Therapy. Chest. 2004; 126(3 Suppl): p. 204S233S. 


\section{Chapter 6}

34. Hron G, Kollars M, Binder BR, Eichinger S, Kyrle PA. Identification of patients at low risk for recurrent venous thromboembolism by measuring thrombin generation. Jama. 2006; 296(4): p. 397-402.

35. Al Dieri R, Peyvandi F, Santagostino E, Giansily M, Mannucci PM, Schved JF, Beguin S, Hemker HC. The thrombogram in rare inherited coagulation disorders: its relation to clinical bleeding. Thromb Haemost. 2002; 88(4): p. 576-582.

36. Azar AJ, Koudstaal PJ, Wintzen AR, van Bergen PF, Jonker JJ, Deckers JW. Risk of stroke during long-term anticoagulant therapy in patients after myocardial infarction. Ann Neurol. 1996; 39(3): p. 301-307.

37. Hemker HC, Beguin S. Phenotyping the clotting system. Thromb Haemost. 2000; 84(5): p. 747-751.

38. Butenas S, van't Veer C, Mann KG. "Normal" thrombin generation. Blood. 1999; 94(7): p. 2169-2178.

39. Andrew M, Vegh P, Johnston M, Bowker J, Ofosu F, Mitchell L. Maturation of the hemostatic system during childhood. Blood. 1992; 80(8): p. 1998-2005.

40. Woodward M, Lowe GD, Rumley A, Tunstall-Pedoe H, Philippou H, Lane DA, Morrison CE. Epidemiology of coagulation factors, inhibitors and activation markers: The Third Glasgow MONICA Survey. II. Relationships to cardiovascular risk factors and prevalent cardiovascular disease. $\mathrm{Br} J$ Haematol. 1997; 97(4): p. 785-797.

41. Al Dieri R, Alban S, Beguin S, Hemker HC. Fixed dosage of low-molecular-weight heparins causes large individual variation in coagulability, only partly correlated to body weight. J Thromb Haemost. 2006; 4(1): p. 83-89.

42. Freyburger G, Macouillard G, Labrouche S, Sztark F. Coagulation parameters in patients receiving dabigatran etexilate or rivaroxaban: two observational studies in patients undergoing total hip or total knee replacement. Thromb Res. 2011; 127(5): p. 457-465.

43. Jesty J, Lorenz A, Rodriguez J, Wun TC. Initiation of the tissue factor pathway of coagulation in the presence of heparin: control by antithrombin III and tissue factor pathway inhibitor. Blood. 1996; 87(6): p. 2301-2307.

44. Hemker HC, Choay J, Beguin S. Free factor Xa is on the main pathway of thrombin generation in clotting plasma. Biochim Biophys Acta. 1989; 992(3): p. 409-411.

45. Herbert JM, Bernat A, Tibirica E. Effect of SR 27417, a novel PAF antagonist on antigen-induced hypotension in the rat. $J$ Lipid Mediat Cell Signal. 1997; 15(2): p. 115-123. 
46. Gerotziafas GT, Elalamy I, Depasse F, Perzborn E, Samama MM. In vitro inhibition of thrombin generation, after tissue factor pathway activation, by the oral, direct factor Xa inhibitor rivaroxaban. J Thromb Haemost. 2007; 5(4): p. 886-888.

47. Samama MM, Martinoli JL, LeFlem L, Guinet C, Plu-Bureau G, Depasse F, Perzborn E. Assessment of laboratory assays to measure rivaroxaban--an oral, direct factor Xa inhibitor. Thromb Haemost. 2010; 103(4): p. 815-825. 



\section{Chapter 7}

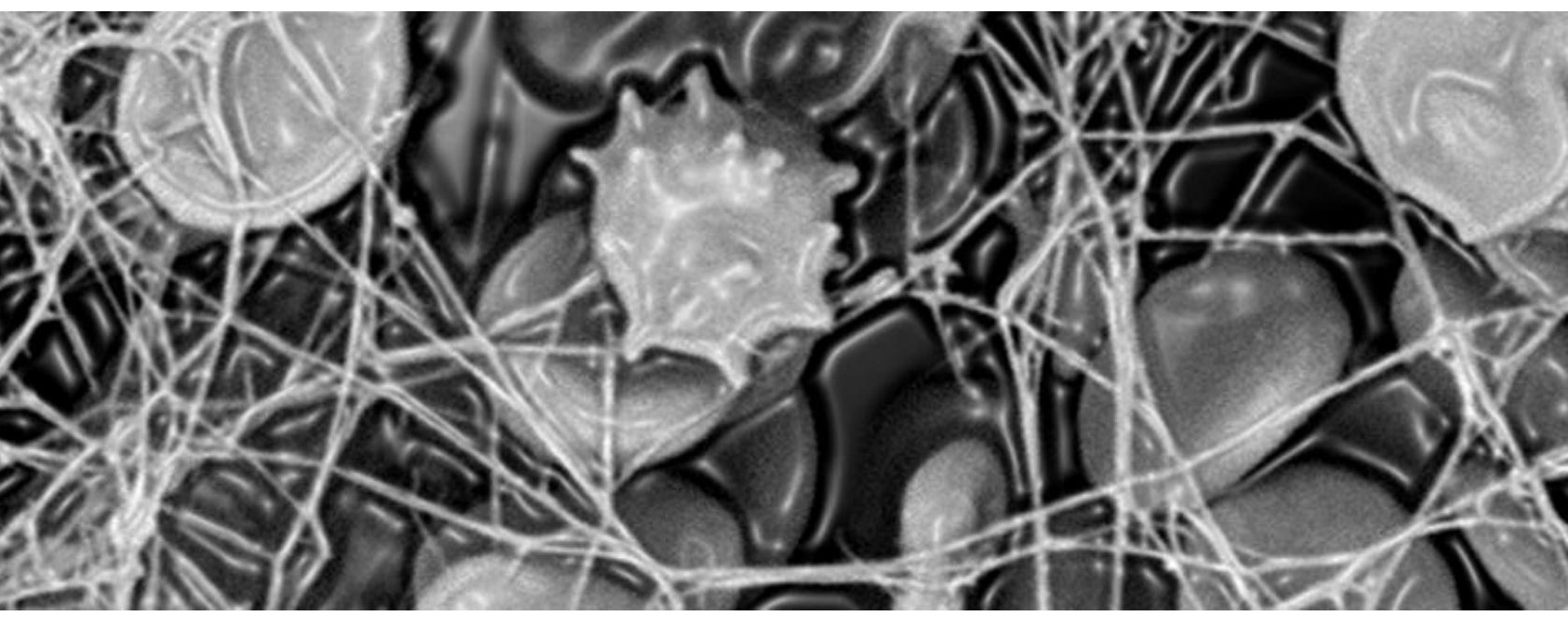

Thrombin peak suppression in the presence of direct factor Xa inhibitors

Saartje Bloemen, Dana Huskens, Tilman Hackeng, Bas de Laat, H. Coenraad Hemker, Raed Al Dieri

In preparation 


\section{Abstract}

Background: Several studies have shown an atypical shape of the thrombin peak when direct factor $\mathrm{Xa}$ inhibitors are present in plasma during thrombin generation tests.

Materials \& methods: Thrombin generation (TG) was assessed in platelet poor plasma with and without rivaroxaban. TG was also measured in several clotting factor deficient plasmas, activated with tissue factor, FIXa or kaolin.

Results: Rivaroxaban inhibited the peak height of TG curves strongly whereas the endogenous thrombin potential (ETP) was only decreased marginally, due to a suppression of the TG curve. When the intrinsic pathway was bypassed, the first part of the abnormal peak was affected. Evading the extrinsic pathway, predominantly affected the second atypical part of the peak.

Conclusion: When direct factor Xa inhibitors were present we found a suppressed TG curve in which the first part was mainly due to reactions mediated by FVIII and FIX and the second part to TF-dependent reactions. The shape of the curve in the presence of rivaroxaban indicates a longer duration of thrombin formation at a reduced concentration compared to curves in the absence of rivaroxaban. 


\section{Introduction}

Over the past years new types of anticoagulants have been developed to circumvent the difficulties that were associated with the use of vitamin $K$ antagonists and heparins, which still are the mainstay of treatment for thrombotic diseases [1]. Two main groups of agents have emerged as promising candidates: the direct thrombin inhibitors and the direct factor $(F) \mathrm{Xa}$ inhibitors [2]. These agents were shown to have more stable pharmacokinetic properties and have a short onset and offset. Both inhibitors do not require antithrombin to exert their effect and the result is that they can inhibit both free as well as bound thrombin/FXa [2-4]. The new, non-vitamin $\mathrm{K}$ antagonist oral anticoagulants are said not to require monitoring. However, several groups have indicated that it might be beneficial to individualize the doses for patients. There are difficulties in finding the appropriate laboratory assays to measure the effect of the direct inhibitors. Therefore it would be useful to have a test available which could measure the anticoagulant effect of these agents, especially during situations that require immediate action [5].

Over the last years it has become apparent that thrombin generation tests are useful in clinical settings. The effect of anticoagulants can be tested in vitro as well as ex vivo [4]. All the anticoagulants (old and new) tested so far have been shown to affect thrombin generation (TG) and these effects vary for different classes of anticoagulants. Direct thrombin inhibitors have a profound effect on the lag time, whereas their inhibitory effect on the endogenous thrombin potential (ETP) and peak is similar [6]. Addition of dermatan sulfate results in a larger inhibition of the ETP compared to the peak height. However, for most types of anticoagulant the effect on the peak is more pronounced than the inhibition of the ETP [6]. In direct FXa inhibitors this effect is more evident than any other antithrombotic agent that we have tested up to this point [6]. In fact, the TG curve is characterized by a relatively steep initial slope, a long plateau phase and a down slope, whereas TG curves normally are characterized by their bell-shaped appearance. From this point on we will define this shape as a 'suppressed' TG curve. 


\section{Chapter 7}

Several studies have reported a larger effect on the peak height as compared to the ETP [7-11], but until now no clear description was given of the suppression of the TG curve caused by direct FXa inhibitors. This differently shaped curve, as compared to other anticoagulants, among which indirect $\mathrm{FXa}$ inhibitors (i.e. fondaparinux), might also contribute to a different clinical outcome. Direct thrombin inhibitors for instance, were indicated to have more bleeding complications compared to direct FXa inhibitors.

\section{Materials and methods}

\section{Reagents}

Phospholipid vesicles consisted of phosphatidylserine, phosphatidylethanolamine and phosphatidylcholine (1:1:3 mol:mol) (Avanti, Alabaster, AL, USA). Recombinant human tissue factor (TF) was Innovin (Dade-Behring, Marburg, Germany). The fluorogenic substrate Z-Gly-Gly-Arg-aminomethylcoumarine (ZGGR-AMC) was purchased from Interface Biomaterials (Geleen, the Netherlands). A calibrator ( $\alpha_{2}$ macroglobulin $\left(\alpha_{2} M\right)$-thrombin) was prepared according to Hemker et al. [12]. Hepes buffers containing $5 \mathrm{mg} / \mathrm{ml}$ or $60 \mathrm{mg} / \mathrm{ml}$ bovine serum albumin (BSA5 and BSA60, respectively) were prepared as described by Hemker et al. [13]. Rivaroxaban (Xarelto) was obtained from Bayer (Berlin, Germany). Pentasaccharide (Org31540/SR90107 A or fondaparinux) was a kind gift from Dr. Petitou (Sanofi-Recherche, Toulouse, France). Otamixaban (a direct FXa inhibitor) was a gift from Sanofi-Aventis (Frankfurt, Germany), melagatran (a direct thrombin inhibitor) was from AstraZeneca (Zoetermeer, the Netherlands), UFH (Liquemin® N) was provided by Hoffman-La Roche AG (Basel, Switzerland), dermatan sulfate (Mistral) was a gift from Mediolanum Farmaceutici S.p.A. (Milan, Italy). Russel's viper venom enzymes activating FX (RVV-X) were a kind gift from Dr. Govers-Riemslag (Department of Biochemistry, Maastricht, the Netherlands). Siemens control plasma $\mathrm{N}$ was obtained from Siemens Healthcare (Marburg, Germany). Factor VIII (FVIII), deficient plasma was from George King Bio-Medical (Overland Park, KS, USA). Factor IX (FIX) deficient plasma was 
purchased from Stago BNL (Leiden, the Netherlands). Human FIXa was prepared according to Fujikawa by activating human FIX with isolated FXIa [14].

\section{Blood collection}

Blood was collected from apparently healthy donors through antecubital venipuncture into $\mathrm{BD}$ vacutainer tubes (1 volume of trisodium citrate $3.2 \%$ to 9 volumes of blood). The blood was centrifuged at $2900 \mathrm{~g}$ for $10 \mathrm{~min}$ in order to obtain platelet poor plasma (PPP). Plasma was aspirated and the centrifugation was repeated. Normal pooled plasma (NPP) was prepared by pooling the PPP of at least 24 healthy donors. Aliquots of $2 \mathrm{ml}$ were prepared and stored at $-80^{\circ} \mathrm{C}$. All healthy volunteers signed an informed consent form according to the Helsinki declaration and the study was approved by the local ethical committee (METC aZM/UM).

\section{Calibrated automated thrombinography}

Calibrated automated thrombinography was performed as described previously by Hemker et al. [12]. Thrombin generation tests were performed in a 96-well plate (Immulon $2 \mathrm{HB}$, Thermo Scientific, Rochester, USA) and measured in a fluorometer (Fluoroskan Ascent, Thermolabsystems, Helsinki, Finland). Thrombin generation wells consisted of $80 \mu \mathrm{l}$ of plasma and $10 \mu \mathrm{l}$ of BSA5 buffer containing phospholipids (final concentration of $4 \mu \mathrm{M}$ ) and an initiator as indicated in the experiments. Ten microliters of BSA5 buffer with or without the anticoagulant (rivaroxaban or pentasaccharide) were added. Calibrator wells contained $20 \mu \mathrm{l}$ of $\mathrm{a}_{2} \mathrm{M}$-thrombin $(600 \mathrm{nM})$ and $80 \mu \mathrm{l}$ of plasma. The plate was placed in the fluorometer for $10 \mathrm{~min}$ to enable heating to $37^{\circ} \mathrm{C}$. After dispensing $20 \mu \mathrm{l}$ of ZGGRAMC $(2.5 \mathrm{mM})$ and $\mathrm{CaCl}_{2}(100 \mathrm{mM})$ in $\mathrm{BS} 60$ buffer into the wells to initiate the reaction and shaking for $10 \mathrm{~s}$, registration of the fluorescence started. All experiments were performed in triplicate. Dedicated software (Thrombinoscope BV, Maastricht, the Netherlands) was used to transform the raw TG data into thrombin generation curves and to retrieve the accompanying parameters. 


\section{Chapter 7}

Dose response curves were constructed to determine the concentrations of rivaroxaban and pentasaccharide. In the experiments three concentrations were used, which contained concentrations around $\mathrm{IC}_{50}$ and concentrations which approximated the therapeutic plasma concentrations.

\section{Results}

Suppression of the thrombin generation peak by rivaroxaban in control plasma

When comparing direct FXa inhibitors to other anticoagulants it is clear that FXa inhibitors display a TG curve that is very distinct from the other agents (Figure 1). The curve is characterized by an initial slope, followed by a plateau and a downslope. The other anticoagulants still display a bell-shaped TG curve, which can be broadened however. The addition of different concentrations of the direct factor Xa inhibitor rivaroxaban to platelet poor plasma activated with 5 pM TF leads to a dose-dependent suppression of the thrombin generation peak (Figure 2). Consequently, at increasing concentrations of rivaroxaban the peak is inhibited strongly whereas the ETP is only marginally inhibited. The effect of the direct FXa inhibitors on the TG parameters consists of a strong inhibition of the peak height $(78 \%)$, while the ETP is only marginally affected $(28 \%$, average of 3 curves measured in triplicate at a rivaroxaban concentration of $400 \mathrm{nM}$ and $5 \mathrm{pM}$ TF). 


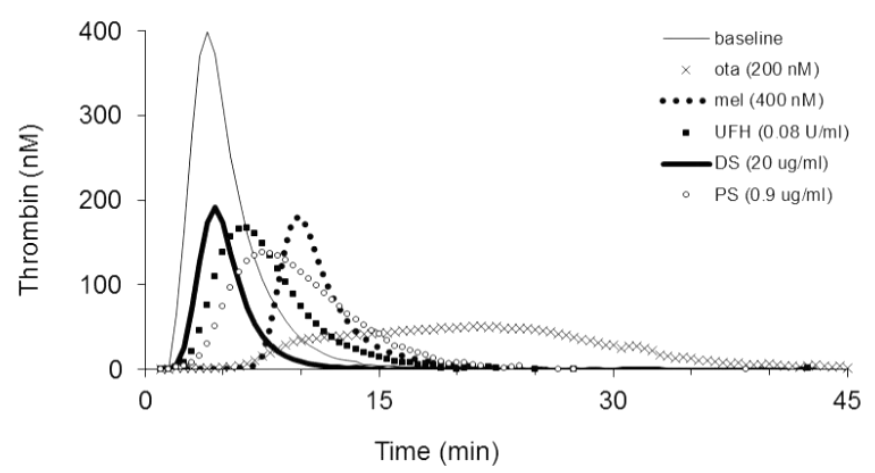

Figure 1: Effect of anticoagulants on thrombin generation in normal pooled plasma. Thin black line: no anticoagulant added, line of Xs: $200 \mathrm{nM}$ otamixaban, closed dots: $400 \mathrm{nM}$ melagatran, squares: $0.08 \mathrm{U} / \mathrm{ml}$ unfractionated heparin, bold black line: $20 \mu \mathrm{g} / \mathrm{ml}$ dermatan sulfate, open dots: $0.9 \mu \mathrm{g} / \mathrm{ml}$ pentasaccharide. (derived from chapter 6 )

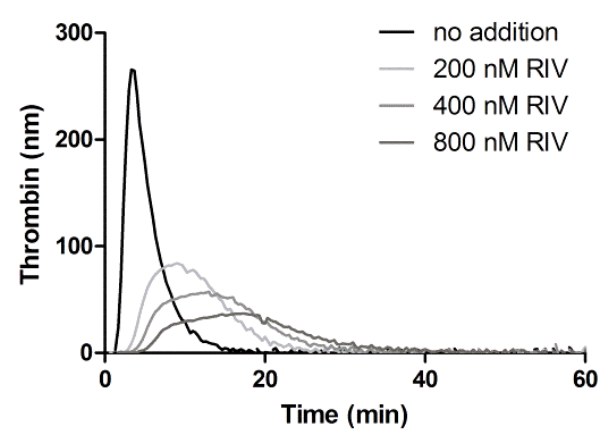

Figure 2: Rivaroxaban (RIV) in control plasma activated with tissue factor. Increasing concentrations of rivaroxaban were added to control plasma activated with $5 \mathrm{pM}$ of tissue factor.

The effect of rivaroxaban on the peak was also investigated when TG was induced by different triggers. When activating the reaction with a low concentration of TF the suppressed peak is clearly visible (Figure $3 \mathrm{~A}$ ). Triggering the reaction via the intrinsic system (with kaolin) does not result in a suppression of the peak (Figure $3 \mathrm{~B}$ ). If the reaction is initiated with FIXa, a suppressed peak is still present but only 


\section{Chapter 7}

at higher rivaroxaban concentrations (Figure 3C). The first part resembles the peak which is obtained by triggering with TF, yet the down-slope is not as steep. If RVV$X$ is used to directly activate $F X$, a smaller effect on the thrombin peak is seen, but the plateau is absent (Figure 3D).
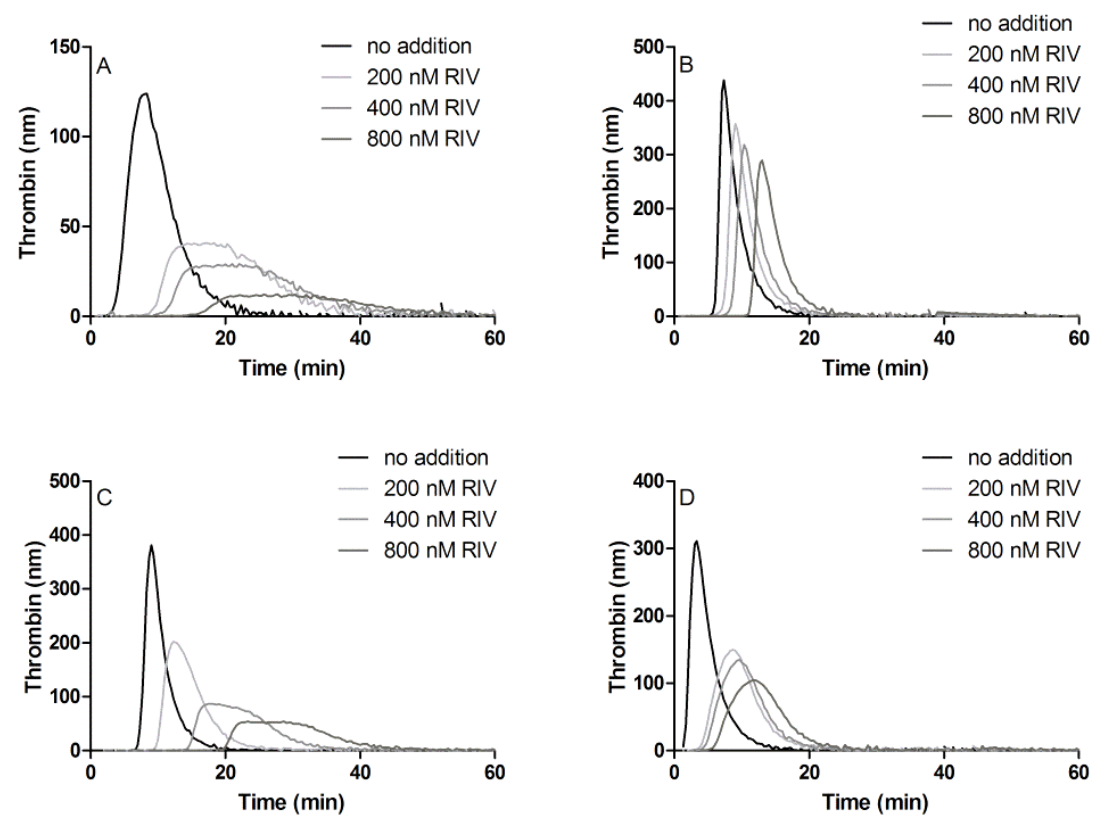

Figure 3: The effect of rivaroxaban (RIV) in control plasma after activation with different initiators. A) Activation with $1 \mathrm{pM}$ tissue factor; B) activation with kaolin (plasma concentration of 55.6 $\mu \mathrm{g} / \mathrm{ml})$; C) activation with $5 \mathrm{nM} \mathrm{FIXa;} \mathrm{D)} \mathrm{activation} \mathrm{with} \mathrm{RVV-X} \mathrm{(1/48000).}$

Since a suppressed peak was found after starting the reaction with FIXa and not with kaolin, the concentration of kaolin was decreased. Both initiating agents result in an activation of the intrinsic system; however, with the concentration of kaolin normally used the reaction might proceed too fast for a suppression of the peak to occur. As can be seen in figure 4, with reduced concentrations of kaolin, the suppression of the peak does become notable, resembling the TG curve after activation by FIXa. 


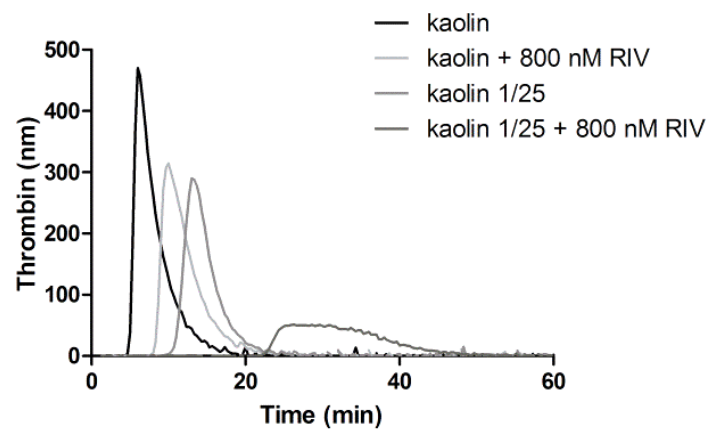

Figure 4: The influence of rivaroxaban (RIV) in plasma activated with kaolin. Control plasma was activated with different concentrations of kaolin $(55.6 \mu \mathrm{g} / \mathrm{ml}$ and $2.22 \mu \mathrm{g} / \mathrm{ml}$ in plasma) in the presence of $800 \mathrm{nM}$ of rivaroxaban.

Next, the TF concentrations were increased in order to find out if the same effect would be found as for the reactions initiated by kaolin. Indeed it can be seen that with increasing concentrations of TF in the presence of rivaroxaban the suppression of the peak is overcome (Figure 5).

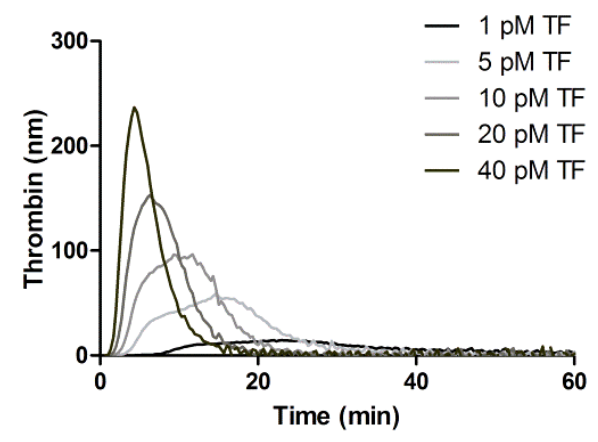

Figure 5: Increasing concentrations of tissue factor (TF). Control plasma was activated with increasing concentrations of tissue factor in the presence of $800 \mathrm{nM}$ of rivaroxaban.

In order to see whether the suppression of the thrombin peak occurs for all types of FXa inhibitors we used pentasaccharide, an indirect FXa inhibitor that accelerates 


\section{Chapter 7}

the inhibition of FXa by antithrombin. No suppressed peak could be seen independent of the trigger that was used (Figure 6). Initiating the reaction with FIXa leads to a very sensitive system resulting in the absence of thrombin generation after addition of these concentrations pentasaccharide.
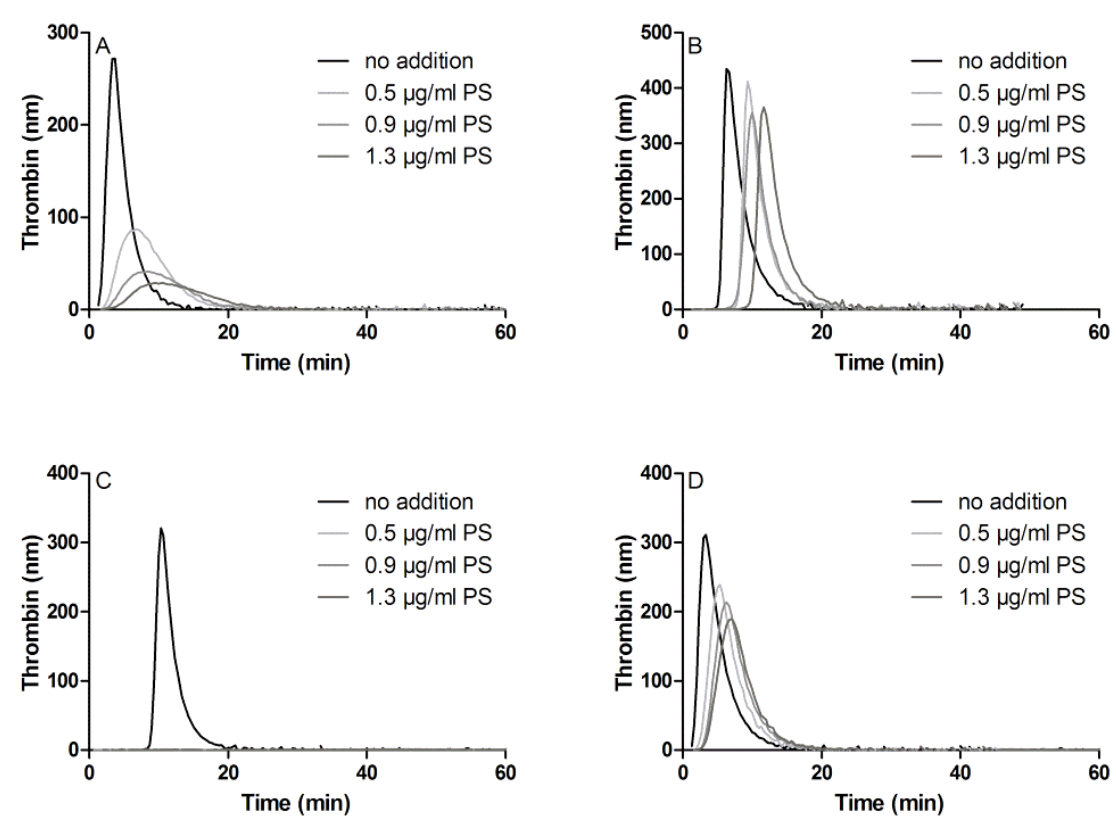

Figure 6: The effect of pentasaccharide (PS) in control plasma (control experiment) after activation with different triggers. A) Activation with $5 \mathrm{pM}$ tissue factor; B) activation with kaolin (55.6 $\mu \mathrm{g} / \mathrm{ml}$ in plasma); C) activation with $5 \mathrm{nM}$ FIXa; D) activation with RVV-X (1/48000).

Effect of rivaroxaban on the thrombin peak in factor deficient plasmas

When activating FVIII and FIX deficient plasmas in the presence of rivaroxaban with $5 \mathrm{pM} \mathrm{TF}$, the first ascending part of the thrombin generation peak becomes less pronounced (Figure 7). This led us to believe that under these low procoagulant conditions the first part of the peak is mainly due to the activity of the 
propagation loop and the second part of the peak largely portrays the activity of the extrinsic tenase.
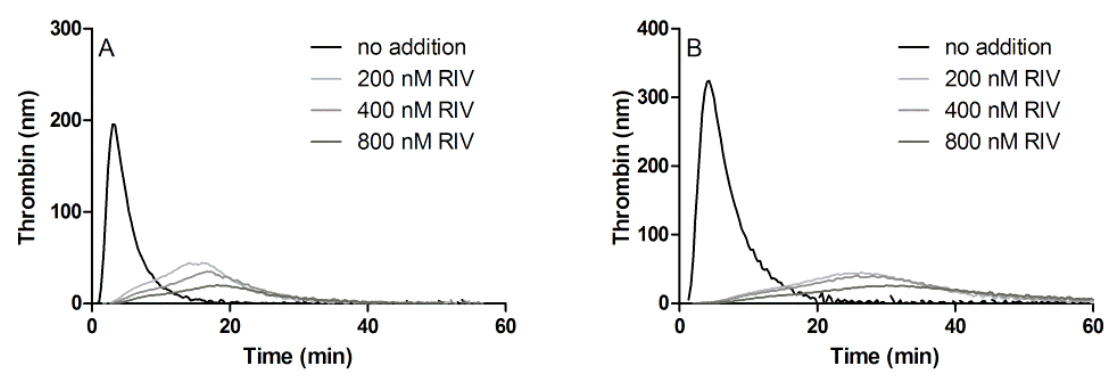

Figure 7: The effect of rivaroxaban (RIV) in factor deficient plasmas. Factor VIII (A) and factor IX (B) deficient plasma in the presence of increasing concentrations of rivaroxaban after activation with 5 pM TF.

\section{Discussion}

When measuring the effect of direct factor $\mathrm{Xa}$ inhibitors on a thrombin generation test in PPP, the curve that is obtained displays a specific shape. The peak is inhibited strongly, but the curve still shows a rather steep initial slope, followed by a long plateau phase and a down slope. This leads to an only marginally affected ETP and a suppressed thrombin curve. This type of curve is not only seen when the inhibitor is added to the plasma in vitro [7-11], but also when a patient has ingested the agent and the samples are tested ex vivo (data not shown). When indirect FXa inhibitors are used, such as pentasaccharide (fondaparinux), this suppressed curve with a plateau is not observed, although with these agents the peak is also more strongly inhibited compared to the ETP [6].

During this study we tested rivaroxaban in thrombin generation using various triggers. When triggering with $1 \mathrm{pM}$ of TF the specific shape of the curve is more obvious compared to triggering with $5 \mathrm{pM}$ TF. If the reaction is initiated through 


\section{Chapter 7}

factors of the intrinsic pathway (FIXa of kaolin) a different shape is found. When testing commonly used concentrations of kaolin, the suppressed peak is not visible. Yet, at lower concentrations the peak was suppressed and the first upward part of the peak was more pronounced, with a steeper initial slope, compared to the second part. We hypothesize that this could possibly be a result of the feedback loop of thrombin to FXI that is set into motion at lower concentrations of an initiator and this will lead to activation of FIX, while this is not the case at higher levels of kaolin or TF. At low rivaroxaban concentrations, the suppression of the curve is not visible since the thrombin generation proceeds fast due to the lower level of inhibition. When excluding the intrinsic pathway by using FVIII or FIX deficient plasma, the first part of the peak is not as high as when FVIII and FIX are present. Instead of reaching a plateau immediately, which occurs if 1 pM TF is used as a trigger in control plasma, the peak height only reaches the maximal value in the second part of the peak. Thrombin generation was also initiated by triggering $\mathrm{FX}$ directly with RVV-X and also under these conditions rivaroxaban did not induce a suppression of the TG curve. Stimulating the extrinsic system with very high TF concentrations (up to $40 \mathrm{pM}$ ) renders a fast reaction that does not result in a suppressed curve.

In general the shape of the TG curve in the presence of direct FXa inhibitors suggests that there is more thrombin formed in total compared to other anticoagulant agents, but at each point in time less thrombin is present resulting in a strong inhibition of the peak. It is possible that this could have an effect on the bleeding rate of patients taking these drugs. This is likely to be advantageous over other types of inhibitors, since thrombin generation is inhibited but thrombin remains present for a longer period of time. Possibly the differences in the shapes of TG curves when different anticoagulants are present might give some information about bleeding rates in patients. Whether these data have a direct implication on the bleeding rate in patients taking direct FXa inhibitors, could be verified by analysis of the individual bleeding cases in phase III trials. Previously our group has shown that a bleeding tendency was associated with an ETP value below $20 \%$ of the average ETP in a normal population [15]. Due to the shape of 
the curve, the ETP is not inhibited to the same extent as the peak by these direct FXa inhibitors. The fibrin formation could also be altered in the presence of direct FXa inhibitors compared to other antithrombotic agents. Since the thrombin generation test is a laboratory test which only in part represents the situation in the body, we cannot predict the clinical impact of the thrombin generation curve shape change. To gain more insight in the prognostic value of thrombin generation as an intermediate phenotype, clinical studies implementing thrombin generation tests to evaluate the effect of these agents compared to other inhibitors will have to be performed. 


\section{Chapter 7}

\section{References}

1. Ansell J, Hirsh J, Poller L, Bussey H, Jacobson A, Hylek E. The pharmacology and management of the vitamin K antagonists: the Seventh ACCP Conference on Antithrombotic and Thrombolytic Therapy. Chest. 2004; 126(3 Suppl): p. 204S2335 .

2. King CS, Holley AB, Moores LK. Moving toward a more ideal anticoagulant: the oral direct thrombin and factor Xa inhibitors. Chest. 2013; 143(4): p. 1106-1116.

3. Al Dieri R, de Laat B, Hemker HC. Thrombin generation: what have we learned? Blood Rev. 2012; 26(5): p. 197-203.

4. Bloemen S, De Laat M, De Laat B, Hemker HC, Al Dieri R. Will one size of anticoagulant dosage fit all? Drug Develop Res. 2013; 74(7): p. 406-412.

5. Ten Cate $\mathrm{H}$. Monitoring new oral anticoagulants, managing thrombosis, or both? Thromb Haemost. 2012; 107(5): p. 803-805.

6. Bloemen S, Hemker HC, Al Dieri R. Large inter-individual variation of the pharmacodynamic effect of anticoagulant drugs on thrombin generation. Haematologica. 2013; 98(4): p. 549-554.

7. Douxfils J, Chatelain C, Chatelain B, Dogne JM, Mullier F. Impact of apixaban on routine and specific coagulation assays: a practical laboratory guide. Thromb Haemost. 2013; 110(2): p. 283-294.

8. Samama MM, Mendell J, Guinet C, Le Flem L, Kunitada S. In vitro study of the anticoagulant effects of edoxaban and its effect on thrombin generation in comparison to fondaparinux. Thromb Res. 2012; 129(4): p. e77-82.

9. Freyburger G, Macouillard G, Labrouche S, Sztark F. Coagulation parameters in patients receiving dabigatran etexilate or rivaroxaban: two observational studies in patients undergoing total hip or total knee replacement. Thromb Res. 2011; 127(5): p. 457-465.

10. Douxfils J, Mullier F, Loosen C, Chatelain C, Chatelain B, Dogne JM. Assessment of the impact of rivaroxaban on coagulation assays: laboratory recommendations for the monitoring of rivaroxaban and review of the literature. Thromb Res. 2012; 130(6): p. 956-966.

11. Perzborn E, Heitmeier S, Buetehorn U, Laux V. Direct thrombin inhibitors, but not the direct factor $\mathrm{Xa}$ inhibitor rivaroxaban, increase tissue factor-induced hypercoagulability in vitro and in vivo. J Thromb Haemost. 2014; 12(7): p. 10541065. 
12. Hemker HC, Giesen P, Al Dieri R, Regnault V, de Smedt E, Wagenvoord R, Lecompte T, Beguin S. Calibrated automated thrombin generation measurement in clotting plasma. Pathophysiol Haemost Thromb. 2003; 33(1): p. 4-15.

13. Hemker HC, Hemker PW, Al Dieri R. The technique of measuring thrombin generation with fluorescent substrates: 4. The $\mathrm{H}$-transform, a mathematical procedure to obtain thrombin concentrations without external calibration. Thromb Haemost. 2009; 101(1): p. 171-177.

14. Fujikawa K, Legaz ME, Kato H, Davie EW. The mechanism of activation of bovine factor IX (Christmas factor) by bovine factor Xla (activated plasma thromboplastin antecedent). Biochemistry. 1974; 13(22): p. 4508-4516.

15. Al Dieri R, Peyvandi F, Santagostino E, Giansily M, Mannucci PM, Schved JF, Beguin S, Hemker HC. The thrombogram in rare inherited coagulation disorders: its relation to clinical bleeding. Thromb Haemost. 2002; 88(4): p. 576-582. 



\section{Chapter 8}

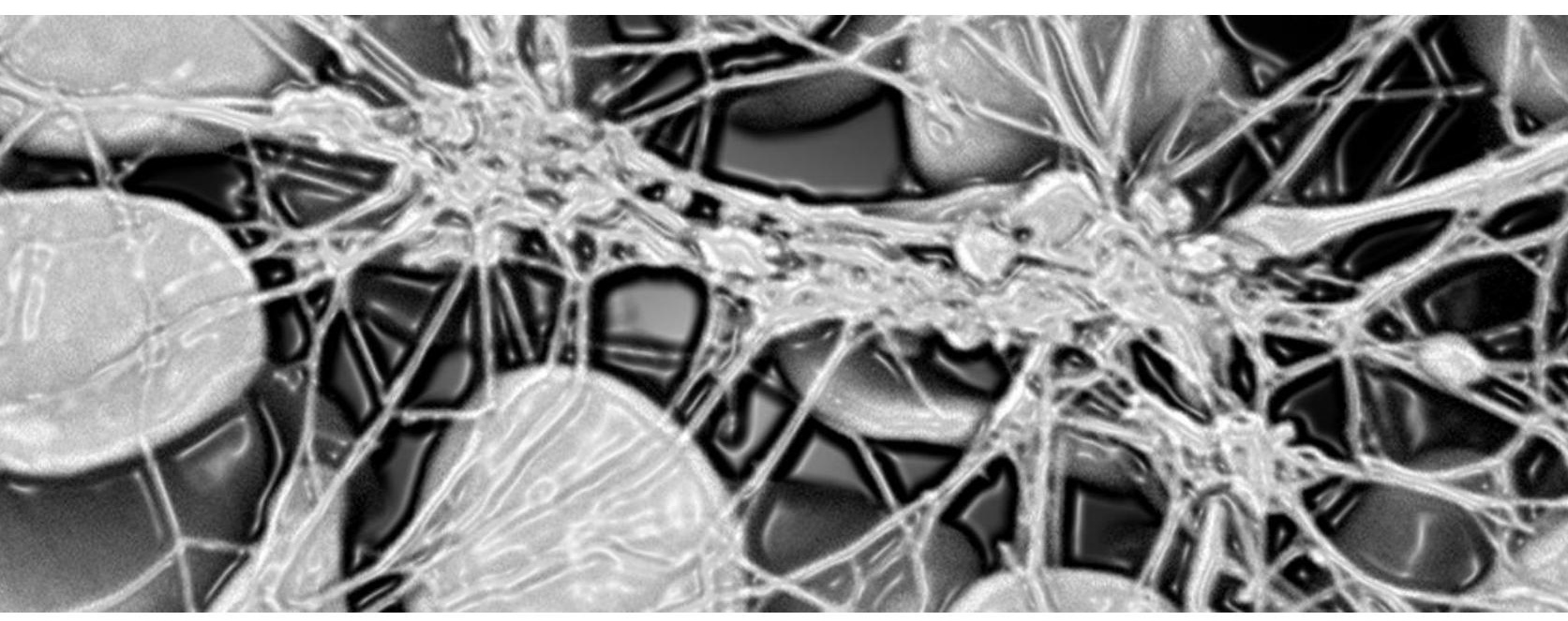

\section{Will one size of anticoagulant dosage fit all?}

Saartje Bloemen, Marieke de Laat, Bas de Laat, H. Coenraad Hemker, Raed Al Dieri

Drug Development Research 2013; 74(7): 406-412. 


\section{Abstract}

New, direct thrombin and factor (F) Xa inhibitors have been developed to reduce the well-established drawbacks of currently available anticoagulants such as a protracted action and high inter- and intra-individual variation of dose-effect. New anticoagulants are non-inferior and no less effective for thromboprophylaxis than low-molecular-weight heparins (LMWH) or vitamin $\mathrm{K}$ antagonists. They are currently administered at fixed doses without control of their effect on the clotting system. Whether they need monitoring cannot be answered because relevant data are lacking and present means of monitoring are inadequate. The individual response to a standard dose of (any) anticoagulant - the modern direct inhibitors included - is highly variable ( $\sim 30 \%)$ and the clinical effect of all anticoagulants is not dose independent. Therefore a fixed dose that is optimal for the average patient is suboptimal for a fair percentage of patients that are low responders (risk of re-thrombosis) and dangerous for an equally high percentage of high responders (risk of bleeding). A better understanding of individual differences in the response, either low or high, to anticoagulants, irrespective of their mode of action, should be a primary objective for pharmacotherapy over the next decade. 


\section{Introduction}

Venous thromboembolism (VTE) is the third most common cardiovascular disease after acute coronary syndrome and stroke [1]. For its prevention and treatment heparins and vitamin $\mathrm{K}$ antagonists (VKA) are commonly used. They are standard in patients undergoing knee- or hip-replacement surgery [2]. Despite effective prophylaxis, subclinical venous thrombosis still develops shortly after surgery in $15 \%$ to $40 \%$ of these patients [3]. Apart from VTE, VKA are very effective for the prevention of stroke in patients with atrial fibrillation (AF) [4, 5]. Also the risk of coronary infarction is reduced by prophylaxis with VKA [6] or heparins [7, 8].

The routinely available prophylactic methods have important practical limitations. Heparins require subcutaneous injection and can cause thrombocytopenia. VKA have a narrow therapeutic range that is not easy to maintain because of variability in response and interactions with drugs and food. They therefore require monitoring, which, however, does not exclude a risk of bleeding [9-11]. Alternatives to the conventional anticoagulants have therefore been long anticipated.

\section{New anticoagulants}

New anticoagulants have been developed that directly and reversibly inhibit either factor $(F)$ Xa or thrombin (Table 1). Direct inhibition means that, unlike heparin (derivatives or -likes), they do not require plasma antithrombins for their action. These new direct inhibitors have the advantage over heparin (-derivatives) that they are administered orally. The advantage over VKA is that their onset and offset are short and that they display minimal interactions with other drugs and food. It is claimed that they wouldn't require routine monitoring [12].

Recent clinical evaluations of direct inhibitors of $\mathrm{FXa}[13,14]$ or thrombin $[15,16]$ indicate that these new drugs are non-inferior and no less effective for thromboprophylaxis in AF and after major joint surgery compared to low-molecularweight heparins $(\mathrm{LMWH})$ or vitamin $\mathrm{K}$ antagonists. Some question whether switching from VKA to the newer agents is necessary for the individual patient that 


\section{Chapter 8}

has a stable International Normalized Ratio (INR) for a long time already. Others claim that there is always less intracranial hemorrhage with the newer agents (dabigatran, rivaroxaban and apixaban) than with warfarin, regardless of INR control [17].

However, it is a drawback that antidotes are still under development and not routinely available. Due to their rapid onset and termination of action, antidotes may possibly be less frequently required than for VKA therapy.

Although the results of the clinical trials are in favor of the new agents, efficacy and safety as found in the trials cannot automatically be extrapolated to daily practice. Participants in clinical trials have been selected as to age, adherence, concomitant disease and known risk of hemorrhage and thrombotic tendency. Importantly, none of the studies had a very long follow up, hence long term effects remain unknown. Gathering these long term effects is important because major bleeding is the most common complication particularly in patients with $\operatorname{AF}[18,19]$. Also adherence to therapy is much more important for the new anticoagulants than for VKA because the half-life of the new anticoagulant effect is much shorter (Table 1). Some new agents need to be taken twice daily, which adds to this problem. Patients might be at increased risk of an embolic complication even if they miss one dose of these new agents. Moreover the anticoagulation clinics will no longer be there to signal non-compliance [20]. 
Table 1: Characteristics of anticoagulants

\begin{tabular}{|c|c|c|c|c|c|}
\hline Anticoagulant & Target & $\begin{array}{l}\text { Half-life } \\
\text { (h) }\end{array}$ & $\begin{array}{c}\text { Route of } \\
\text { administration }\end{array}$ & Antidotes & Clinical use \\
\hline \multicolumn{6}{|l|}{ Heparins } \\
\hline Unfractionated heparin & $\begin{array}{l}\mathrm{Ila} / \mathrm{Xa} \\
\text { (via AT) }\end{array}$ & $0.5-2.5$ & IV/SC & Protamine sulphate & VTE therapy, VTE prophylaxis and ACS \\
\hline $\begin{array}{l}\text { Low-molecular-weight } \\
\text { heparin }\end{array}$ & $\begin{array}{l}\text { Ila/Xa } \\
\text { (via AT) }\end{array}$ & $3-6$ & SC & Protamine sulphate & VTE therapy, VTE prophylaxis and ACS \\
\hline Pentasaccharide & Xa (via AT) & $17-21$ & SC & Recombinant VIla† & $\begin{array}{l}\text { VTE therapy, VTE prophylaxis and ACS } \\
\text { (without interventions) }{ }^{*}\end{array}$ \\
\hline Vitamin $K$ antagonists & $\begin{array}{l}\text { II, VII, IX, X, } \\
\text { PC, PS }\end{array}$ & 40 & Oral & Vitamin K, PCC & $\begin{array}{l}\text { VTE prophylaxis, thromboprohylaxis } \\
\text { after AF or prosthetic heart valves, AMI }\end{array}$ \\
\hline \multicolumn{6}{|l|}{ Thrombin inhibitors } \\
\hline Dabigatran etexilate & Ila & $8-15$ & Oral & No specific antidote & $\begin{array}{l}\text { non-valvular AF, thomboprophylaxis } \\
\text { after knee- or hip-replacement }\end{array}$ \\
\hline \multicolumn{6}{|l|}{ FXa inhibitors } \\
\hline Rivaroxaban & $\mathrm{Xa}$ & $7-11$ & Oral & $\mathrm{PCC}+$ & $\begin{array}{l}\text { non-valvular AF, thromboprophylaxis } \\
\text { after knee- or hip-replacement, DVT* }\end{array}$ \\
\hline Apixaban & $\mathrm{Xa}$ & $8-15$ & Oral & No specific antidote & $\begin{array}{l}\text { thromboprophylaxis after knee- or hip- } \\
\text { replacement* }\end{array}$ \\
\hline Edoxaban & $\mathrm{Xa}$ & $9-11$ & Oral & No specific antidote & Under investigation \\
\hline
\end{tabular}

${ }^{*}$ According to the European Medicines Agency.

†Experimental treatment [21]

AT, antithrombin; PC, protein C; PS, protein S; IV, intravenous; SC, subcutaneous; PCC, prothrombin complex concentrate; VTE, venous thromboembolism; ACS, acute coronary syndrome; AF, atrial fibrillation; AMI, acute myocardial infarction; DVT, deep venous thrombosis

\section{Single measurement of activity or frequent monitoring?}

The new, selective direct inhibitors of thrombin or FXa are currently given at fixed doses without control of their effect on the clotting system. This is defended by some and debated by others. Some argue that the anticoagulant effect of a fixed dose of the new agents is highly predictable and there is no evidence that (re)thrombosis or bleeding correlate with any measured biologic activity or drug concentration in plasma [22]. Also, there is as yet no evidence that an individualized regimen with frequent monitoring and dose change is safer or more effective than a standard dose regimen. Others argue that in real life, contrary to a clinical trial, there are abundant factors such as body weight, age, renal and liver function (and probably many unknown ones), that influence the plasma levels and the anticoagulant effect of these agents, so that fine tuning of the dosage to the 


\section{Chapter 8}

individual needs might be preferable [23]. They recognize however that this is difficult because to this point we do not dispose of reliable laboratory methods to judge the anticoagulant effect.

Indeed the question: "Can we measure the effect of these drugs?" precedes the question: "Should we measure the effect of these drugs?". Whether new anticoagulants need monitoring or not cannot be answered at this moment because relevant data are lacking. Monitoring with the present means of the routine coagulation lab serves little purpose [22]. This may be because monitoring is of no use or because the methods used for monitoring are inadequate. The results of clinical trials [22] do not settle the point either unless each individual patient is comparable to the presumed "average" patient of the study [24]. If this is not the case, then it might well be that the new drugs could do much better than VKA when their use would be tailored to the needs of the patient.

\section{Current methods are unsuitable for therapy monitoring}

The activated partial thromboplastin time (aPTT) is a routine test that is far from being reliable and it has a poor predictive value for bleeding and re-thrombosis, if any $[25,26]$. Moreover it is difficult to standardize [27]. We measured the aPTT in 432 non zero-time samples from 12 healthy volunteers who received unfractionated heparin (UFH) or one of three types of LMWH (9000 aXa units); $98 \%$ contained heparin, as judged from elevated anti-FXa activity (aXa) but only in $34 \%$ the aPTT was prolonged. So the aPTT is insensitive to the effect of any heparin given at a typical dose. The anti-FXa activity determines the concentration of antithrombin-binding heparin but not its effect on the clotting system of the patient. Indeed the $\mathrm{aXa}$ is a bad predictor of bleeding risk and antithrombotic efficacy [28].

The aPTT has been suggested as a possible assay for monitoring dabigatran [29] and aXa assays have been used for determining the effects of rivaroxaban and apixaban $[30,31]$. From these studies it can be concluded that these tests are not 
ideal for this purpose. Therefore we wondered whether thrombin generation (TG) would do better.

\section{Thrombin generation}

There is increasing evidence that the capacity of blood to form thrombin is a reliable intermediate endpoint in hemostatic and thrombotic diseases. High thrombin generation is found in all known prothrombotic conditions and predisposes for (recurrence of) venous thrombosis [32-34]. Thrombin generation is also superior to classic clotting assays in which hypercoagulability (e.g. antiphospholipid syndrome) does not result in significant shortening of the clotting time [35]. Thrombin generation is diminished in haemophilic patients and can be restored by substitution therapy [32,33]. Antithrombotics with completely different modes of action have one thing in common: they all lower TG (Figure 1) [36, 37]. Even platelet antagonists lower thrombin generation in platelet rich plasma [38]. Thrombin generation is superior to the aPTT in detecting the heparin effect. In the study mentioned above, $83 \%$ of the samples showed significant decrease of TG [39]. TG is also sensitive to the effects of direct inhibitors [36]. A rough estimate of the therapeutic window is $30-60 \%$ of the TG capacity of normal pooled plasma, which is equivalent to INR 2-3 as calculated from Brocal et al. [40]. A definite bleeding risk is associated with $\mathrm{TG}<20 \%$ of normal pooled plasma [41]. Also thrombotic tendency in patients with G20210A prothrombin mutation is associated with higher TG (>2 SDs above the mean) than in the age-matched control subjects [42]. 


\section{Chapter 8}
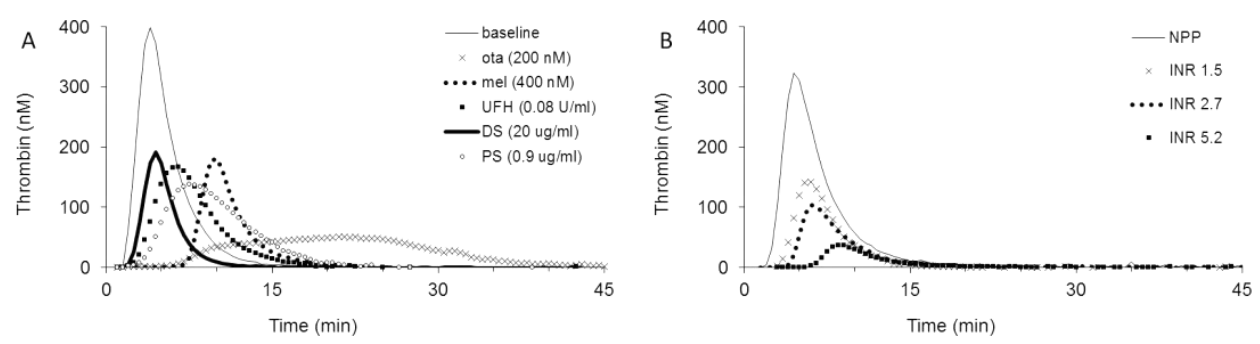

Figure 1: Effect of different anticoagulant agents on thrombin generation. (A) Normal plasma was spiked in vitro with different anticoagulant agents (around $\mathrm{IC}_{50}$ concentration). Otamixaban (200 nM), a direct factor $(\mathrm{F}) \mathrm{Xa}$ inhibitor; melagatran $(400 \mathrm{nM})$, a direct thrombin inhibitor; unfractionated heparin (0.08 U/ml), inhibits FXa and thrombin by potentiating antithrombin; pentasaccharide $(0.9 \mu \mathrm{g} / \mathrm{ml})$, inhibits FXa via antithrombin. Tissue factor and phospholipid concentrations were $5 \mathrm{pM}$ and $4 \mu \mathrm{M}$, respectively. Since some anticoagulants inhibit the peak more than the endogenous thrombin potential (ETP) and some affect both to a similar extent, an unequivocal IC $_{50}$ could not be determined. Therefore we chose the concentration at which the sum of the inhibitions of ETP and peak was between $80 \%$ and $120 \%$. (B) Thrombin generation curves of patients taking vitamin $\mathrm{K}$ antagonists with different International Normalized Ratio (INR) values compared to normal pooled plasma (NPP). TG conditions are similar to $(\mathrm{A})$.

Indeed thrombin generation is applicable in a clinical laboratory setting [32, 33]. Admittedly calibrated thrombin generation [43] is as yet insufficiently standardized to obtain satisfactory inter-laboratory comparability of absolute values, but the intra-laboratory $\mathrm{CV}$ of $\sim 5 \%$ allows a reliable measurement relative to a normal standard. Together these findings suggest that TG might favorably be used to monitor therapy.

That thrombin generation assays might be a candidate to be used for the analysis of the effect of new anticoagulants was pointed out by some groups [29, 44]. Thrombin generation has also been used to test the reversal of several conventional and new anticoagulants [45-47]. 


\section{Is every individual patient comparable to the average of the trial population?}

If thrombin generation is to be used to assess the effect of anticoagulants, one question needs to be answered first. Thrombosis and hemostasis always have a local and a systemic component. The local component can be assumed to be randomly distributed in a well-chosen trial population. The systemic component depends upon the capacity of the blood to produce thrombin. The variation of thrombin generating capacity in a normal untreated population is large (coefficient of variation (CV) 16\%) [41]. In untreated populations, the thrombotic tendency as well as the bleeding tendency appears to be related to the TG capacity. Rethrombosis is 4 times more frequent in people with an above average TG than in those below average [48]. Surgical bleeding is more abundant in people with a TG below average than in those above average $[49,50]$. Due to the large CV, in a normal population there must be a fair percentage with an innate tendency to bleed and another with a tendency for thrombosis. Even if a drug could be found that stably reduces the TG capacity by $50 \%$ in the whole population, some would reach the danger zone of bleeding ( $<20 \%$ of normal pooled plasma) and the TG of others would not decrease significantly to below that of normal pooled plasma. In an untreated patient population the $\mathrm{CV}$ is likely to be even higher than that in the normal population (>16\%) [41].

After administration of a standard dose of any anticoagulant, two types of variability superimpose upon the variability of the thrombin generating capacity of the patients. The same dose of anticoagulant given orally will give rise to variable plasma levels (pharmacokinetics) and the same plasma level of a drug may inhibit the clotting system to a different extent in plasma from different individuals (pharmacodynamics).

Population pharmacokinetics show a variability of the pharmacokinetic constants of $\sim 18 \%$ for a thrombin inhibitor [51] and of $\sim 10 \%$ for a FXa inhibitor [52]. For a synthetic pentasaccharide (fondaparinux) variation is comparably high [53]. 


\section{Chapter 8}

The variability in the pharmacodynamic effect is also high. The variability of the response of thrombin generation to a fixed level of heparin (UFH and LMWH) added in vitro is large. This may be attributed to inter-individual variations in antithrombin (AT), heparin binding proteins, procoagulant factors and platelet activation giving rise to the shedding of PF4, but also to concomitant medication, etc. [54]. A fixed dose of heparin (LMWHs and UFH alike) causes a highly variable effect on TG in healthy volunteers ( $C V \sim 25 \%)$ that cannot be attributed to the weight of the subjects [55].

After the in vitro addition of a fixed concentration of direct thrombin and FXa inhibitors, the inter-individual coefficient variation was $18 \%-43 \%$. The new anticoagulants did not perform better than the heparins $[37,56]$.

On basis of these data we estimate that the variability of the response to a standard dose of direct thrombin and FXa inhibitors and heparins is $30 \%$ or higher, so that the individual patient is unlikely to react as the hypothetical "average patient" of the trials [24]. If the variability is that large, the therapeutic window should be enormous to justify standard dosage. A simple subset analysis of existing phase III trials can settle this point. The plasmas of the patients that bled or suffered from a re-thrombosis can be tested post hoc in vitro for their reaction to a fixed dose of anticoagulant and thus stratified as average, low or high responders. If bleeding is more frequent in high responders and thrombosis in low responders, then individualization of dosage would be useful. We would be happy to cooperate with trials to sort this out.

\section{Conclusion}

The clinical effect of all anticoagulants is dose dependent because treatment is better than no treatment and overdose always carries a bleeding risk. The individual response to a standard dose of any anticoagulant - the modern direct inhibitors included - has been shown to be highly variable (CV 30\%). Therefore a unique dose that is optimal for the average patient is suboptimal for a fair percentage of patients that are low responders and dangerous for an equally high 140 
percentage of high responders. It is urgent and would be easy to determine whether in trial populations bleeding did indeed occur among high responders and re-thrombosis among low responders, as predicted from the data discussed above. 


\section{Chapter 8}

\section{References}

1. Goldhaber SZ. Pulmonary embolism thrombolysis: a clarion call for international collaboration. J Am Coll Cardiol. 1992; 19(2): p. 246-247.

2. Geerts WH, Bergqvist D, Pineo GF, Heit JA, Samama CM, Lassen MR, Colwell CW. Prevention of venous thromboembolism: American College of Chest Physicians Evidence-Based Clinical Practice Guidelines (8th Edition). Chest. 2008; 133(6 Suppl): p. 381S-453S.

3. Geerts WH, Pineo GF, Heit JA, Bergqvist D, Lassen MR, Colwell CW, Ray JG. Prevention of venous thromboembolism: the Seventh ACCP Conference on Antithrombotic and Thrombolytic Therapy. Chest. 2004; 126(3 Suppl): p. 338S400S.

4. Fuster V, Ryden LE, Cannom DS, Crijns HJ, Curtis AB, Ellenbogen KA, Halperin JL, Le Heuzey JY, Kay GN, Lowe JE, Olsson SB, Prystowsky EN, Tamargo JL, Wann S. ACC/AHA/ESC 2006 guidelines for the management of patients with atrial fibrillation-executive summary: a report of the American College of Cardiology/American Heart Association Task Force on Practice Guidelines and the European Society of Cardiology Committee for Practice Guidelines (Writing Committee to Revise the 2001 Guidelines for the Management of Patients with Atrial Fibrillation). Eur Heart J. 2006; 27(16): p. 1979-2030.

5. Lip GY, Tse HF, Lane DA. Atrial fibrillation. Lancet. 2012; 379(9816): p. 648-661.

6. Loeliger EA, Hensen A, Kroes F, van Dijk LM, Fekkes N, de Jonge H, Hemker HC. A double-blind trial of long-term anticoagulant treatment after myocardial infarction. Acta Med Scand. 1967; 182(5): p. 549-566.

7. Neri Serneri GG, Rovelli F, Gensini GF, Pirelli S, Carnovali M, Fortini A. Effectiveness of low-dose heparin in prevention of myocardial reinfarction. Lancet. 1987; 1(8539): p. 937-942.

8. Neri Serneri GG, Modesti PA, Gensini GF, Branzi A, Melandri G, Poggesi L, Rostagno C, Tamburini C, Carnovali M, Magnani B. Randomised comparison of subcutaneous heparin, intravenous heparin, and aspirin in unstable angina. Studio Epoorine Sottocutanea nell'Angina Instobile (SESAIR) Refrattorie Group. Lancet. 1995; 345(8959): p. 1201-1204.

9. Hart RG, Benavente O, McBride R, Pearce LA. Antithrombotic therapy to prevent stroke in patients with atrial fibrillation: a meta-analysis. Ann Intern Med. 1999; 131(7): p. 492-501. 
10. Ansell J, Hirsh J, Poller L, Bussey H, Jacobson A, Hylek E. The pharmacology and management of the vitamin K antagonists: the Seventh ACCP Conference on Antithrombotic and Thrombolytic Therapy. Chest. 2004; 126(3 Suppl): p. 204S$233 S$.

11. King CS, Holley AB, Moores LK. Moving toward a more ideal anticoagulant: the oral direct thrombin and factor Xa inhibitors. Chest. 2013; 143(4): p. 1106-1116.

12. Weitz JI, Gross PL. New oral anticoagulants: which one should my patient use? Hematology Am Soc Hematol Educ Program. 2012; 2012: p. 536-540.

13. Eriksson BI, Borris LC, Friedman RJ, Haas S, Huisman MV, Kakkar AK, Bandel TJ, Beckmann H, Muehlhofer E, Misselwitz F, Geerts W. Rivaroxaban versus enoxaparin for thromboprophylaxis after hip arthroplasty. N Engl J Med. 2008; 358(26): p. 2765-2775.

14. Lassen MR, Ageno W, Borris LC, Lieberman JR, Rosencher N, Bandel TJ, Misselwitz F, Turpie AG. Rivaroxaban versus enoxaparin for thromboprophylaxis after total knee arthroplasty. N Engl J Med. 2008; 358(26): p. 2776-2786.

15. Eriksson BI, Dahl OE, Rosencher N, Kurth AA, van Dijk CN, Frostick SP, Kalebo P, Christiansen AV, Hantel S, Hettiarachchi R, Schnee J, Buller HR. Oral dabigatran etexilate vs. subcutaneous enoxaparin for the prevention of venous thromboembolism after total knee replacement: the RE-MODEL randomized trial. Journal of thrombosis and haemostasis : JTH. 2007; 5(11): p. 2178-2185.

16. Eriksson BI, Dahl OE, Rosencher N, Kurth AA, van Dijk CN, Frostick SP, Prins MH, Hettiarachchi R, Hantel S, Schnee J, Buller HR. Dabigatran etexilate versus enoxaparin for prevention of venous thromboembolism after total hip replacement: a randomised, double-blind, non-inferiority trial. Lancet. 2007; 370(9591): p. 949956.

17. Granger CB, Armaganijan LV. Newer oral anticoagulants should be used as firstline agents to prevent thromboembolism in patients with atrial fibrillation and risk factors for stroke or thromboembolism. Circulation. 2012; 125(1): p. 159-164; discussion 164.

18. Hylek EM, Evans-Molina C, Shea C, Henault LE, Regan S. Major hemorrhage and tolerability of warfarin in the first year of therapy among elderly patients with atrial fibrillation. Circulation. 2007; 115(21): p. 2689-2696.

19. Poli D, Antonucci E, Marcucci R, Fatini C, Alterini B, Mannini L, Falciani M, Abbate $\mathrm{R}$, Gensini GF, Prisco D. Risk of bleeding in very old atrial fibrillation patients on 
warfarin: relationship with ageing and CHADS2 score. Thromb Res. 2007; 121(3): p. 347-352.

20. Schulman S, Crowther MA. How I treat with anticoagulants in 2012: new and old anticoagulants, and when and how to switch. Blood. 2012; 119(13): p. 3016-3023.

21. Levi M, Eerenberg E, Kamphuisen PW. Bleeding risk and reversal strategies for old and new anticoagulants and antiplatelet agents. J Thromb Haemost. 2011; 9(9): p. 1705-1712.

22. Bounameaux H, Reber G. New oral antithrombotics: a need for laboratory monitoring. Against. J Thromb Haemost. 2010; 8(4): p. 627-630.

23. Mismetti $\mathrm{P}$, Laporte $\mathrm{S}$. New oral antithrombotics: a need for laboratory monitoring. For. J Thromb Haemost. 2010; 8(4): p. 621-626.

24. Rothwell PM. Can overall results of clinical trials be applied to all patients? Lancet. 1995; 345(8965): p. 1616-1619.

25. Eikelboom JW, Hirsh J. Monitoring unfractionated heparin with the aPTT: time for a fresh look. Thromb Haemost. 2006; 96(5): p. 547-552.

26. Hirsh J, Warkentin TE, Shaughnessy SG, Anand SS, Halperin JL, Raschke R, Granger C, Ohman EM, Dalen JE. Heparin and low-molecular-weight heparin: mechanisms of action, pharmacokinetics, dosing, monitoring, efficacy, and safety. Chest. 2001; 119(1 Suppl): p. 64S-94S.

27. van den Besselaar AM. Standardization of the activated partial thromboplastin time for monitoring of heparin therapy: where should we go? Ric Clin Lab. 1989; 19(4): p. 371-377.

28. Greaves M. Limitations of the laboratory monitoring of heparin therapy. Scientific and Standardization Committee Communications: on behalf of the Control of Anticoagulation Subcommittee of the Scientific and Standardization Committee of the International Society of Thrombosis and Haemostasis. Thromb Haemost. 2002; 87(1): p. 163-164.

29. Douxfils J, Mullier F, Robert S, Chatelain C, Chatelain B, Dogne JM. Impact of dabigatran on a large panel of routine or specific coagulation assays. Laboratory recommendations for monitoring of dabigatran etexilate. Thromb Haemost. 2012; 107(5): p. 985-997.

30. Tripodi A, van den Besselaar A. Laboratory monitoring of anticoagulation: where do we stand? Semin Thromb Hemost. 2009; 35(1): p. 34-41.

31. Douxfils J, Mullier F, Loosen C, Chatelain C, Chatelain B, Dogne JM. Assessment of the impact of rivaroxaban on coagulation assays: laboratory recommendations 
for the monitoring of rivaroxaban and review of the literature. Thromb Res. 2012; 130(6): p. 956-966.

32. van Veen JJ, Gatt A, Makris M. Thrombin generation testing in routine clinical practice: are we there yet? Br J Haematol. 2008; 142(6): p. 889-903.

33. Adams M. Assessment of thrombin generation: useful or hype? Semin Thromb Hemost. 2009; 35(1): p. 104-110.

34. Baglin T. Unraveling the thrombophilia paradox: from hypercoagulability to the prothrombotic state. J Thromb Haemost. 2010; 8(2): p. 228-233.

35. de Laat B, van Os G, Ninivaggi M, Agar C, de Groot P, Hemker HC, Lindhout T, Meijers J. Anti-domain I antibodies have a prothrombotic character on coagulation by inhibiting the anticoagulant effect of beta2GPI. J Thromb Haemost. 2010; 9(suppl. 02): p. (abstract).

36. Robert S, Ghiotto J, Pirotte B, David JL, Masereel B, Pochet L, Dogne JM. Is thrombin generation the new rapid, reliable and relevant pharmacological tool for the development of anticoagulant drugs? Pharmacol Res. 2009; 59(3): p. 160-166.

37. Bloemen S, Hemker HC, Al Dieri R. Large inter-individual variation of the pharmacodynamic effect of anticoagulant drugs on thrombin generation. Haematologica. 2013; 98(4): p. 549-554.

38. Reverter JC, Beguin S, Kessels H, Kumar R, Hemker HC, Coller BS. Inhibition of platelet-mediated, tissue factor-induced thrombin generation by the mouse/human chimeric 7E3 antibody. Potential implications for the effect of c7E3 Fab treatment on acute thrombosis and "clinical restenosis". J Clin Invest. 1996; 98(3): p. 863874.

39. al Dieri R, Alban S, Beguin S, Hemker HC. Thrombin generation for the control of heparin treatment, comparison with the activated partial thromboplastin time. $J$ Thromb Haemost. 2004; 2(8): p. 1395-1401.

40. Brocal I, Marco P, Lucas J, Verdu J, Tarin F. Thrombin generation test in patients under anticoagulant therapy with vitamin $\mathrm{K}$ antagonists. Thromb Haemost. 2009; 101(3): p. 594-595.

41. Al Dieri R, Peyvandi F, Santagostino E, Giansily M, Mannucci PM, Schved JF, Beguin S, Hemker HC. The thrombogram in rare inherited coagulation disorders: its relation to clinical bleeding. Thromb Haemost. 2002; 88(4): p. 576-582.

42. Kyrle PA, Mannhalter C, Beguin S, Stumpflen A, Hirschl M, Weltermann A, Stain M, Brenner B, Speiser W, Pabinger I, Lechner K, Eichinger S. Clinical studies and thrombin generation in patients homozygous or heterozygous for the G20210A 
mutation in the prothrombin gene. Arterioscler Thromb Vasc Biol. 1998; 18(8): p. 1287-1291.

43. Hemker HC, Giesen P, AIDieri R, Regnault V, de Smed E, Wagenvoord R, Lecompte T, Beguin S. The calibrated automated thrombogram (CAT): a universal routine test for hyper- and hypocoagulability. Pathophysiol Haemost Thromb. 2002; 32(5-6): p. 249-253.

44. Molenaar PJ, Dinkelaar J, Leyte A. Measuring Rivaroxaban in a clinical laboratory setting, using common coagulation assays, Xa inhibition and thrombin generation. Clin Chem Lab Med. 2012; 50(10): p. 1799-1807.

45. Gatt A, van Veen JJ, Woolley AM, Kitchen S, Cooper P, Makris M. Thrombin generation assays are superior to traditional tests in assessing anticoagulation reversal in vitro. Thromb Haemost. 2008; 100(2): p. 350-355.

46. Dinkelaar J, Molenaar PJ, Ninivaggi M, de Laat B, Brinkman HJ, Leyte A. In vitro assessment, using thrombin generation, of the applicability of prothrombin complex concentrate as an antidote for Rivaroxaban. J Thromb Haemost. 2013; 11(6): p. 1111-1118.

47. Eerenberg ES, Kamphuisen PW, Sijpkens MK, Meijers JC, Buller HR, Levi M. Reversal of rivaroxaban and dabigatran by prothrombin complex concentrate: a randomized, placebo-controlled, crossover study in healthy subjects. Circulation. 2011; 124(14): p. 1573-1579.

48. Hron G, Kollars M, Binder BR, Eichinger S, Kyrle PA. Identification of patients at low risk for recurrent venous thromboembolism by measuring thrombin generation. Jama. 2006; 296(4): p. 397-402.

49. Bosch $\mathrm{Y}, \mathrm{Al}$ Dieri R, ten Cate H, Nelemans P, Bloemen S, Hemker C, Weerwind P, Maessen J, Mochtar B. Preoperative thrombin generation is predictive for the risk of blood loss after cardiac surgery: a research article. J Cardiothorac Surg. 2013; 8: p. 154.

50. Coakley M, Hall JE, Evans C, Duff E, Billing V, Yang L, McPherson D, Stephens E, Macartney N, Wilkes AR, Collins PW. Assessment of thrombin generation measured before and after cardiopulmonary bypass surgery and its association with postoperative bleeding. J Thromb Haemost. 2011; 9(2): p. 282-292.

51. Gustafsson D, Elg M. The pharmacodynamics and pharmacokinetics of the oral direct thrombin inhibitor ximelagatran and its active metabolite melagatran: a minireview. Thromb Res. 2003; 109 Suppl 1: p. S9-15. 
52. Mueck W, Borris LC, Dahl OE, Haas S, Huisman MV, Kakkar AK, Kalebo P, Muelhofer E, Misselwitz F, Eriksson BI. Population pharmacokinetics and pharmacodynamics of once- and twice-daily rivaroxaban for the prevention of venous thromboembolism in patients undergoing total hip replacement. Thromb Haemost. 2008; 100(3): p. 453-461.

53. Delavenne X, Zufferey P, Baylot D, Nguyen P, Borg JY, Fontenay M, Deygas B, Mismetti P, Laporte S. Population pharmacokinetics of fondaparinux administered at prophylactic doses after major orthopaedic surgery in everyday practice. Thromb Haemost. 2010; 104(2): p. 252-260.

54. Hacquard M, Perrin J, Lelievre N, Vigneron C, Lecompte T. Inter-individual variability of effect of 7 low molecular weight antithrombin-dependent anticoagulants studied in vitro with Calibrated Automated Thrombography. Thromb Res. 2011; 127(1): p. 29-34.

55. Al Dieri R, Alban S, Beguin S, Hemker HC. Fixed dosage of low-molecular-weight heparins causes large individual variation in coagulability, only partly correlated to body weight. J Thromb Haemost. 2006; 4(1): p. 83-89.

56. Bostrom SL, Hansson GF, Kjaer M, Sarich TC. Effects of melagatran, the active form of the oral direct thrombin inhibitor ximelagatran, and dalteparin on the endogenous thrombin potential in venous blood from healthy male subjects. Blood Coagul Fibrinolysis. 2003; 14(5): p. 457-462. 



\section{Chapter 9}

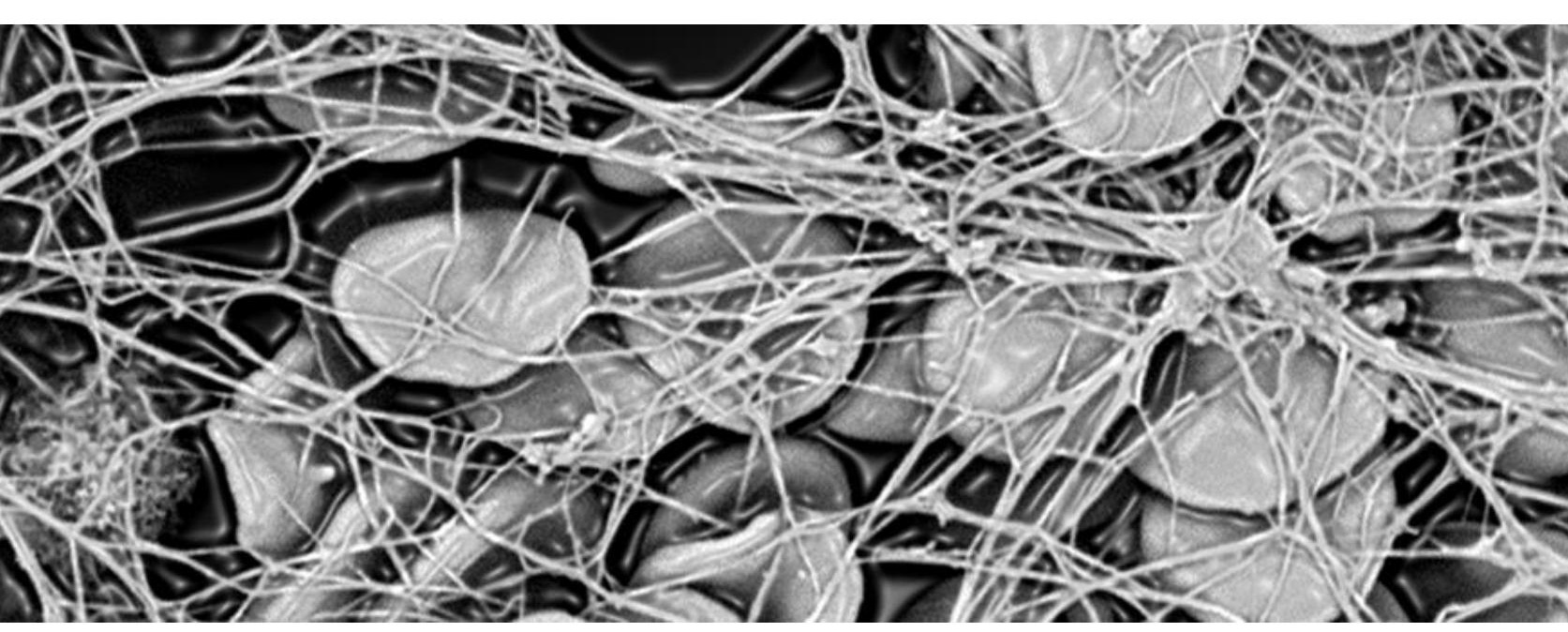

General discussion and summary 


\section{Thrombin generation}

An increasing number of studies show that, for the judgment of the hemostatic or prothrombotic capacity of blood, the level of thrombin activity that can be generated is more important than the time it takes to form a clot [1]. The clot is formed as soon as traces of thrombin appear, at the end of the lag time before the thrombin burst. Thus, the greater part of thrombin (95-98\%) does not appear until after the clot is established [2]. The total amount of thrombin that is formed, indicates a thrombotic tendency when higher than normal and a tendency to bleed when lower than normal. The conversion of fibrinogen into fibrin is only one of the many functions of thrombin. Thrombin also plays a role in fibrinolysis by activating thrombin activatable fibrinolysis inhibitor (TAFI), in activating platelets and affects surrounding tissues. By measuring the functional activity of thrombin in a thrombin generation (TG) test the full potential of thrombin formed in a sample can be detected. Unlike clotting time-based assays, the TG test represents the complete hemostatic/thrombotic function of blood (or plasma). TG tests have been shown to detect both hyper- and hypocoagulable states [3-6] and are susceptible to the action of all anticoagulants tested so far [1, 7]. TG is usually tested in platelet poor plasma (PPP) and in platelet rich plasma (PRP) [8]. More recently calibrated automated thrombinography (CAT) was developed in whole blood [9], excluding the need for centrifugation and paving the way for point-of-care testing.

Although different triggers can be used to start the TG reaction, usually tissue factor (TF) is chosen. The system favors the extrinsic pathway with increasing TF concentrations and is sensitized to the reinforcement loop via factors VIII and IX at low concentrations of TF $(\sim 1 \mathrm{pM})$. Depending on whether or not platelets are present in the plasma, $4 \mu \mathrm{M}$ of phospholipids are added. The Z-Gly-Gly-Arg-7amino-4-methylcoumarin substrate is used to register the activity of thrombin [8].

Whole blood CAT is a new technique which uses a rhodamine-based substrate to avoid quenching of the fluorescent signal by red blood cells. This substrate has a high fluorescent yield and is consumed very little during the measurement. The 
method is performed on a thin paper matrix that entraps the red blood cells and reduces erroneous signals due to sedimentation and clot retraction. The presence of red blood cells reduces the fluorescence, but to a tolerable extent [9]. The fluorescent signal can be converted mathematically into a TG curve [10], but in contrast to the plasma CAT no correction for the inner filter effect is necessary. In this test red blood cells provide a procoagulant phospholipid surface and were found to contribute more to TG compared to platelets. The advised TF concentration is $0.5 \mathrm{pM}$, which includes factors $(\mathrm{F}) \mathrm{VIII}, \mathrm{IX}$ and $\mathrm{XI}$ in the reaction [9].

\section{Adding thrombomodulin to thrombin generation tests to probe the APC system}

Protein $\mathrm{C}$ is a vitamin $\mathrm{K}$ dependent protein that is converted into activated protein C (APC) upon cleavage by thrombin in complex with the endothelial membrane protein thrombomodulin (TM). APC degrades factors (F) Va and VIIla, consequently downregulating TG [11]. Protein $S$ serves as a cofactor during the inactivation of both FVa and FVIIla and FV is a cofactor for the degradation of FVIIla [12].

The APC system plays a role in several disease states. Patients with APC resistance, both congenital and acquired, have a prothrombotic phenotype. APC and TM resistance can be associated with several causes: deficiency in protein $\mathrm{C}$ or $\mathrm{S}$, the FV Leiden mutation, the use of oral contraceptives, increased levels of FVIII or prothrombin and others [13].

\section{Thrombomodulin in plasma CAT}

When TG is initiated with TF, the protein C pathway has only a minor influence. In order to get a better representation of the physiological situation and study the full APC pathway, including the function of protein C, soluble TM is added to the TG test. As an alternative to TM APC can be added, but then the function of protein C 


\section{Chapter 9}

is short circuited and only the function of FV, FVIII and protein S is studied. In normal pooled plasma the addition of $20 \mathrm{nM}$ of TM results in an inhibition of TG of approximately $50 \%$ (chapter 3 ), while the same concentration in whole blood CAT, causes an inhibition of $\pm 30 \%$ (chapter 4 ).

The concentration of TM varies in different studies and is difficult to determine as $\mathrm{TM}$ is a membrane-bound protein and the concentration is estimated to diverge from less than $1 \mathrm{nM}$ in large vessels to between 100 and $500 \mathrm{nM}$ in capillaries [14].

Dargaud et al. investigated the addition of TM to the TG test in subjects with a prothrombotic tendency (among which patients with protein $\mathrm{C}$ or $\mathrm{S}$ deficiencies and patients with FV Leiden) in comparison to healthy donors. Their results suggest that high ETP values measured in the presence of TM correspond to a prothrombotic phenotype [15].

In chapter 3 , protein $\mathrm{C}$ and protein $\mathrm{S}$ levels were reduced due to the use of vitamin $\mathrm{K}$ antagonists. The addition of TM also better represents the physiological processes compared to the tests in which no TM is added. The decrease in thrombin generation due to the vitamin $\mathrm{K}$ antagonists was reduced in the presence of TM compared to the absence of TM. This is a result from the inhibition of protein $\mathrm{C}$ and protein $\mathrm{S}$ which is not detected when TM is not added to the TG test.

APC resistance caused by FV Leiden can also be detected by adding TM to the CAT assay. However, addition of APC may be preferred in such situation since it excludes a defect in protein $C$. Factor $V$ Leiden affects not only the degradation of FVa, but also affects the cleavage of FVIII, during which FV acts as a cofactor [11].

Patients with cirrhosis were studied by Tripodi et al. [16] and are characterized by reduced clotting factor levels, resulting in a prolonged prothrombin time (PT) and activated partial thromboplastin time (aPTT). When TG was measured without TM, the ETP was reduced in samples from cirrhosis patients compared to healthy controls. In the presence of TM, however, no difference was found between the ETP of the control group and the ETP of the patients with cirrhosis. The reduced ETP in the absence of TM could be explained by a decrease in prothrombin levels. 
The decrease in protein $\mathrm{C}$ levels normalizes the ETP in the presence of TM. These data are supported by the observation that patients with cirrhosis only rarely bleed compared to patients with a comparable level of coagulation factors due to congenital and acquired deficiencies. Lisman et al. [17] described similar results in patients undergoing liver transplantation. In samples collected during and after liver transplantation, APC resistance was detected. In these patients almost no effect of TM was found, resulting in a higher TG in the presence of TM compared to healthy controls. This contradicts the prolonged PT and aPTT, but comes in agreement with the higher risk of post-operative thrombosis in these patients. The TM resistance in these patients results from decreased protein $C$ and protein $S$ levels and elevated FVIII levels. The PT and aPTT are only sensitive to the procoagulant factors, while the TG test, in the presence of $T M$, also includes the protein $C$ and $S$ function. In other words, the PT and aPTT provide misleading results in pathologies that affect the APC system.

\section{Thrombomodulin in whole blood CAT}

In chapter 4, TG was measured in 129 patients taking vitamin $\mathrm{K}$ antagonists in whole blood as well as in platelet rich plasma (PRP) and platelet poor plasma (PPP). A significant correlation was found between the four TG parameters (ETP, peak height, lag time and time to peak) in whole blood and both PRP and PPP. This indicates that the test in whole blood is suitable for assessing the coagulation status in these patients. At the same time we verified whether the addition of TM to the whole blood CAT can also represent the diminished protein $\mathrm{C}$ and protein $\mathrm{S}$ levels as it does in plasma. In the INR group between 1.0 and 1.5 addition of 20 $\mathrm{nM}$ of TM to PRP or PPP resulted in an inhibition between 50 and $70 \%$ of ETP or peak height (as in healthy donors) which decreased to $30-40 \%$ inhibition in patients with a higher INR. In whole blood, on the other hand, this inhibition proved to be around $30 \%$ in all groups (5 groups with INR of 1.0 to 6.0 ). To understand the different inhibitory effects of TM in whole blood versus plasma CAT, further research is required. 


\section{Whole blood CAT to detect bleeding tendency}

Since the addition of TM to whole blood CAT to test the TG of patients on VKAs is not completely elucidated, we tested 129 patients taking these oral anticoagulants using the whole blood technique without the addition of TM. Twenty-six of these patients had clinically relevant bleeding episodes while taking the VKAs. Previously it was shown that CAT in plasma can predict a bleeding tendency in patients on cardio-pulmonary bypass [18]. Therefore, we questioned whether bleeding in patients taking VKAs could be detected as well. In chapter 5 we show that plasma CAT and INR are not able to predict a bleeding tendency in patients taking VKAs. The whole blood CAT, however, was able to detect bleeding in these patients. No difference in hematocrit or hemoglobin was observed between the bleeders and non-bleeders, indicating that the predictive value of whole blood CAT does not simply result from the presence of the red blood cells. Our data are suggestive of an important interaction between the coagulation system and the red blood cells. Previously it was demonstrated that around $0.6 \%$ of red blood cells display phosphatidylserine on their membrane and enable the binding of prothrombinase in TF activated whole blood $[19,20]$. The red blood cells were found to stimulate thrombin generation via the meizothrombin pathway. Phospholipid asymmetry is a characteristic of senescent blood cells and these are present in approximately the same amount as the phosphatidylserine-expressing cells. The authors hypothesize that this population of cells might be responsible for the thrombin generating potential of red blood cells [19]. White blood cells were also found to have a prothrombotic phenotype in some disease states [21, 22], even though their concentration is much lower than that of red blood cells.

\section{Using CAT to investigate the mechanism of action of anticoagulants}

The CAT test is a versatile test and by using different triggers the full coagulation system can be studied. In chapter 7 we used this flexibility to investigate the suppression of the TG curve in PPP in the presence of direct, reversible FXa 154 
inhibitors. Using varying deficient plasmas and triggering thrombin generation by TF, FIXa, kaolin and RVV-X, we attempted to elucidate the formation of a suppressed peak. Several studies have shown this atypical shape of the peak in the presence of different direct FXa inhibitors (rivaroxaban, apixaban and otamixaban) [7, 23-26]. The result is a stronger inhibition of the peak height compared to the ETP. When investigating the inhibition more closely, we hypothesize that the first part of the suppressed peak is mainly due to reactions involving FVIII and FIX, whereas TF-dependent reactions contribute strongly to the second part of the peak. Whether the strong effect on the TG peak and the smaller effect on the ETP will have any consequences on the results of the anticoagulant in vivo, still needs to be investigated.

\section{Variability in anticoagulant effect}

In chapter 6 the pharmacodynamics of direct FXa and thrombin inhibitors were compared to those of the indirect inhibitors by spiking plasma with a fixed concentration of the anticoagulants. Although all anticoagulants were found to inhibit TG, the peak height and ETP were not inhibited to the same extent for most agents tested, with the exception of melagatran. Most agents affected the peak more extensively than the ETP, an effect that was best observed in the presence otamixaban. Dermatan sulfate was the only anticoagulant that induced a higher inhibitory effect on the ETP compared to the peak.

Given that the direct inhibitors are claimed to have predictable pharmacokinetics, allowing their usage in fixed doses for all patients, we mainly focused on the interindividual variability in our study. The variation in the response to the direct anticoagulants was, however, comparable to the indirect inhibitors, suggesting that caution should be taken in prescribing fixed doses to all patients, even though the direct inhibitors have been shown to be non-inferior to warfarin treatment [27-30]. Clinical studies are performed in strictly selected groups of patients which do not necessarily represent the population. Additionally, by omitting regular monitoring the level of adherence will decrease, which can be problematic due to the short 


\section{Chapter 9}

half-life of these agents. Additionally, studies in which the pharmacokinetic profile of direct thrombin and FXa inhibitors was examined, demonstrated substantial inter-individual variation [25, 31, 32].

\section{Future perspectives}

In conclusion, despite its recent development, the whole blood thrombin generation based on the CAT method already successfully found its way into the first clinical studies. By including the contribution of all blood cells, this assay more closely resembles the physiological situation. When using whole blood instead of plasma the development of a point-of-care device also becomes a feasible objective and this opens perspectives for near-patient testing [33]. An additional advantage of the whole blood CAT is possibility to easily fixate samples after clot formation and obtain additional information on fibrin structure by SEM. Although such structural analysis is also possible with clots created by plasma CAT, the thin matrix used in the whole blood CAT facilitates the analysis of the SEM images. The new technique also raises interesting research questions, especially about the differential effects of the APC system after addition of TM as compared to plasma. Possibly, the binding of prothrombinase to red blood cells results in different effects than in plasma. In order to optimally determine the usefulness and added value of this test, additional clinical studies need to be performed, implementing the technique and comparing the results to other established assays. However, the results in patients taking VKAs are promising. To facilitate implementation of the assay, efforts should be put into making the test more user-friendly. Currently, the test can only be executed by skilled technicians and still then a high inter-operator variability exists. Finally, to resemble the physiological situation even more closely, whole blood TG measurements under conditions corresponding to venous and arterial blood flow are currently being developed and clinically validated [34]. 


\section{References}

1. Al Dieri R, de Laat B, Hemker HC. Thrombin generation: what have we learned? Blood Rev. 2012; 26(5): p. 197-203.

2. Hemker HC, Giesen PL, Ramjee M, Wagenvoord R, Beguin S. The thrombogram: monitoring thrombin generation in platelet-rich plasma. Thromb Haemost. 2000; 83(4): p. 589-591.

3. Hemker HC, Giesen P, AIDieri R, Regnault V, de Smed E, Wagenvoord R, Lecompte T, Beguin S. The calibrated automated thrombogram (CAT): a universal routine test for hyper- and hypocoagulability. Pathophysiol Haemost Thromb. 2002; 32(5-6): p. 249-253.

4. Al Dieri R, Peyvandi F, Santagostino E, Giansily M, Mannucci PM, Schved JF, Beguin S, Hemker HC. The thrombogram in rare inherited coagulation disorders: its relation to clinical bleeding. Thromb Haemost. 2002; 88(4): p. 576-582.

5. Dargaud Y, Beguin S, Lienhart A, Al Dieri R, Trzeciak C, Bordet JC, Hemker HC, Negrier $C$. Evaluation of thrombin generating capacity in plasma from patients with haemophilia A and B. Thromb Haemost. 2005; 93(3): p. 475-480.

6. van Hylckama Vlieg A, Christiansen SC, Luddington R, Cannegieter SC, Rosendaal FR, Baglin TP. Elevated endogenous thrombin potential is associated with an increased risk of a first deep venous thrombosis but not with the risk of recurrence. Br J Haematol. 2007; 138(6): p. 769-774.

7. Bloemen S, Hemker HC, Al Dieri R. Large inter-individual variation of the pharmacodynamic effect of anticoagulant drugs on thrombin generation. Haematologica. 2013; 98(4): p. 549-554.

8. Hemker HC, Giesen P, Al Dieri R, Regnault V, de Smedt E, Wagenvoord R, Lecompte T, Beguin S. Calibrated automated thrombin generation measurement in clotting plasma. Pathophysiol Haemost Thromb. 2003; 33(1): p. 4-15.

9. Ninivaggi M, Apitz-Castro R, Dargaud Y, de Laat B, Hemker HC, Lindhout T. Whole-blood thrombin generation monitored with a calibrated automated thrombogram-based assay. Clin Chem. 2012; 58(8): p. 1252-1259.

10. Hemker HC, Kremers R. Data management in thrombin generation. Thromb Res. 2013; 131(1): p. 3-11.

11. Dahlback B, Villoutreix BO. The anticoagulant protein C pathway. FEBS Lett. 2005; 579(15): p. 3310-3316. 


\section{Chapter 9}

12. Dahlback B. Blood coagulation and its regulation by anticoagulant pathways: genetic pathogenesis of bleeding and thrombotic diseases. J Intern Med. 2005; 257(3): p. 209-223.

13. Castoldi E, Rosing J. APC resistance: biological basis and acquired influences. $J$ Thromb Haemost. 2010; 8(3): p. 445-453.

14. Esmon CT. The protein C pathway. Chest. 2003; 124(3 Suppl): p. 26S-32S.

15. Dargaud Y, Trzeciak MC, Bordet JC, Ninet J, Negrier C. Use of calibrated automated thrombinography +/- thrombomodulin to recognise the prothrombotic phenotype. Thromb Haemost. 2006; 96(5): p. 562-567.

16. Tripodi A, Salerno F, Chantarangkul V, Clerici M, Cazzaniga M, Primignani M, Mannuccio Mannucci $P$. Evidence of normal thrombin generation in cirrhosis despite abnormal conventional coagulation tests. Hepatology. 2005; 41(3): p. 553558.

17. Lisman T, Bakhtiari K, Pereboom IT, Hendriks HG, Meijers JC, Porte RJ. Normal to increased thrombin generation in patients undergoing liver transplantation despite prolonged conventional coagulation tests. J Hepatol. 2010; 52(3): p. 355-361.

18. Bosch $\mathrm{Y}, \mathrm{Al}$ Dieri R, ten Cate H, Nelemans $\mathrm{P}$, Bloemen S, Hemker C, Weerwind P, Maessen J, Mochtar B. Preoperative thrombin generation is predictive for the risk of blood loss after cardiac surgery: a research article. J Cardiothorac Surg. 2013; 8: p. 154.

19. Whelihan MF, Zachary V, Orfeo T, Mann KG. Prothrombin activation in blood coagulation: the erythrocyte contribution to thrombin generation. Blood. 2012; 120(18): p. 3837-3845.

20. Peyrou V, Lormeau JC, Herault JP, Gaich C, Pfliegger AM, Herbert JM. Contribution of erythrocytes to thrombin generation in whole blood. Thromb Haemost. 1999; 81(3): p. 400-406.

21. Coller BS. Leukocytosis and ischemic vascular disease morbidity and mortality: is it time to intervene? Arterioscler Thromb Vasc Biol. 2005; 25(4): p. 658-670.

22. Nijziel $M$, van Oerle $R$, van 't Veer C, van Pampus E, Lindhout T, Hamulyak K. Tissue factor activity in human monocytes is regulated by plasma: implications for the high and low responder phenomenon. Br J Haematol. 2001; 112(1): p. 98-104.

23. Douxfils J, Chatelain C, Chatelain B, Dogne JM, Mullier F. Impact of apixaban on routine and specific coagulation assays: a practical laboratory guide. Thromb Haemost. 2013; 110(2): p. 283-294. 
24. Douxfils J, Mullier F, Loosen C, Chatelain C, Chatelain B, Dogne JM. Assessment of the impact of rivaroxaban on coagulation assays: laboratory recommendations for the monitoring of rivaroxaban and review of the literature. Thromb Res. 2012; 130(6): p. 956-966.

25. Freyburger G, Macouillard G, Labrouche S, Sztark F. Coagulation parameters in patients receiving dabigatran etexilate or rivaroxaban: two observational studies in patients undergoing total hip or total knee replacement. Thromb Res. 2011; 127(5): p. 457-465.

26. Perzborn E, Heitmeier S, Buetehorn U, Laux V. Direct thrombin inhibitors, but not the direct factor $\mathrm{Xa}$ inhibitor rivaroxaban, increase tissue factor-induced hypercoagulability in vitro and in vivo. J Thromb Haemost. $2014 ; 12(7)$ : p. 10541065.

27. Connolly SJ, Ezekowitz MD, Yusuf S, Eikelboom J, Oldgren J, Parekh A, Pogue J, Reilly PA, Themeles E, Varrone J, Wang S, Alings M, Xavier D, Zhu J, Diaz R, Lewis BS, Darius H, Diener HC, Joyner CD, Wallentin L. Dabigatran versus warfarin in patients with atrial fibrillation. N Engl J Med. 2009; 361(12): p. 11391151.

28. Granger CB, Alexander JH, McMurray JJ, Lopes RD, Hylek EM, Hanna M, AlKhalidi HR, Ansell J, Atar D, Avezum A, Bahit MC, Diaz R, Easton JD, Ezekowitz JA, Flaker G, Garcia D, Geraldes M, Gersh BJ, Golitsyn S, Goto S, Hermosillo AG, Hohnloser SH, Horowitz J, Mohan P, Jansky P, Lewis BS, Lopez-Sendon JL, Pais P, Parkhomenko A, Verheugt FW, Zhu J, Wallentin L. Apixaban versus warfarin in patients with atrial fibrillation. N Engl J Med. 2011; 365(11): p. 981-992.

29. Patel MR, Mahaffey KW, Garg J, Pan G, Singer DE, Hacke W, Breithardt G, Halperin JL, Hankey GJ, Piccini JP, Becker RC, Nessel CC, Paolini JF, Berkowitz $\mathrm{SD}$, Fox KA, Califf RM. Rivaroxaban versus warfarin in nonvalvular atrial fibrillation. N Engl J Med. 2011; 365(10): p. 883-891.

30. Schulman S, Kearon C, Kakkar AK, Mismetti P, Schellong S, Eriksson H, Baanstra D, Schnee J, Goldhaber SZ. Dabigatran versus warfarin in the treatment of acute venous thromboembolism. N Engl J Med. 2009; 361(24): p. 2342-2352.

31. Stangier J. Clinical pharmacokinetics and pharmacodynamics of the oral direct thrombin inhibitor dabigatran etexilate. Clin Pharmacokinet. 2008; 47(5): p. 285295.

32. Ten Cate H. New oral anticoagulants: discussion on monitoring and adherence should start now! Thromb J. 2013; 11(1): p. 8. 


\section{Chapter 9}

33. Krishnamoorthy G, De A, Ninivaggi M, Apitz-Castro R, Carlen ET, Ten Cate-Hoek AJ, Hemker CH, De Bas L, Lindhout T. Thrombin generation monitored in capillary blood with a calibrated automated thrombogram-based assay. $J$ Thromb Haemost. 2013; 11: p. 367 (abstract).

34. Kelchtermans H, Pelkmans L, Ninivaggi M, Al Dieri R, Hemker CH, De Laat B. Simultaneous measurement of thrombin generation and fibrin formation in plasma and whole blood applying continuous flow. J Thromb Haemost. 2013; 11: p. 317 (abstract). 


\section{Samenvatting}




\section{Samenvatting}

In dit proefschrift wordt het gebruik van de trombinegeneratie test beschreven voor het controleren van therapie met antistollingsmiddelen (anticoagulantia). De trombinegeneratie (TG) test of 'Calibrated Automated Thrombinography (CAT)' is een test die tot op heden voornamelijk in onderzoekslaboratoria gebruikt wordt en nog niet is ingevoerd als test in routinelaboratoria van ziekenhuizen. Aan de bestaande routinetesten zijn voor- en nadelen verbonden. Enkele voordelen zijn dat de metingen snel gebeuren en dat de testen vaak simpel uit te voeren zijn. Nadelen zijn dat de testen niet specifiek zijn, meestal niet het hele stollingssysteem voorstellen en dat één test niet de effecten van alle anticoagulantia kan meten.

Een overzicht van de algemene hemostase wordt gegeven in hoofdstuk 1. De verschillende anticoagulantia die in gebruik zijn of recent ontwikkeld zijn, worden aangehaald en hun werking, samen met de aangrijpingspunten in het stollingsschema, wordt omschreven. Ook wordt de TG test uitgelegd en worden redenen aangedragen waarom dit een veelbelovende test is die zich goed leent voor het evalueren van de effecten van de verschillende anticoagulantia. De TG test in volbloed is recent ontwikkeld en wordt in dit inleidend hoofdstuk eveneens besproken.

Hoofdstuk 2 licht het gebruik van de TG test verder toe. De redenen waarom deze test gebruikt kan worden en de manier waarop de test geïnterpreteerd kan worden komen aan bod. De TG test is een goede techniek om een tromboseneiging, maar ook een bloedingsneiging op te sporen. Aangezien deze test ook gevoelig is voor alle anticoagulantia die tot nu getest werden, zou deze techniek kunnen gebruikt worden voor het controleren van een behandeling met anticoagulantia. Wanneer de endogene trombine potentiaal (ETP), een parameter van de TG test, lager is dan $20 \%$ van de normale waarde stijgt het bloedingsrisico. Wanneer deze waarde gestegen is ( $>100 \%$ ) is er een verhoogd risico op trombose. Naast plaatjesarm plasma kan ook plaatjesrijk plasma getest worden, waardoor de invloed van bloedplaatjes op de stollingsprocessen kan onderzocht worden. 
Vitamine $\mathrm{K}$ antagonisten (VKAs) zijn wereldwijd de meest en langst gebruikte orale anticoagulantia. In hoofdstuk 3 werden patiënten die VKAs nemen onderzocht door middel van CAT. In dit onderzoek werd bekeken of de toevoeging van trombomoduline (TM) aan de test in plasma meer informatie geeft over het effect van deze orale anticoagulantia. VKAs remmen namelijk niet alleen de procoagulante factoren II, VII, IX en X, maar ook de anticoagulante proteïnes $C$ en $S$. TM is een eiwit dat zich op de vaatwand bevindt en moet daarom, net als weefselfactor, aan de test worden toegevoegd. Wanneer het gevormde trombine bindt aan TM, activeert dit proteïne $C$ dat vervolgens samen met cofactor proteïne $S$ factor Va en VIIla remt. Dus door TM aan de test toe te voegen kunnen we ook de remming van proteïne $\mathrm{C}$ en $\mathrm{S}$ door VKAs bestuderen. In dit hoofdstuk hebben we aangetoond dat er, door de daling van proteïne C- en S-activiteit veroorzaakt door de VKAs, TM resistentie optreedt waardoor de trombinevorming verhoogd is in deze patiënten. Dit was vooral duidelijk bij de groep met een International Normalized Ratio (INR) tussen 1.0 en 2.0. Uit deze studie kan worden afgeleid dat toevoeging van TM resulteert in een betere weergave van de fysiologische processen.

In hoofdstuk 4 wordt verder ingegaan op de effecten van TM bij het testen van de stolling van patiënten die VKAs innemen en ditmaal niet alleen in plasma, maar ook in volbloed. Door TG te meten in volbloed kan ook de functie van rode en witte bloedcellen samen met de bloedplaatjes in de stolling bestudeerd worden. Aangezien dit de eerste studie was die VKAs in volbloed analyseert, werd eerst onderzocht of de parameters van volbloed TG evenveel informatie geven als de parameters van TG in plasma. Alle parameters in volbloed bleken significant te correleren met de parameters in plasma. De TG parameters (in volbloed en plasma) correleerden met de INR. De tijdsafhankelijke parameters (lag time en time-to-peak) correleerden lineair positief met de INR terwijl de functionele parameters (ETP en peak) op hyperbole wijze negatief correleerden met de INR. De concentraties aan stollingsfactoren werden eveneens bepaald. Hieruit kon worden besloten dat, in vergelijking met gezonde donoren, er geen significant verschil was voor antitrombine en factor V. De factoren II, VII, IX en X, alsook 


\section{Samenvatting}

proteïnes $\mathrm{C}$ en $\mathrm{S}$ waren naar verwachting significant lager in de patiënten. Factor VIII en fibrinogeen, daarentegen, waren significant verhoogd in de patiënten (184\% vs. $118 \%$ en $4.0 \mathrm{~g} / \mathrm{l}$ vs. $3.2 \mathrm{~g} / \mathrm{l}$, respectievelijk). Dit kan eventueel resulteren in een hoger risico op trombose na het stopzetten van de therapie. De fibrinenetwerken gevormd tijdens de volbloed TG test werden bestudeerd door middel van 'scanning electron microscopy' (SEM). De fibrinevezels van de patiënten waren significant dunner dan die van de gezonde donoren, hoewel er minder trombine werd gevormd. De verhoogde fibrinogeen concentratie biedt hier een mogelijke verklaring voor.

De informatie van dezelfde patiënten wordt in hoofdstuk 5 verder geanalyseerd. Hiermee werd aangetoond dat de TG test in volbloed een voorspellende waarde heeft voor het optreden van bloedingen in patiënten die VKAs innemen. Hematocriet, hemoglobine concentratie, TG in plasma en de INR gaven geen uitsluitsel over een hoger risico op bloeden bij de patiënten. Dit wijst erop dat het phospholipide oppervlak dat voorzien wordt door de rode bloedcellen tijdens de stolling een rol speelt in de bloedingpathologie van deze patiënten. Op welke wijze dit gebeurt, moet echter verder onderzocht worden.

Naast VKAs bestaan er verschillende andere soorten anticoagulantia, bv. heparines die parenteraal worden toegediend, maar ook de nieuwe, niet-vitamine $\mathrm{K}$ antagonist orale anticoagulantia (NOACs) worden steeds vaker gebruikt. $\mathrm{Er}$ wordt beweerd dat patiënten die deze directe trombine (factor Ila) en factor Xa remmers innemen, in tegenstelling tot de VKAs, geen opvolging nodig hebben. De in vitro effecten van verschillende soorten anticoagulantia worden vergeleken in hoofdstuk 6. Hier bekeken we de invloed van een vaste concentratie ongefractioneerd heparine (indirecte Ila en Xa remmer), pentasaccharide (indirecte Xa remmer), dermataan sulfaat (indirecte lla remmer), melagatran (directe Ila remmer) en otamixaban (directe Xa remmer) op de TG test. De remming vertoont een hoge variabiliteit tussen de verschillende donoren. Deze variatie was niet minder bij de directe inhibitoren vergeleken met de indirecte remmers. Hieruit blijkt dat er voorzichtigheid is geboden bij het besluiten tot niet controleren van het effect van de nieuwe anticoagulantia bij patiënten. 
Wanneer we de TG bepaalden in de aanwezigheid van directe factor Xa remmers (zoals otamixaban en rivaroxaban) werd een atypische curve gevonden. In hoofdstuk 7 wordt deze curve beschreven. Deze curve vertoont namelijk een vrij steile initiële helling gevolgd door een plateau en daarna een steile neerwaartse helling. Wanneer de intrinsieke factoren uitgeschakeld werden, wijzigde het eerste deel van de curve. Het tweede deel van de curve daarentegen veranderde wanneer de extrinsieke factoren niet bij de reactie betrokken werden. Dit wijst erop dat de intrinsieke en extrinsieke stollingscascade in verschillende mate bijdragen tot verschillende delen van de TG curve. Verder onderzoek moet uitwijzen of de vorm van de curve ook een relatie heeft met de klinische uitwerking van deze medicijnen. Mogelijk komen er minder bloedingen voor wanneer trombine onder deze omstandigheden gevormd wordt.

In hoofdstuk 8 bestuderen we de nieuwe anticoagulantia en hun invloed op de TG test. We gaan ook dieper in op de vraag of monitoring van de anticoagulantia al dan niet nuttig kan zijn. Aangezien patiënten die deelnemen aan de klinische trials een strenge selectie hebben ondergaan, komen deze populaties vaak niet overeen met de normale populatie. In het echte leven kunnen hierdoor meer bloedingen en tromboses voorkomen dan in de studiepopulaties. Bijgevolg is een vaste dosis van de directe remmers die patiënten voorgeschreven krijgen, waarschijnlijk niet voor elk individu optimaal.

De belangrijkste conclusies worden samengevat en besproken in hoofdstuk 9. De toegevoegde waarde van de aanwezigheid van TM tijdens de TG test wordt toegelicht met behulp van de resultaten uit verschillende studies. De eindconclusie is dat het toevoegen van TM aan de test een betere weergave geeft van de fysiologische processen die in het lichaam plaatsvinden. De onduidelijke resultaten verkregen na toevoeging van TM in volbloed vereisen verder onderzoek. Daarnaast wordt de mogelijkheid van de TG test besproken om de uitwerking van verschillende anticoagulantia te onderzoeken, zowel ex vivo als in vitro. Hieruit is gebleken dat de volbloed TG test een voorspellende waarde heeft voor bloedingen in patiënten die VKAs innemen. Ook werd de TG test gebruikt om de interindividuele variatie van verschillende anticoagulantia te bestuderen. De atypische 
vorm van de TG curve in de aanwezigheid van directe factor Xa remmers werd tevens onderzocht.

We tonen aan dat de volbloed TG test voor het eerst met succes in klinische studies werd gebruikt. Deze test ligt dichter bij de fysiologie, aangezien alle bloedcellen in de reactie betrokken worden. Het effent ook de weg voor een pointof-care test die het makkelijker maakt om patiënten op een snelle manier te testen. Om de fysiologie nog beter na te bootsen werd er recent ook een test ontwikkeld die volbloed kan analyseren onder continue stroming. Na een succesvolle technische validatie wordt de toegevoegde waarde van deze veelbelovende techniek momenteel getest in verschillende klinische studies. 


\section{Valorization}




\section{Valorization}

In this thesis we investigated the effects of anticoagulants on the thrombin generation (TG) test. More people die from thrombotic and bleeding complications than of any other cause. The ways to treat or prevent thrombosis hardly changed over the past 60 years. Vitamin K antagonists (VKAs) and heparins are the most frequently used oral and parenteral anticoagulants. Recently new developments have been made regarding the novel non-vitamin $\mathrm{K}$ antagonist oral anticoagulants (NOACs). Two dominant clotting factors are targeted by these agents, thrombin and factor (F) Xa. The first direct thrombin inhibitor to be developed was (xi)melagatran. This agent showed promising results in clinical trials, but was later withdrawn from the market due to hepatotoxic effects. Dabigatran was the next direct thrombin inhibitor to be approved. Several direct FXa inhibitors were developed of which otamixaban was the only parenteral drug. However, studies with otamixaban as treatment have been cancelled by the manufacturer due to inferior results compared to the existing drugs. Rivaroxaban, apixaban and edoxaban are oral direct FXa inhibitors of which the first two are already on the market for several indications and the latter is still under investigation.

Until today mostly clotting times are used to assess the activity of the coagulation system. However, they correlate poorly with the clinical picture, since they represent only the time needed for the fibrin clot to form. The greater part of thrombin $(95-98 \%)$ is not converted until the clot is already established. In addition, clotting times are incapable of detecting prothrombotic phenotypes. The TG test or calibrated automated thrombinography (CAT) is a functional measure of the amount of thrombin that can be generated. The total amount of thrombin formed, indicates a thrombotic tendency when higher than normal and a bleeding tendency when lower than normal. All anticoagulants that were tested influence TG despite different modes of action. Since the routine tests that are available are not sensitive to the action of all anticoagulants, TG might be a candidate for monitoring the effect of new anticoagulants. The TG test has also been used to test the reversal of both new and older anticoagulants. If TG is indeed a more complete test providing a better assessment of the effect of anticoagulant treatment, 
incorporation of the technique may give beneficial results for the patients and possibly less cases of bleeding or (re)thrombosis.

In this thesis (chapters 3-5) we investigated the addition of soluble thrombomodulin (TM) to the test-samples applying TG. We hypothesized that such addition yields a better representation of the physiological situation of the clotting system in patients taking VKAs. VKAs can be used for the treatment of patients with venous thromboembolism, atrial fibrillation, prosthetic heart valves, stroke, myocardial infarction and the antiphospholipid syndrome. By adding TM, the TG test becomes more sensitive to the activated protein $C$ (APC) system of the patient, which is hampered by the action of the VKAs. Thus, in the future application of the TG test might improve the outcome of patients on VKAs. This action of the VKAs is not detected by the prothrombin time (PT) that is used for monitoring the action of these agents by calculating the international normalized ratio (INR). This PT-test, in contrast to the TG test, also does not evaluate the effect of the VKAs on factor IX. Consequently, significantly different effects on TG parameters were found in the patients taking VKAs, which were not reflected by the INR. By the use of a more sensitive, functional test a better diagnosis can be made and healthcare costs can be reduced due to a reduced use of insensitive tests.

Also this is the first time the TG test in whole blood (WB) is implemented in a clinical study assessing patients on VKAs. We concluded that the WB TG test is the only laboratory test that has a predictive value for the bleeding that occurs in these patients. Currently this analysis relies on clinical decision scores, such as the HAS-BLED score. However, both the endogenous thrombin potential (ETP, an indication of the total amount of thrombin that can be converted) and the peak height (the highest amount of active thrombin present during the reaction) of the WB TG test display favorable results when comparing the receiver operating curves to that of the HAS-BLED score. Once the WB CAT becomes more userfriendly and there is less inter-operator variability this technique could be implicated in routine settings. The analysis in WB would be easier to convert to a point-of-care device which can provide a simple and fast measurement in nearpatient settings. When implemented in the hematology labs of hospitals, these 
tests could provide a safer treatment with VKAs. According to a report (2011) by the Dutch Federation of Anticoagulation clinics, in the Netherlands alone over 380.000 patients are treated with VKAs and this number is likely to increase over the coming years. If we can implement the WB TG test and have a better idea of patients at risk for bleeding, the costs for treatment of the bleedings can be significantly reduced.

As was already mentioned earlier, TG tests can also evaluate the effect of the new, direct inhibitors. At this moment there is still discussion as to which of the routine tests is best to use in order to determine the effect of these inhibitors. The activated partial thromboplastin time (aPTT) was suggested for the monitoring of dabigatran. Yet, this test was shown to be insensitive to the effect of heparin. AntiFXa assays were proposed for monitoring rivaroxaban and apixaban, but these assays determine the concentration of the anti-FXa activity and not the effect on the clotting system of the patient. Maybe the CAT would offer a better alternative. Based on clinical trials in highly selected patient populations the conclusion was made that the NOACs do not need monitoring. When we compared the pharmacodynamics of these agents using TG testing, we found that the variability of their effect in healthy donors is as high as the classic, indirect inhibitors (heparins). Considering that pharmacokinetic processes add extra variation with the notion that the populations used in the clinical trials don't represent the 'normal' populations receiving the drugs, we would like to suggest some caution in prescribing a fixed dose to patients and completely omitting monitoring of the anticoagulant effects.

In figure 1 the findings of this thesis concerning the use of TG for the evaluation of anticoagulant effects are summarized. 


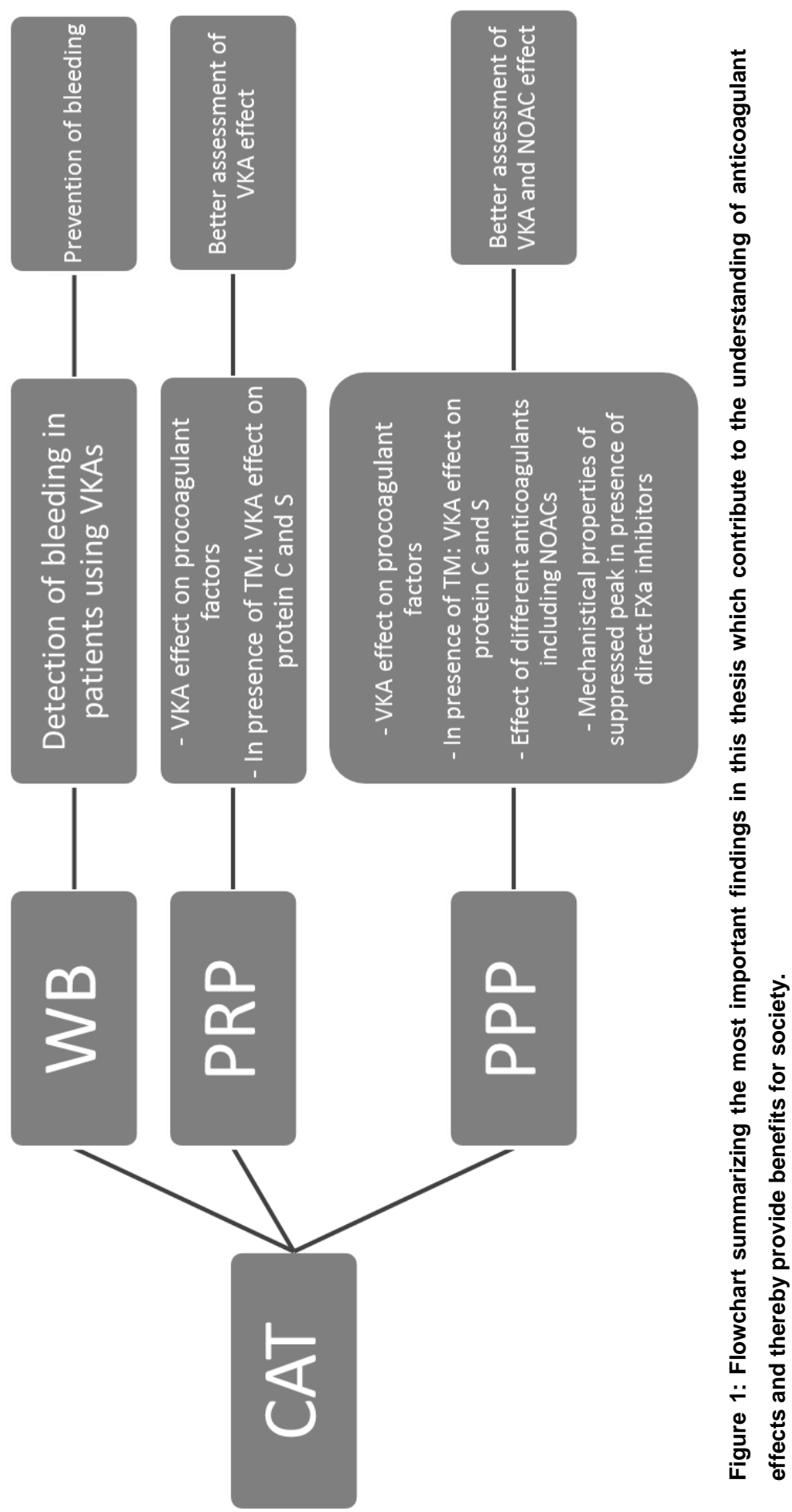





\section{Curriculum Vitae}


Saartje Bloemen was born on November 10th 1986 in Bree (Belgium). In 2004 she concluded her secondary education at WICO campus Mater Dei in Overpelt. Following this, she attended the transnational University Limburg (Hasselt University), studying Biomedical Sciences and obtained a master's degree with honor in Clinical Molecular Sciences in 2009. In 2010 she went on to graduate as a teacher at the adult education center 'Hoger Instituut der Kempen' in Geel. Later in 2010 she started a PhD program at Synapse BV and the Department of Biochemistry of Maastricht University under the supervision of dr. R. Al Dieri, dr. B. de Laat, Prof. dr. T.M. Hackeng and Prof. dr. H. C. Hemker. Starting January 2015 she will be working as a postdoc at the Department of Pathology and Laboratory Medicine of Weill Cornell Medical College in New York (USA). 
Publications 


\section{Scientific publications}

- Al Dieri R, Ten Cate-Hoek A, Bloemen S, Ten Cate H, Hemker HC. Procoagulant effect of vitamin K antagonists? J Thromb Haemost. 2011 Dec;9(12):2511-2512.

- Bloemen S, Pieters M, Hemker HC, Al Dieri R. No effect of ethanol intake on thrombin generation parameters. Thromb Res. 2012 Apr;129(4):530-531.

- Al Dieri R, Bloemen S, Kelchtermans H, Wagenvoord R, Hemker HC. A new regulatory function of activated factor $\mathrm{V}$ : inhibition of the activation by tissue factor/factor VII(a) of factor X. J Thromb Haemost. 2013 Mar;11(3):503-511.

- Bloemen S, Hemker HC, Al Dieri R. Large inter-individual variation of the pharmacodynamic effect of anticoagulant drugs on thrombin generation. Haematologica. 2013 Apr;98(4):549-554.

- Bosch Y, Al Dieri R, ten Cate H, Nelemans P, Bloemen S, Hemker C, Weerwind $\mathrm{P}$, Maessen $\mathrm{J}$, Mochtar $\mathrm{B}$. Preoperative thrombin generation is predictive for the risk of blood loss after cardiac surgery: a research article. $\mathrm{J}$ Cardiothorac Surg. 2013 Jun 12;8:154.

- Bosch Y, Al Dieri R, ten Cate H, Nelemans P, Bloemen S, de Laat B, Hemker $C$, Weerwind $\mathrm{P}$, Maessen J, Mochtar B. Measurement of thrombin generation intra-operatively and its association with bleeding tendency after cardiac surgery. Thromb Res. 2014 Mar;133(3):488-494.

- Bloemen S, Huskens D, Hackeng T, de Laat B, Hemker HC, Al Dieri R. Thrombin peak suppression in the presence of direct factor Xa inhibitors. In preparation

- Bloemen S, de Laat M, ten Cate-Hoek A, van Meel R, ten Cate H, de Laat B, Hemker HC, Al Dieri R. Vitamin K antagonist therapy can be evaluated by whole blood CAT and results in high plasma levels of factor VIII as well as fibrinogen. In preparation 
- Bloemen S, ten Cate-Hoek A, ten Cate H, de Laat B. Detection of bleeding risk in patients taking vitamin $\mathrm{K}$ antagonists. Submitted

- Ninivaggi M, de Laat M, Konings J, Pelkmans L, Linssen-Thuis I, Lancé M, Peters T, Bloemen S, Govers-Riemslag J, Lindhout T, Krishnamoorthy G, Hemker HC, de Laat B. Hypoxia induces a prothrombotic state: results from the "redmeetswhite" study. Submitted

- Lagrange J, Walton LA*, Bloemen $\mathbf{S}^{*}$, de Laat B, Thornton SN, Derby B, Sherratt MJ, Austin C, Lacolley P, Akhtar R, Cruickshank JK, Regnault V. Obesity increases vascular inflammation, thrombin generation and decreases fibrinolysis in Zucker rats. *equal contribution. In preparation

- Ignjatovic V, Pelkmans L, Kelchtermans H, Al Dieri R, Hemker HC, Kremers R, Bloemen S, Karlaftis V, Attard C, de Laat B, Monagle P. Differences in the mechanism of fibrin clot formation, structure and strength in infants and children compared to adults. In preparation

\section{Review articles}

- Bloemen S, De Laat B, Hemker HC, Al Dieri R. Is there a reason for testing thrombin generation? Journal of Applied Hematology. 2012 Mar;3(1):9-17.

- Bloemen S, De Laat M, De Laat B, Hemker HC, Al Dieri R. Will one size of anticoagulant dosage fit all? Drug Development Research. 2013 Nov;74:406412.

- Bloemen S, Huskens D, Hemker HC, de Laat B. Adding thrombomodulin to thrombin generation tests. Treatment Strategies - Hematology. 2014 Aug; 4(2) (invited review) 


\section{Abstracts}

- Bloemen S, Hemker HC, Al Dieri R. Large inter-individual variation of the pharmacodynamics effect of anticoagulant drugs on thrombin generation. SSC, Liverpool, United Kingdom, 2012

- Bloemen S, de Laat M, Ninivaggi M, Lenderink T, Leers MP, de Laat B, Hemker HC, Al Dieri R. Large inter-individual variability of the response to new oral anticoagulants. EHA, Stockholm, Sweden, 2013

- Bloemen S, de Laat M, ten Cate-Hoek A, ten Cate H, de Laat B, Hemker HC, Al Dieri R. Control of vitamin $\mathrm{K}$ antagonist treatment by measuring thrombin generation in whole blood - Effect of thrombomodulin. EHA, Stockholm, Sweden, 2013

- Bloemen S, de Laat M, Ninivaggi M, Lenderink T, Leers MP, de Laat B, Hemker HC, Al Dieri R. Large inter-indidual variability of the response to new oral anticoagulants. ISTH, Amsterdam, the Netherlands, 2013

- Bloemen S, de Laat M, ten Cate-Hoek A, ten Cate H, de Laat B, Hemker HC, Al Dieri R. Control of vitamin $\mathrm{K}$ antagonist treatment by measuring thrombin generation in whole blood - Effect of thrombomodulin. ISTH, Amsterdam, the Netherlands, 2013

- Bosch Y, Al Dieri R, Bloemen S, de Laat B, ten Cate H, Nelemans P, Hemker $\mathrm{HC}$, Weerwind $\mathrm{P}$, Maessen J, Mochtar B. Preoperative thrombin generation is predictive for the risk of blood loss after cardiac surgery. ISTH, Amsterdam, the Netherlands, 2013

- Al Dieri R, Bloemen S, Kelchtermans H, Wagenvoord R, de Laat B, Hemker $\mathrm{HC}$. A new regulatory function of activated factor $\mathrm{V}$ : Inhibition of the activation by tissue factor/factor VII(a) of factor X. ISTH, Amsterdam, the Netherlands, 2013 
- Kremers R, Ninivaggi M, Bloemen S, Chayouâ W, Kleinegris MC, Koek G, ten Cate-Hoek A, Wagenvoord R, Hemker HC. Effect of functional alpha-2macroglobulin and antithrombin concentration on thrombin generation and decay in liver cirrhosis patients. ISTH, Amsterdam, the Netherlands, 2013

- Bloemen S, de Laat B, Hemker HC, Al Dieri R. Mechanism of peak protraction in thrombin generation after administration of direct factor Xa inhibitors. ASH, New Orleans, USA, 2013

- Bloemen S, de Laat M, ten Cate-Hoek A, ten Cate H, de Laat B, Hemker HC, Al Dieri R. Thrombin generation measurement in whole blood as a control for vitamin $\mathrm{K}$ antagonist treatment - Effect of thrombomodulin. ASH, New Orleans, USA, 2013

- Ingnjatovic V, Pelkmans L, Bloemen S, Karlaftis V, Attard C, Al Dieri R, de Laat $B$, Monagle $P$. The first report of differences in fibrin clot nanostructure and response to tissue plasminogen activator (TPA) and unfractionated heparin (UFH) in infants compared to adults. ASH, New Orleans, USA, 2013

- Kremers R, Bloemen S, Al Dieri R, Hemker HC, Karlaftis V, Attard C, de Laat $\mathrm{B}$, Monagle $\mathrm{P}$, Ignjatovic $\mathrm{V}$. Alpha-2-macroglobulin is a major determinant of a lower thrombin generation in infants and children compared to adults. ASH, New Orleans, USA, 2013

- Bloemen S, de Laat M, ten Cate-Hoek A, ten Cate H, de Laat B, Hemker HC, Al Dieri R. Vitamin $\mathrm{K}$ antagonist therapy induces high plasma levels of factor VIII and fibrinogen and reduces thickness of fibrin fibers. SSC, Milwaukee, USA, 2014

- Bloemen S, Huskens D, de Laat B, Hemker HC, Al Dieri R. Presence of direct factor Xa inhibitors leads to a protracted thrombin generation peak. SSC, Milwaukee, USA, 2014

- Ninivaggi $M$, de Laat $M$, Linssen-Thuis I, Lancé $M$, Konings $J$, Peters $T$, Bloemen S, Govers-Riemslag J, Lindhout T, Krishnamoorthy G, Hemker HC, 
de Laat B. Hypoxia induces a prothrombotic state: results from the "red meets white" study. SSC, Milwaukee, USA, 2014

- Bloemen S, ten Cate-Hoek A, ten Cate H, de Laat B. Detecting bleeding risk in patients taking vitamin $\mathrm{K}$ antagonists using thrombin generation tests. $\mathrm{ASH}$, San Francisco, USA, 2014

- Huskens D, Roest $\mathrm{M}^{*}$, Remijn $\mathrm{JA}^{*}$, Bloemen S, Konings J, Schurgers E, Kremers R, Selmeczi A, Dienava-Verdoold I, Kelchtermans $H$, van Meel R, Kleinegris MC, Ninivaggi M, de Laat B. Strenuous exercise induces increased platelet reactivity and thrombin generation in both plasma and whole blood. ASH, San Francisco, USA, 2014; * equal contribution

\section{Awards}

Young investigator award. SSC 2012, Liverpool, United Kingdom. 
Dankwoord 
Wanneer ik terugkijk op de laatste 4 jaar van mijn promotieonderzoek is het opvallend hoe snel de tijd voorbij gevlogen is. Mijn tijd bij Synapse zal mij bijblijven als een tijd waarin er hard gewerkt werd, maar waar er ook ruimte was voor ontspanning. Ik zou bij deze graag de mensen willen bedanken die mij tijdens mijn doctoraatsperiode hebben bijgestaan.

Om te beginnen wil ik graag mijn promotor en copromotores bedanken. Prof. Dr. Tilman Hackeng, mijn promotor, ik zou u graag willen bedanken voor de goede raad bij het schrijven van mijn thesis.

Graag zou ik ook mijn dankbaarheid willen overmaken aan Prof. Dr. Coen Hemker, mijn promotor de facto. Ik herinner me nog goed dat u tijdens mijn sollicitatie zei: 'Een wetenschapper probeert dingen gewoon uit in geval van twijfel'. Ik ben dan ook nog steeds blij dat tijdens dat sollicitatiegesprek de wetenschapper in $u$ de bovenhand nam en dat u mij een kans gegeven hebt ondanks uw twijfels. Bedankt voor de wijze raad en de leerrijke gesprekken die ik met u gehad heb over mijn studies.

Dr. Raed Al Dieri, my first copromotor; dear Raed, thank you for introducing me into the world of blood clotting, for always making time to answer my questions, for the discussions about the results and for giving me valuable tips on presenting data. You always stay friendly, calm and diplomatic (even in situations in which I lost my calmness). I admire your enthusiasm for research and the ideas you had regarding the studies we have worked on together. I would like to wish you the best of luck with the new chapter in your career.

Dr. Bas de Laat, mijn tweede copromotor; beste Bas, vooral tijdens de laatste maanden van mijn doctoraat hebben we nauw samengewerkt. Ik vind het bewonderenswaardig dat je zelfs tijdens de periode rond de geboorte van je zoontje toch nog de tijd vond om hoofdstukken na te lezen en mee te schrijven aan artikels. Ook zou ik je graag willen bedanken voor de kansen die ik in veel andere labs niet gekregen zou hebben, zoals de Red meets white (Mont Blanc) en de Red meets gold (Amstel Gold) studies. Het waren ervaringen die ik niet snel zal 
vergeten. Bovendien wil ik je bedanken om mij aan te bevelen bij Prof. Rand en mij zo een postdoc positie te bezorgen.

I would also like to thank my assessment committee for taking the time out of their busy schedules to evaluate my thesis. Prof. Dr. Harry Crijns, Prof Dr. Leon de Windt, Prof Dr. Saskia Middeldorp and Dr. Trevor Baglin, thank you very much for critically reading my thesis.

Mijn collega's bij Synapse verdienen natuurlijk ook een welgemeende dankuwel. Hilde en Dana, ik vind het super dat jullie mijn paranimfen willen zijn. Jullie zijn altijd fijn gezelschap, maar vooral de congresfeestjes in Amsterdam zullen mij nog lang bijblijven. Bedankt om mij op te peppen wanneer ik het nodig had (al dan niet met een chocoladereep). Hilde, bedankt om altijd een luisterend oor te bieden zowel op professioneel als persoonlijk vlak. Als ik ergens hulp bij nodig had stond je altijd klaar. Dana, wat was het fijn toen er iemand het klinisch lab kwam versterken en nog beter dat we ook nog eens goed met mekaar kunnen opschieten. Ook bij jou kon ik terecht voor steun en tips. Leonie, als we ergens niet uitkwamen (vooral statistische problemen) zochten we vaak samen naar een oplossing. Ik heb hier veel door bijgeleerd. Ook bedankt voor de fijne babbels en ik ben ervan overtuigd dat binnen een jaar je Vlaamse woordenschat nog veel uitgebreider is (ook al wil je dit zelf misschien liever niet). Joke, jij hebt me veel goede tips gegeven voor het opmaken van mijn thesis en de voorbereiding op weg hier naartoe. Ik apprecieer dit heel erg. Iris, je staat altijd paraat om ons te helpen met administratie. Het was heel fijn om met je samen te werken. Erik, samen met Hilde en Dana hebben we lange tijd samen naar het werk gereden. De tijd gaat toch sneller wanneer je iemand hebt om tegen te praten in de auto. Marisa, jij hebt mij verteld dat er een positie beschikbaar was bij Synapse, dus dankjewel daarvoor. Ook bedankt voor de fijne reizen die we samen gemaakt hebben. Mijn andere collega's en voormalige collega's wil ik natuurlijk ook bedanken voor hun bijdrages: Tessa, Romy, Evelien, Martijn, Rob, Theo, Adam, Ilze, Veerle, Marieke, Vivian, Ganesh en Rafael. Bedankt voor jullie opmerkingen, de discussies over mijn resultaten en voor de gezellige sfeer tijdens onze Synapse-uitstapjes en de jaarlijkse kerstlunches. Ik wil ook nog graag voornamelijk de vrouwen binnen 
Synapse bedanken voor de toffe quiz- en filmavonden. Verder wil ik ook nog mijn appreciatie uitdrukken aan iedereen die mijn thesis heeft nagelezen. Dr. Mark Roest en Prof. Dr. Flip de Groot, ik wil jullie veel succes wensen met jullie nieuwe job bij Synapse. Hopelijk krijgen we nog eens de kans om samen te werken.

Beste Trees en Lidewij, bedankt om mij te helpen met het in orde brengen van papierwerk.

Een doctoraat kan je niet alleen volbrengen en ik heb het geluk gehad om met een aantal mensen te kunnen samenwerken. Dr. Arina ten Cate-Hoek, Prof. Dr. Hugo ten Cate en Jolanda Claessens, alsook alle medewerkers van de trombosedienst Maastricht: zonder een goede samenwerking met de trombosedienst was dit proefschrift niet tot stand gekomen. Bedankt voor jullie advies bij het opzetten van de studie en voor jullie hulp tijdens het verloop van de studie. Dr. Yvonne Bosch, bedankt om mij te betrekken bij je studie, het was fijn om hieraan te kunnen meewerken. Veel succes nog met je doctoraat. Prof. Dr. Vera Ignjatovic, it was nice getting to know you during your time in Maastricht. I am happy that I was able to be of some help for your project.

Ik zou ook graag Bart Verlaak willen bedanken voor het ontwerpen van de kaft van mijn boekje en het maken van de uitnodigingen.

Bedankt aan mijn vrienden om me te helpen met het verzetten van mijn gedachten. Stefanie, Sofie en Liese, we hebben veel te weinig de kans om nog af te spreken, maar toch wil ik jullie bij deze bedanken voor de fijne tijden die we hebben gehad. Stefanie, ik hoop dat ik aanwezig kan zijn wanneer je gaat trouwen in 2015. Ik wil je dan ook verder veel geluk toewensen samen met Joeri.

Eveneens zou ik alle personen willen bedanken die financieel hebben bijgedragen tot het organiseren van deze dag.

Dan zou ik ook mijn familie willen bedanken en enkele personen in het bijzonder. Oma en bompa (Ellikom) en oma en opa (Brogel) bedankt voor jullie steun en bezorgdheid. Ik wil mijn nicht Joke en haar man Rob ook nog in het bijzonder 
bedanken om mij als meter te vragen voor hun dochtertje Lien. Ik vind het een hele eer. Lien, ik hoop dat je alles uit het leven kan halen wat je wenst. Als je wilt kan je alles bereiken en laat niemand je iets anders vertellen (ondertussen wel lief blijven voor je grote broer Daan). Mijn zus en schoonbroer Sanne en Kristof, ook jullie bedankt voor alles wat jullie voor mij gedaan hebben. Hopelijk worden jullie heel gelukkig in jullie nieuwe huis. Mama en papa, ik kan me geen betere ouders wensen. Bedankt om altijd voor mij klaar te staan! 